ROBERTA HARUE TSUNODA

\title{
Efeitos da pentoxifilina sobre a qualidade espermática e hemodinâmica uterina em equinos
}




\section{Efeitos da pentoxifilina sobre a qualidade espermática e hemodinâmica uterina em equinos}

Dissertação apresentada ao Programa de PósGraduação em Reprodução Animal da Faculdade de Medicina Veterinária e Zootecnia da Universidade de São Paulo para a obtenção do título de Mestre em Ciências

\section{Departamento:}

Reprodução Animal

Área de concentração:

Reprodução Animal

\section{Orientadora:}

Profa. Dra. Eneiva Carla Carvalho Celeghini De acordo:

Orientadora

São Paulo 
Autorizo a reprodução parcial ou total desta obra, para fins acadêmicos, desde que citada a fonte.

\section{DADOS INTERNACIONAIS DE CATALOGAÇÃO-NA-PUBLICAÇÃO}

(Biblioteca Virginie Buff D'Ápice da Faculdade de Medicina Veterinária e Zootecnia da Universidade de São Paulo)

T.2847

FMVZ

Tsunoda, Roberta Harue

Efeitos da pentoxifilina sobre a qualidade espermática e hemodinâmica uterina em equinos / Roberta Harue Tsunoda. -- 2013

$110 \mathrm{f}$ : il.

Dissertação (Mestrado) - Universidade de São Paulo. Faculdade de Medicina Veterinária e Zootecnia. Departamento de Reprodução Animal, São Paulo, 2013.

Programa de Pós-Graduação: Reprodução Animal.

Área de concentração: Reprodução Animal.

Orientador: Profa. Dra. Eneiva Carla Carvalho Celeghini.

1. Diluidor. 2. Endometrite. 3. Doppler. 4. Sêmen. 5. Membranas. I. Título. 


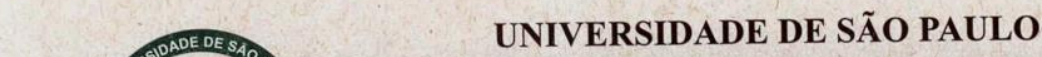

FACULDADE DE MEDICINA VETERINÁRIA E ZOOTECNIA

Comissão de Ética no uso de animais

\section{CERTIFICADO}

Certificamos que o Projeto intitulado "Efeito da pentoxifilina sobre a qualidade espermática, a hemodinâmica uterina e a fertilidade em equinos", protocolado sob o $\mathrm{n}^{\mathrm{o}} 2315 / 2011$, utilizando 24 (vinte e quatro) éguas, sob a responsabilidade do(a) Profa. Dra. Eneiva Carla Carvalho celeghini, está de acordo com os princípios éticos de experimentação animal da "Comissão de Ética no uso de animais" da Faculdade de Medicina Veterinária e Zootecnia da Universidade de São Paulo e foi aprovado em reunião de 19/9/2012.

We certify that the Research "Pentoxifylline effect on sperm quality, uterine blood flow and fertility rate in equine", protocol number 2315/2011, utilizing 24 (twenty for) horses, under the responsibility Profa. Dra. Eneiva Carla Carvalho celeghini, agree with Ethical Principles in Animal Research adopted by "Ethic Committee in the use of animals" of the School of Veterinary Medicine and Animal Science of University of São Paulo and was approved in the meeting of day $9 / 19 / 2012$.

São Paulo, 20 de setembro de 2012.

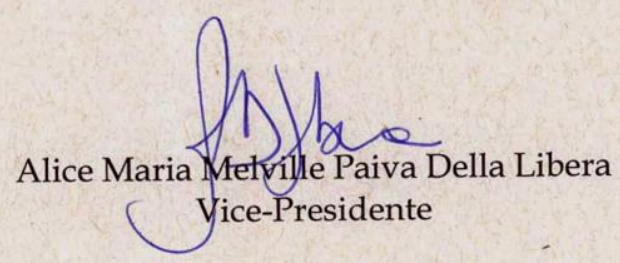




\section{FOLHA DE AVALIAÇÃO}

Nome: TSUNODA, Roberta Harue

Título: Efeitos da pentoxifilina sobre a qualidade espermática e hemodinâmica uterina em equinos

Dissertação apresentada ao Programa de Pós-Graduação em Reprodução Animal da Faculdade de Medicina Veterinária e Zootecnia da Universidade de São Paulo para a obtenção do título de Mestre em Ciências

Data:

\section{Banca Examinadora}

Prof. Dr.:

Instituição: Julgamento:

Prof. Dr.:

Instituição: Julgamento:

Prof. Dr.:

Instituição: Julgamento: 
Dedico,

À Deus, pelos seus ensinamentos diários, por cuidar de mim ainda que muitas vezes eu não mereça;

Aos meus pais, Maria Regina e Nelson Tadashi, por me proporcionarem o maior amor do mundo, o incondicional! Pelos conhecimentos da integridade de caráter, dignidade e me ensinarem que tudo é possivel quando confiamos em Deus;

À minha irmã Fernanda Tomie, pela amizade eterna, por me ajudar da melhor forma possível, me guiando e fortalecendo com sua sabedoria e incentivo de procurar sempre em Deus a força para superar os obstáculos;

Ao meu noivo Cássio Giacon, meu amor! Amigo de todas as horas, com quem quero passar o resto da minha vida junto e retribuir todo carinho e respeito que recebo;

Ao meu cunhado Josué, pela amizade, pela paciência, por estar sempre disposto a me ajudar e me ensinar; Às minhas avós Fumiko e Eunice, pelo amor, carinho e alegria que trazem para minha vida. 


\section{AGRADECIMENTOS}

À Deus, por fazer com que tudo sempre ocorra de forma melhor do que eu tinha planejado, por ter permitido que esse experimento ocorresse, o qual me trouxe tantas aprendizagens tanto para a vida profissional como para a pessoal;

À minha família, obrigada por estarem sempre ao meu lado, me incentivarem e apoiarem na concretização de um sonho, que souberam compreender meus períodos de ausência;

Ao Cássio, obrigada pelo companheirismo, incentivo diário, por torcer por mim, por me acalmar e me ajudar a enfrentar meus medos e minha ansiedade;

À professora Eneiva Carla, obrigada pela oportunidade, pela amizade, por ter confiado em mim. Professora, você é um exemplo de ser humano para mim, honesta e humilde, com quem tive muito prazer em trabalhar;

À Bruna Marcele Oliveira, obrigada pela amizade, pelo apoio desde que entrei para a equipe, obrigada por ter aceitado a aventura, pelo companheirismo em momentos difíceis, e pelas risadas que ficaram de tudo que passamos juntas;

À minha ex-equipe, Andressa, Diego João, Rodrigo obrigada pelos ensinamentos, pela amizade, pelas risadas, pelas viagens de projetos, foi um prazer conhecê-los e conviver com cada um de vocês;

Ao meu amigo querido Marcilio, quem não mediu esforços para me ajudar nesta Dissertação, obrigada pelos ensinamentos, pela paciência, pelos conselhos, por ter estado ao meu lado desde que cheguei à USP;

À Mariana Rodrigues, obrigada pela amizade, pelo companheirismo, por me ouvir tantas vezes que precisei e por me ajudar a enxergar uma saída em dias tensos;

À Carolina Rocha, obrigada por tudo que já fez por mim, pela amizade que construímos no decorrer deste mestrado, você faz muita falta no meu dia-dia.

À minha atual equipe, Doci, Leo, Shirley, Guapa, Helder, obrigada por me acolherem, por estarem sempre dispostos a me ajudar, tenho um carinho enorme por vocês. Fico muito feliz de ter feito parte desse grupo;

À minhas roomates, Laís Vieira e Júlia Soares, pessoas que eu tive o prazer de conhecer e dividir o mesmo teto, obrigada pela amizade, pelas risadas, pelos conselhos, vocês são um exemplo para mim de dedicação;

Queridos de Pirassununga, Milena, Roney, Estela, Moana, Everton, Saara, Arroz, Henrique, Kleber, Tiaciano, Fernanda, Renata, Milton, Gisele, Mariana, e aos queridos de São Paulo, Daniel, Bruno, Givago, Cris, Liege, Fernanda, Carina, Manuel, Rodrigo, Robertinha, Marcela, Bruno, Bruna, Mili, Adriano gostaria de agradecer imensamente pela ajuda, amizade, conversas, risadas; 
À Professora Valquíria e ao Professor Renato, gostaria de agradecer pela oportunidade de prestar o mestrado, foi um prazer conhecê-los e ter trabalhado no L.A;

Ao Professor Rubens Arruda, por ter disponibilizado o Laboratório de Andrologia para meu experimento, obrigada;

À Guta, gostaria de agradecer pela imensa vontade de ajudar, todas as vezes que precisei, você sempre se disponibilizou, sem medir esforços;

Ao Professor Luciano Silva, pela atenção que me deu, pela paciência e vontade em me ajudar mesmo atarefado disponibilizava de seu tempo para conversar comigo;

Ao Fabio e Reno, pela ajuda no Doppler, que se dispuseram a atender minhas dúvidas, muito obrigada;

À todos os professores do Departamento de Reprodução Animal, pelas disciplinas ministradas, pelas conversas, e incentivo;

À todos os funcionários: Roberta, Thais, Miguel, Daura, Neusa, Elza, Tereza, Clayton, Alexandra, Sandra, João, Marcio, Ira, Belau, Luiz, obrigada pela atenção, foi um prazer conhecê-los;

À Harumi, obrigada por sempre estar disposta a me ajudar, pelas conversas e amizade;

Agradeço a FAPESP, pela bolsa e Auxílio que me foram concedidos, permitindo a realização deste projeto (processo ${ }^{\circ}$ 2012/14927-6 e 2012/15736-0). 


\section{RESUMO}

TSUNODA, R. H. Efeitos da Pentoxifilina sobre a qualidade espermática e hemodinâmica uterina em equinos. [Effects of Pentoxifylline on sperm quality and on uterine hemodinamics in equine]. 2013. 110f. Dissertação (Mestrado em Ciências) Faculdade de Medicina Veterinária e Zootecnia, Universidade de São Paulo, São Paulo, 2013.

A resposta inflamatória uterina pós-cobertura ocorre para remoção de espermatozoides e contaminantes; todavia, o atraso em debelar este processo têm sido identificado, em equinos, como a principal causa de endometrite persistente pós-cobertura. A pentoxifilina atua como um inibidor da fosfodiesterase e aumenta as características de motilidade espermática, ainda tem sido relatada sua participação como agente reológico, aumentando o fluxo sanguíneo de tecidos comprometidos, e como agente imunomodulador. O propósito deste estudo foi examinar os efeitos da pentoxifilina adicionada ao diluidor seminal pós-descongelação, sobre a motilidade espermática, membranas plasmática, acrossomal e mitocondrial e integridade de cromatina, bem como sobre a resposta inflamatória uterina após a inseminação artificial de éguas. Dez partidas de sêmen de um único garanhão foram criopreservadas $\left(100 \times 10^{6}\right.$ espermatozoides/palheta $0,5 \mathrm{~mL}$ ) em sistema automatizado (TK 3000) e mantidas em botijão criogênico, sendo posteriormente utilizadas para análises laboratoriais e inseminação artificial. Para análise laboratorial duas palhetas de sêmen de cada partida foram descongeladas $\left(37^{\circ} \mathrm{C} / 30\right.$ segundos) e diluídas em diluidor à base de leite desnatado (controle) e diluidor à base de leite desnatado contendo pentoxifilina $(7,18 \mathrm{mM})$. As alíquotas de cada tratamento foram mantidas em banho-Maria seco $\left(37^{\circ} \mathrm{C}\right)$ e analisadas em quatro momentos: 5 (T0), 30 (T30), 60 (T60) e 120 minutos (T120) pós-diluição e incubação. As amostras foram analisadas quanto às características de movimento espermático, por sistema computadorizado de análise espermática (CASA), membranas plasmática, acrossomal e mitocondrial por associação de sondas fluorescentes (PI, H342, FITC-PSA e JC-1), morfologia espermática por contraste de interferência diferencial e integridade da cromatina pelo Azul de Toluidina. Para avaliar os efeitos do diluidor contendo ou não pentoxifilina na resposta inflamatória uterina, foram utilizadas 15 éguas distribuídas em cinco grupos: Grupo Control (controle): sem deposição de sêmen, nem diluidor, mimetizando-se o procedimento da IA; Grupo SM Extender: deposição de diluidor sem pentoxifilina (Botusemen ${ }^{\circledR}$, Botupharma); Grupo SM Extender + PTX: deposição de diluidor contendo pentoxifilina; Grupo Sêmen: deposição de 
sêmen diluído com diluidor sem pentoxifilina; Grupo Sêmen + PTX: deposição de sêmen diluído com diluidor contendo pentoxifilina $(7,18 \mathrm{mM})$. A hemodinâmica uterina foi avaliada por ultrassonografia nos modo color e espectral realizadas nos períodos: imediatamente antes da indução da ovulação (aproximadamente 30 horas antes da IA, T-30), imediatamente antes da inseminação artificial (TIA) e 2 (T2), 6 (T6), 12 (T12), 24 (T24) e 48 (T48) horas após a inseminação artificial. Uma amostra para citologia endometrial foi coletada, por escova ginecológica no momento T6. A análise estatística foi realizada utilizando-se análise de variância (ANOVA), sendo as médias comparadas pelo LSD test, SAS versão 9.3 (2010). A adição de pentoxifilina não exerceu efeito sobre a motilidade progressiva, porém, a pentoxifilina aumentou velocidade de trajeto, velocidade progressiva e velocidade curvilinear quando comparada ao controle. Não houve diferença significativa na porcentagem de células apresentando membrana plasmática intacta, acrossoma intacto e alto potencial mitocondrial (PIAIC). Nenhuma diferença estatística foi encontrada no fluxo sanguíneo uterino de éguas após os tratamentos. Porém, a citologia endometrial demonstrou maior resposta inflamatória em grupos contendo pentoxifilina quando comparado aos controles. Concluiu-se que a pentoxifilina exerce efeito positivo sobre parâmetros de velocidade, mas não influencia as membranas celulares e a cromatina. No entanto, quando as éguas são inseminadas com sêmen contendo pentoxifilina, uma resposta inflamatória mais intensa é observada.

Palavras-chave: Diluidor. Endometrite. Doppler. Sêmen. Membranas. 


\begin{abstract}
TSUNODA, R. H. Effects of Pentoxifylline on sperm quality and uterine hemodinamics in equine. [Efeitos da Pentoxifilina na qualidade espermática e hemodinâmica uterina em equinos]. 2013. 110 f. Dissertação (Mestrado em Ciências) - Faculdade de Medicina Veterinária e Zootecnia, Universidade de São Paulo, São Paulo, 2013.
\end{abstract}

The post breeding uterine inflammatory response occurs due to remove spermatozoa and contaminants; however, delayed uterine clearance has been identified, in equines, as the underlying cause of persistent post breeding endometritis. Pentoxifylline acts as a phosphodiesterase inhibitor and increases sperm motion characteristics, and it has been reported to participate as a rheologic agent, improving blood flow to compromised tissues, and as an immunomodulatory agent. The purpose of this study was to examine the effects of pentoxifylline added to the seminal extender after thawing, on sperm motion, plasmatic, acrosomal and mitochondrial membranes and chromatin integrities, as well as the uterine inflammatory response on mares after artificial insemination. Ten batches of a unique stallion were cryopreserved $\left(100 \times 10^{6}\right.$ spermatozoa/0.5 mL straws), in an automated system (TK 3000) and storaged in cryogenic cylinder for posterior use for laboratory analysis and artificial insemination. For laboratory analysis two semen straws of each batch were thawed $\left(37^{\circ} \mathrm{C} / 30\right.$ seconds) and diluted in skim milk based extender (control) or diluted in skim milk extender containing pentoxifylline $(7.18 \mathrm{mM})$. Aliquots of each treatment were maintained in dry water bath $\left(37^{\circ} \mathrm{C}\right)$ and analyzed at four moments: 5 (T0), 30 (T30), 60 (T60) and 120 minutes (T120) post dilution and incubation. Samples were analyzed for sperm motion characteristics, through Computer-Assisted Semen Analysis (CASA), plasmatic, acrosomal and mitochondrial membranes through fluorescent probes association (PI, H342, FITC-PSA and JC-1), spermatic morphology through differential interference contrast and chromatin integrity through Toluidine blue. To examine the effect of extender containing or not pentoxifylline on uterine inflammatory response 15 mares were divided into 5 groups: Group Ccontrol (control): no uterine deposition of semen, or extender, just mimicking the AI procedure; Group SM Extender: deposition of skim milk based extender (Botusemen ${ }^{\circledR}$, Botupharma); Group SM Extender + PTX: deposition of skim milk based extender containing Pentoxifylline; Group Semen: deposition of semen diluted with extender only; Group Semen 
+ PTX: deposition of semen diluted with extender containing Pentoxifylline (7,18 mM). Uterine hemodynamics were examined through color and spectral mode ultrasonography on moments: immediately before ovulation induction (approximately 30 hours before AI, T-30), immediately before artificial insemination (TAI) and 2 (T2), 6 (T6), 12 (T12), 24 (T24) and 48 (T48) hours after artificial insemination. Samples for endometrial cytology were collected, through cytobrush at T6 moment. Statistical analysis was performed using the analysis of variance (ANOVA), and the range was compared by LSD test, SAS 9.3 version (2010). Pentoxifylline addition did not exert effect on progressive motility, however, pentoxifylline increased path velocity, progressive velocity and curvilinear velocity when compared to controls. There were no significant differences on the percentage of cells presenting intact plasma membrane, intact acrosome and high mitochondrial membrane potential (IPIAH). No statistical difference was found on uterine blood flow of mares after treatments. However, endometrial cytology showed a major inflammatory response on groups containing Pentoxifylline when compared to controls. In conclusion, pentoxifylline exerted a positive effect on velocity parameters, but do not influence cellular membranes and chromatin. Furthermore, when mares were inseminated with semen containing pentoxifylline, an intense inflammatory response was observed.

Key words: Extender. Endometritis. Doppler. Semen. Membranes. 


\section{LISTA FIGURAS}

Figura 1 - Esquema simplificado do experimento de pesquisa................................. 53

Figura 2 - The sonograms of equine uterine horn in transversal section, by color Doppler equipment (M5Vet, Mindray)................................................. 86 


\section{LISTA DE GRÁFICOS}

Graphic 1- Means \pm standard error of endometrial vascularity score (VS, 1-4) of mares in each treatment, from immediately before ovulation induction time until 48 hours

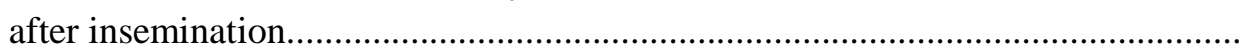

Graphic 2 - Means and standard error of percentage of polymorphonuclear (PMN) cells found in mares after 6 hours from treatment 


\section{LISTA DE TABELAS}

Table 1 - Sperm cells classification in eight groups, according to fluorescence emitted by different

probes.

Table 2 - Mean \pm standard error of motion characteristics obtained by CASA of frozen-thawed equine sperm not diluted and diluted using skim milk extender (SM Extender) or skim milk extender plus pentoxifylline (SM Extender + PTX, at $7.18 \mathrm{mM}) \ldots \ldots \ldots \ldots \ldots \ldots . . . . . .6$.

Table 3 - Mean \pm standard error of plasma and acrosomal membranes integrity and mitochondrial membrane potential of frozen-thawed equine sperm not diluted and diluted using skim milk extender (SM Extender) or skim milk extender plus pentoxifylline (SM Extender + PTX, at $7.18 \mathrm{mM}$ )

Table 4 - Mean \pm standard error of total and progressive motility of frozen-thawed equine sperm diluted using skim milk extender (SM Extender) or skim milk extender containing pentoxifylline (SM Extender+PTX, at $7.18 \mathrm{mM}$ ). Incubated in vitro at $37^{\circ} \mathrm{C}$ during 5 (T0), 30 (T30), 60 (T60), and 120 (T120) minutes.

Table 5 - Mean \pm standard error of motion characteristics of frozen-thawed equine sperm after dilution (with or without pentoxifylline) and in vitro incubation at $37^{\circ} \mathrm{C}$ during 5 (T0), 30 (T30), 60 (T60), and 120 (T120) minutes, regardless on the treatment

Table 6 - Mean \pm standard error of motion characteristics of frozen-thawed equine sperm dilution with skim milk extender (SM Extender) and skim milk extender plus pentoxifylline (SM Extender + PTX, at $7.18 \mathrm{mM}$ ), regardless on the time of analysis...

Table 7 - Mean \pm standard error of motion characteristics of frozen-thawed equine sperm dilution with skim milk extender (SM Extender) and skim milk extender plus pentoxifylline (SM Extender + PTX, at $7.18 \mathrm{mM}$ ). Incubated in vitro at $37^{\circ} \mathrm{C}$ during 5 (T0), 30 (T30), 60 (T60), and 120 (T120) minutes.

Table 8 - Mean \pm standard error of motion characteristics of frozen-thawed equine sperm dilution with skim milk extender (SM Extender) and skim milk extender plus pentoxifylline (SM Extender + PTX, at $7.18 \mathrm{mM}$ ), regardless on the time of analysis

Table 9 - Mean \pm standard error of motion characteristics of frozen-thawed equine sperm dilution with skim milk extender (SM Extender) and skim milk extender plus pentoxifylline (SM Extender + PTX, at $7.18 \mathrm{mM}$ ). Incubated in vitro at $37^{\circ} \mathrm{C}$ during 5 (T0), 30 (T30), 60 (T60), and 120 (T120) minutes.

Table 10 - Mean \pm standard error of membranes status of frozen-thawed equine sperm dilution with skim milk extender (SM Extender) or skim milk extender plus pentoxifylline (SM Extender+PTX, at $7.18 \mathrm{mM}$ ). Incubated in vitro at $37^{\circ} \mathrm{C}$ during 5 (T0), 30 (T30), 60 (T60), and 120 (T120) minutes

Table 11 - Mean \pm standard error of chromatin decondensation classification of frozen-thawed equine sperm diluted with skim milk extender (SM Extender) and skim milk extender plus pentoxifylline (SM Extender + PTX, at $7.18 \mathrm{mM}$ ), regardless on the time of analysis 
Table 12 - Mean \pm standard error of chromatin decondensation classification of frozen-thawed equine sperm incubated in vitro at $37^{\circ} \mathrm{C}$ during $\mathrm{T} 30$ (30 minutes after incubation) and T120 (120 minutes after incubation), regardless on treatment.

Table 13 - Mean \pm standard error of spermatic morphology of frozen-thawed equine sperm dilution with skim milk extender (SM Extender) or skim milk extender plus pentoxifyliine (SM Extender + PTX, at 7,18 mM). Incubated in vitro at $37^{\circ} \mathrm{C}$ during T0 (5 minutes after incubation) and T120 (120 minutes after incubation.

Table 14 - Means \pm standard error of resistance index (RI, 0-1) and vascularity score (VS, 1-4) of groups: with no deposition of semen, or extender, just mimicking the AI procedure (Control), after infusion of skim milk extender (SM Extender) or skim milk extender plus pentoxifylline (SM Extender+ PTX), and semen diluted in skim milk extender (Semen) or semen diluted in skim milk extender plus pentoxifylline (Semen + PTX), regardless on time of analysis.

Table 15 - Means \pm standard error of resistance index (RI, 0-1) and vascularity score (VS, 1-4) of groups: with no deposition of semen, or extender, just mimicking the AI procedure (Control), after infusion of skim milk extender (SM Extender) or skim milk extender plus pentoxifylline (SM Extender +PTX), and semen diluted in skim milk extender (Semen) or semen diluted in skim milk extender plus pentoxifylline (Semen + PTX), at T-30 (immediately before ovulation induction), TIA (immediately before infusion), and 2 (T2), 6 (T6), 12 (T12), 24 (T24), and 48 hours after infusion (T48)

Table 16 - Means \pm standard error of resistance index (RI, 0-1) of uterine arteries. Effect of infusion of groups: with no deposition of semen, or extender, just mimicking the AI procedure (Control), after infusion of skim milk extender (SM Extender) or skim milk extender plus pentoxifylline (SM Extender +PTX), and semen diluted in skim milk extender (Semen) or semen diluted in skim milk extender plus pentoxifylline (Semen + PTX), at T-30 (immediately before ovulation induction), TIA (immediately before infusion), and 2 (T2), 6 (T6), 12 (T12), 24 (T24), and 48 hours after infusion (T4).......

Table 17 - Means \pm standard error of of vascularity score (VS, 1-4) of uterine horns. Effect of infusion of groups: with no deposition of semen, or extender, just mimicking the AI procedure (Control), after infusion of skim milk extender (SM Extender) or skim milk extender plus pentoxifylline (SM Extender +PTX), and semen diluted in skim milk extender (Semen) or semen diluted in skim milk extender plus pentoxifylline (Semen + PTX), at T-30 (immediately before ovulation induction), TIA (immediately before infusion), and 2 (T2), 6 (T6), 12 (T12), 24 (T24), and 48 hours after infusion (T4)........

Table 18 - Endometrial cytology of mares after 6 hours of infusion of the five experimental groups: with no deposition of semen, or extender, just mimicking the AI procedure (Control), after infusion of skim milk extender (SM Extender) or skim milk extender plus pentoxifylline (SM Extender + PTX), and semen diluted in skim milk extender (Semen) or semen diluted in skim milk extender plus pentoxifylline (Semen + PTX). Inflammatory cells in three hundred cells counted per slide. 


\section{LISTA DE ABREVIATURAS E SIGLAS}

$\mu \mathrm{L} \quad$ microlitro

$\mu \mathrm{m} \quad$ micrômetro

ALH amplitude of lateral head displacement

AMI acrosomal membrane integrity

AMPc adenosina monofosfato cíclico

ATI cells without chromatin decondensation

ATII intermediate chromatin decondensation

ATIII high chromatin decondensation

$\mathrm{BCF}$ beat-cross frequency

C5 componente do sistema complemento

C5a fragmento do componente do sistema complemento

$\mathrm{C} 5 \mathrm{~b}$ fragmento do componente do sistema complemento

CASA computer-assisted sperm analysis

DIC differential interference contrast

DNA ácido desoxirribonucleico

DP diluidor com pentoxifilina

DS diluidor sem pentoxifilina

e.g por exemplo

EDV end diastolic velocity

FITC isotiocianato de fluoresceína

FITC-PSA aglutinina de pisum sativum conjugada ao isotiocianato de fluoresceína

g grama

rpm rotação por minuto

H342 hoechst 33342

hCG gonadotrofina coriônica humana

HMMP high mitochondrial membrane integrity

$\mathrm{Hz} \quad$ hetz

IA inseminação artificial

IU unidade internacional

JC-1 Iodeto de 5,5',6,6'- tetracloro-1, 1',3,3' tetraetilbenzimidazol carbocianina 


$\begin{array}{ll}\text { kg } & \text { kilograma } \\ \text { LIN } & \text { linearity } \\ \text { mg } & \text { miligrama } \\ \text { min } & \text { minuto } \\ \text { mL } & \text { mililitro } \\ \text { mm } & \text { Milímetros } \\ \text { mM } & \text { minimolar } \\ \text { PBS } & \text { phosphate buffer saline } \\ \text { PGF } 2 \alpha & \text { prostaglandina f2 alfa } \\ \text { pH } & \text { potencial de hidrogênio } \\ \text { PI } & \text { índice de pulsatilidade } \\ \text { PI } & \text { iodeto de propídio } \\ \text { PMI } & \text { plasmatic membrane integrity } \\ \text { PMN } & \text { polimorfonucleares } \\ \text { PMOT } & \text { progressive motility } \\ \text { PSV } & \text { peak systolic velocity } \\ \text { PTX } & \text { pentoxifilina } \\ \text { RI } & \text { índice de resistência } \\ \text { s } & \text { segundo } \\ \text { SM } & \text { skim milk } \\ \text { STR } & \text { straightness } \\ \text { VV } & \text { score vascularization } \\ \text { TABF } & \text { média de velocidades máximas } \\ \text { TMOT } & \text { total motility } \\ \text { VAF } & \text { fur }\end{array}$




\section{LISTA DE SÍMBOLOS}

$\begin{array}{ll}\% & \text { porcentagem } \\ > & \text { maior } \\ < & \text { menor } \\ \geq & \text { maior ou igual } \\ \pm & \text { mais ou menos } \\ { }^{\circ} \mathrm{C} & \text { grau Celsius } \\ \mathrm{X} & \text { vezes }\end{array}$




\section{SUMÁRIO}

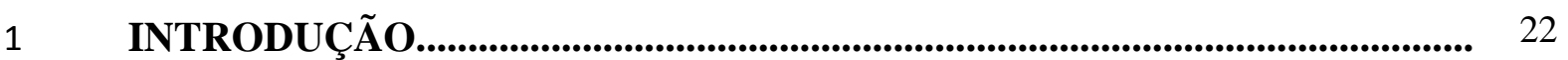

2 REVISÃO DE LITERATURA........................................................................... 24

2.1 SÊMEN CRIOPRESERVADO............................................................................ 24

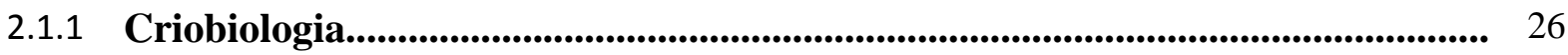

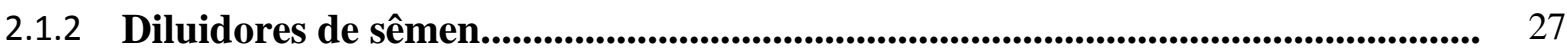

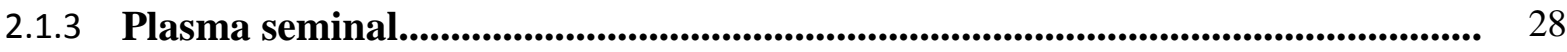

2.2 ANÁLISE ESPERMÁTICA POR SONDAS FLUORESCENTES........................... 30

2.2.1 Integridade de membrana plasmática............................................................ 30

2.2.2 Integridade de membrana acrossomal........................................................... 31

2.2.3 Potencial de membrana mitocondrial.............................................................................. 31

2.3 INTEGRIDADE DE CROMATINA....................................................................... 32

2.4 MORFOLOGIA ESPERMÁTICA...................................................................................... 33

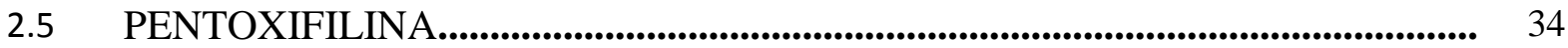

2.5.1 Efeito da pentoxifilina no sêmen.......................................................................... 35

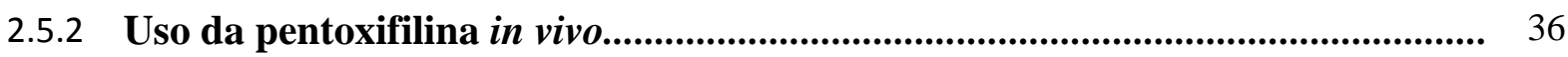

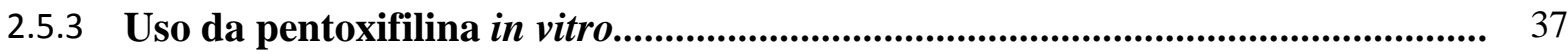

2.5.4 Uso da pentoxifilina antes ou após a criopreservação........................................ 39

2.6 ENDOMETRITE PÓS-COBERTURA..................................................................... 40

2.6.1 Limpeza física do lúmen uterino.................................................................. 43

2.6.2 Mecanismos celulares e imunológicos............................................................ 43

2.6.3 Comprometimento dos mecanismos de limpeza................................................ 44

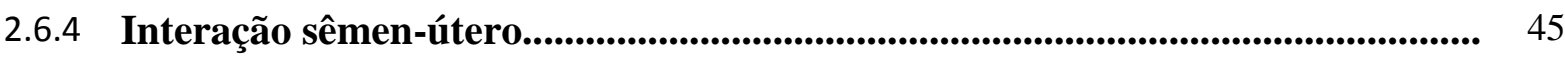

2.7 UNTRASONOGRAFIA DOPPLER........................................................................... 46

2.7.1 Ultrassonografia Doppler na reprodução............................................................... 47

2.7.2 Perfusão vascular do endométrio de éguas........................................................... 48 


$\begin{array}{lcrr}\text { PENTOXIFYLLINE } & \text { MAINTAIN } & \text { SPERM } & \text { MOTION } \\ \text { CHARACTERISTICS AND MEMBRANES } & \text { INTEGRITY } & \text { WITHIN } \\ \text { TWO HOURS OF INCUBATION WHEN ADDED AFTER THAWED } \\ \text { CRYOPRESERVED STALLION SEMEN }\end{array}$

5.2 MATERIALS AND METHODS.

5.2.1 Location and experimental period............................................................. 58

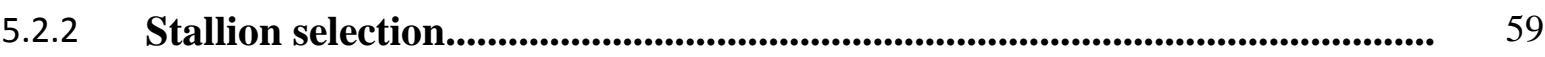

5.2.3 Semen collection and cryopreservation....................................................... 59

5.2.4 Semen thawing, dilution and incubation.............................................................. 60

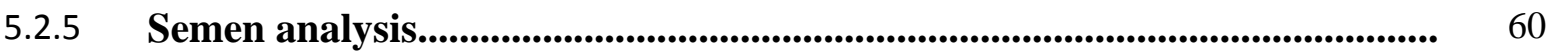

5.2.5.1 Computer-Assisted Sperm Analysis (CASA)...................................................... 60

5.2.5.2 Membranes Analysis.................................................................................. 61

5.2.5.3 Chromatin Denaturation Analysis...................................................................... 63

5.2.5.4 Sperm Morphology................................................................................................................... 63

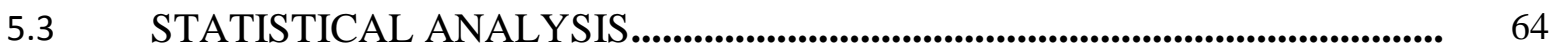

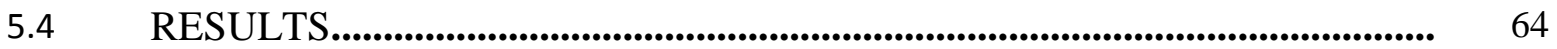

5.4.1 Effect of equine thawed sperm dilution using skim milk extender with pentoxifyline on sperm motion and membranes.............................................. 64

5.4.2 Effect of pentoxifylline addition to skim milk extender to frozen-thawed equine sperm in vitro incubated at $37^{\circ} \mathrm{C}$ has on sperm motion, membranes, chromatin and morphology................................................................. 66

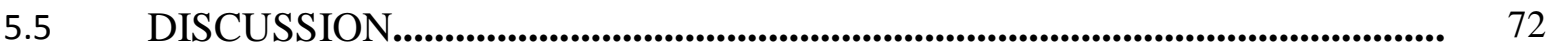

5.5.1 Effect of equine thawed sperm dilution using skim milk extender with pentoxifyline on sperm motion and membranes................................................. $\quad 72$

5.5.2 Effect of pentoxifylline addition to skim milk extender to frozen-thawed equine sperm in vitro incubated at $37^{\circ} \mathrm{C}$ has on sperm motion, membranes, chromatin and morphology. 

RESPONSE ASSESSED BY ENDOMETRIAL CYTOLOGY AND VASCULAR PERFUSION

INTRODUCTION ............................................................................................. 80

6.2 MATERIALS AND METHODS.................................................................................. 82

6.2.1 Location and experimental period........................................................... 82

6.2.2 Management and animal selection.............................................................. 82

6.2.3 Follicular development and ovulation detection........................................... 83

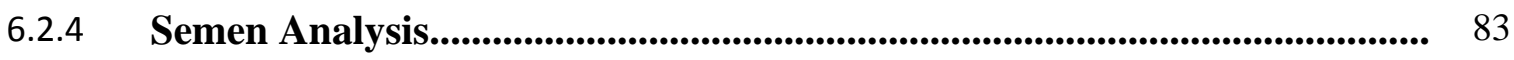

6.2.5 Extenders and artificial insemination........................................................... 84

6.2.6 Assessment of endometrial inflammatory response.................................... 85

6.2.6.1 Vascular perfusion of the endometrium.......................................................... 85

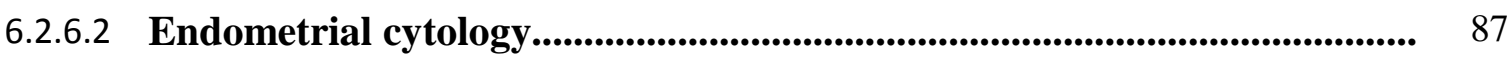

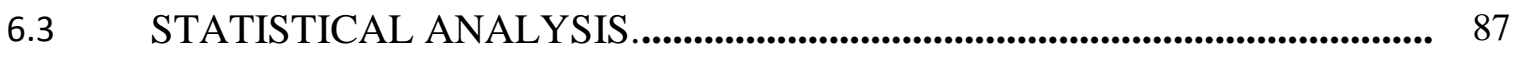

RESULTS................................................................................................................................ 88

6.4.1 Vascular perfusion of the endometrium....................................................... 88

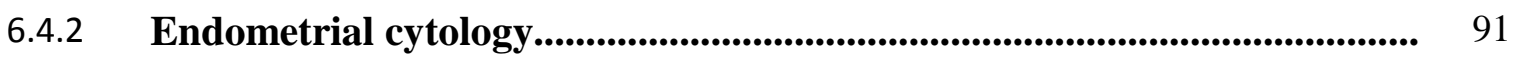

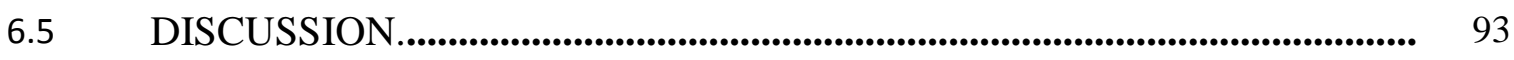

6.5.1 Vascular perfusion of the endometrium............................................................ 93

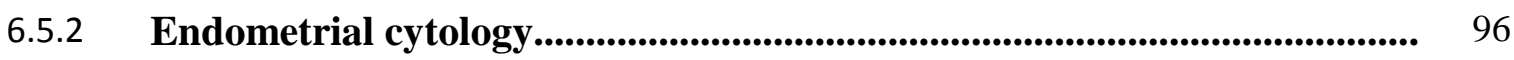

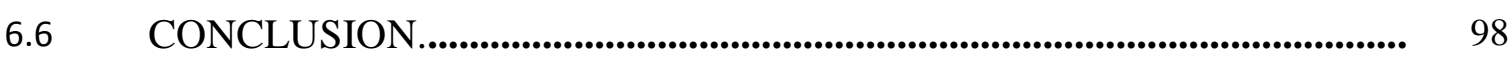

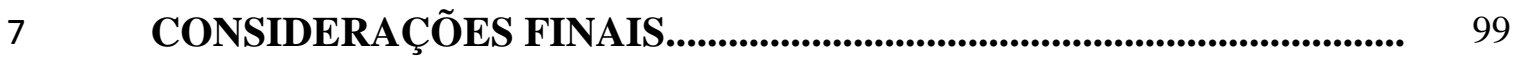

REFERÊNCIAS 


\section{INTRODUÇÃO}

A indústria equina mundial exerce importante papel como fonte geradora de renda e empregos. A equideocultura no país é responsável pela geração de 600 mil empregos diretos e 3,2 milhões de empregos indiretos. As exportações desta atividade já ultrapassaram US\$ 27,4 milhões, receita superior a de produtos como café torrado e cachaça, os quais tem uma divulgação bem mais ampla fora do país. O Brasil tem o quarto maior rebanho equino do mundo, com 5,8 milhões de cabeças, atrás dos Estados Unidos, China e México, sendo o faturamento da indústria do cavalo de R \$ 7,5 bilhões por ano (CFMV, 2010).

O sucesso da equideocultura está intimamente ligado à reprodução, sendo assim grande parte das pesquisas voltadas à reprodução de equinos visa aumentar os índices reprodutivos (e.g., taxa de prenhez ao final da estação de monta, taxa de recuperação embrionária, taxa de prenhez após transferência de embrião), de forma a promover maior retorno econômico à atividade. Estudos estes voltados tanto para os aspectos relativos ao melhoramento da capacidade fertilizante dos espermatozoides, como aspectos voltados às condições do trato reprodutivo das éguas e manipulação do ciclo estral por hormônios (ALONSO, 2013).

Um dos pontos fundamentais para a utilização de biotécnicas da reprodução visando o aumento dos índices reprodutivos é a criopreservação, uma tecnologia por meio da qual células, tecidos ou embriões são preservados a temperaturas abaixo do ponto de congelação da água, tendo como premissa a preservação da composição e da viabilidade das células por tempo indefinido (PEGG, 2002). Apesar dos inúmeros benefícios gerados pela criopreservação, vale salientar que esta técnica é também responsável por danos significativos ao espermatozoide induzidos pelo choque térmico e osmótico, levando à danos de 
membranas, lesões oxidativas, anormalidades morfológicos e funcionais, com redução drástica da motilidade pós-descongelação (WATSON, 2000; PURDY, 2006; SIEME; HARRISON; PETRUNKINA, 2008).

A melhora da qualidade espermática pós-descongelação é de fundamental importância para a melhora nos índices reprodutivos. Neste sentido, vários componentes vêm sendo testados para a melhora na motilidade espermática pós-descongelação, entre eles destaca-se a pentoxifilina. Esta substância inibe a enzima fosfodiesterase, aumentando a concentração de AMPc (adenosina monofosfato cíclico) no interior das células. Desta forma, a geração de energia que atua diretamente no controle flagelar do espermatozoide é mantida, melhorando assim a motilidade dos espermatozoides (CALOGERO et al., 1998, SHEN et al., 1991, GRADIL \& BALL, 2000, MARQUES et al., 2002).

Por outro lado, a pentoxifilina apresenta outros mecanismos de ação: melhora o fluxo sanguíneo de tecidos comprometidos (ação reológica) e a remoção bacteriana (ação imunomoduladora), reduzindo os danos causados nos tecidos pelos neutrófilos (BAUMGARTNER, 2007). Assim, a pentoxifilina adicionada ao diluidor de sêmen poderia atuar tanto na melhora da qualidade espermática pós-descongelação como também favorecer a égua inseminada através da ação desta substância em seu trato reprodutivo.

Com o intuito aprimorar os estudos relacionados a melhoramentos da capacidade fertilizante tanto dos espermatozoides após processo de criopreservação, como aspectos voltados às condições do trato reprodutivo das éguas, este estudo tem como objetivo verificar quais benefícios que a adição da pentoxifilina pode trazer para os parâmetros espermáticos pós-descongelação assim como avaliar de que forma ela pode contribuir para a recuperação endometrial uterina pós-cobertura. 


\section{REVISÃO DE LITERATURA}

A criopreservação do sêmen traz diversos benefícios, porém possui limitações quanto a qualidade seminal pós-descongelação (PURDY, 2006). Por isso se faz necessário o uso de diluidores, pré e pós-descongelação uma vez que são responsáveis por proteger as membranas celulares, controlar pH, osmolaridade e fornecer suprimento energético (AURICH, 2005).

Sendo assim, a pentoxifilina vem sendo estudada quanto a sua atuação no incremento da motilidade espermática (CALOGERO et al., 1998) assim como na vascularização de tecidos, devido propriedades reológicas e imunomoduladoras (WARD; CLISSOLD, 1987). Éguas no período pós-cobertura desenvolvem endometrite transitória, que podem se tornar persistentes devido uma série de falhas nos mecanismos físicos e imunológicos de limpeza (KATILA, 1996).

Nesta revisão serão abordados assuntos relacionados ao processo de criopreservação e o seu efeito na célula espermática, assim como os efeitos que a pentoxifilina exerce tanto no sêmen como na vascularização e sistema imune da égua pós-cobertura.

\subsection{SÊMEN CRIOPRESERVADO}

A criopreservação é a tecnologia por meio da qual células, tecidos ou embriões são preservados a temperaturas abaixo do ponto de congelação da água, tendo como premissa a preservação da composição e da viabilidade das células por tempo indefinido (PEGG, 2002).

A criopreservação de sêmen têm sido vista como um meio de beneficiar a produção animal por aumentar a propagação de material genético de animais de alto valor em menor espaço de tempo e têm sido reconhecida como um contribuinte para a conservação de 
espécies e para superar aspectos da infertilidade masculina em humanos (WATSON, 2000; SALAZAR et al., 2011; SILVA; GUERRA, 2011).

Benefícios da criopreservação do sêmen são numerosos e incluem: (a) menor custo, (b) evita a exposição dos animais à doenças, (c) permite que o sêmen do garanhão seja utilizado, enquanto este estiver em competição (d) torna possível planejar as inseminações, que muitas vezes são limitadas devido às diferenças da estação de monta no hemisfério norte e hemisfério sul (e) permite a utilização do sêmen após a morte do animal (AMANN; PICKETT, 1987), (f) aumenta a possibilidade de inseminação de éguas no momento ideal sem depender da disponibilidade de curta duração do sêmen fresco transportado (SALAZAR et al., 2011).

As desvantagens advêm do menor rendimento de doses por ejaculado devido perda de aproximadamente $50 \%$ de espermatozoides nesse processo, menores taxas de prenhez, devido à baixa crioresistência, variação entre espécies, raças, ejaculados e entre subpopulações espermáticas (RODRIGUEZ-MARTINEZ, 2003; WATSON, 2000; PURDY, 2006). Isto explica as respostas diversificadas à criopreservação, influenciando diretamente na congelabilidade seminal (AMANN; PICKETT, 1987; BORG et al., 1997; VIDAMENT et al., 1997).

Congelabilidade é um termo frequentemente utilizado para representar as taxas de sobrevivência das populações de espermatozoides por meio de testes laboratoriais seguindo um ciclo de congelação e descongelação (SALAZAR et al., 2011). A congelabilidade é uma característica reprodutiva de cada animal e independe da técnica utilizada. Indivíduos podem ser classificados como bom congeladores ou mau congeladores, e isso implica em maior ou menor resistência ao processo de criopreservação (WATSON, 2000). 
Foi estimado que aproximadamente $20 \%$ de garanhões produzem sêmen que congela bem, $60 \%$ que congelam razoavelmente e $20 \%$ que congelam mal. Tais diferenças podem ser de origem genética (VIDAMENT et al., 1997; WATSON, 2000).

Os principais fatores que causam sensibilidade do espermatozoide à procedimentos de congelação convencional são os choques térmico e osmótico. No entanto, há comprometimento das células espermáticas, como danos de membrana, danos oxidativos, comprometimento da integridade de estrutura nuclear, danos morfológicos e funcionais das células (WATSON, 2000; PURDY, 2006; SIEME; HARRISON; PETRUNKINA, 2008).

\subsubsection{Criobiologia}

A solução aquosa no meio intra e extracelular contém eletrólitos, macromoléculas e gases que estão presentes em diferentes estados (PETRUNKINA, 2007). Durante a congelação e descongelação, as concentrações e distribuições destes solutos no meio intra ou extracelular sofrem alterações. Assim como ocorrem alterações na osmolaridade dentro e ao redor das células espermáticas (SIEME; HARRISON; PETRUNKINA, 2008).

Quando a célula espermática é submetida a congelação lenta, há tempo suficiente para que grande quantidade de água intracelular migre para o ambiente extracelular, estabelecendo o equilíbrio entre solvente e soluto. Desta forma, torna-se estritamente necessária a descongelação na mesma intensidade, ou seja, de forma lenta, para que a célula ao ser reidratada não sofra rompimento das membranas biológicas pela rápida reconstituição do volume intracelular (AMANN; PICKETT, 1987; SIEME; HARRISON; PETRUNKINA, 2008; SILVA; GUERRA, 2011). 
O processo de congelação rápida aliada à descongelação lenta, implicará danos causados pela formação de pequenos cristais de gelo os quais podem se agrupar e formar grandes cristais de gelo que rompem a membrana (PEGG, 2002; SILVA; GUERRA, 2011).

Já quando o processo de congelação ocorre de forma muito lenta, a desidratação excessiva, faz com que o meio intracelular fique mais concentrado, apresentando altos níveis de sais os quais são responsáveis por causar danos as células (PETRUNKINA, 2007). Se a taxa de congelação for muito rápida, haverá formação de cristais de gelo intracelular. A taxa de congelação ideal é um equilíbrio entre esses fatores (AMANN; PICKETT, 1987).

\subsubsection{Diluidores de sêmen}

O processamento do sêmen sujeita o espermatozoide ao estresse. A congelação e a descongelação são prejudiciais à membrana plasmática, porém diferentes métodos utilizados nesses processos podem ser mais ou menos danosos (BORG et al., 1997). Considerando o dano celular causado, a eficiência do espermatozoide descongelado em atingir prenhez é muito inferior em comparação ao sêmen fresco (STANIC; SONICKI; SUCHANEK, 2002).

Portanto, além das duas etapas de diluição do sêmen antes da criopreservação, sendo a primeira realizada para diluir o sêmen fresco. E a segunda realizada com crioprotetor após centrifugação (SIEME; HARRISON; PETRUNKINA, 2008). Na tentativa de melhorar a motilidade espermática, se faz necessário a diluição do sêmen pós-descongelação (GRADIL; BALL, 2000).

Diluidores de sêmen tem sido responsáveis por prolongar a vida do espermatozoide, uma vez que estabilizam sistemas enzimáticos, mantém a integridade de membranas (BERGERON; MANJUNATH, 2006), protegem os espermatozoides de danos como choque 
térmico, dos efeitos deletérios do plasma seminal (AURICH, 2005) e dos produtos tóxicos produzidos pelos próprios espermatozoides e previnem o crescimento de microrganismos. Além disso aumentam o volume da dose inseminante, auxiliando no transporte espermático (KATILA, 1997) promove o controle de $\mathrm{pH}$, osmolaridade e fornece suprimento de energia para células espermáticas (AURICH, 2005).

Diversos tipos de diluidores interagem com o sêmen e promovem a proteção dos compartimentos das células espermáticas, durante os processos de refrigeração, congelação e descongelação (HOLT, 2000). O diluidor mais utilizado e constituído por leite em pó desnatado, glicose e antibiótico (KENNEY et al., 1975).

Componentes como micelas de caseína encontradas no leite, interagem com as proteínas da membrana plasmática, conferindo proteção espermática. Estas não permitem a remoção de fosfolipídios e colesterol da membrana plasmática (BERGERON; MANJUNATH, 2006).

Porém a utilização de diluidores à base de leite ou gema de ovo apresentam uma limitação pelo fato de serem substancias biológicas compostas por uma variedade de moléculas distintas que podem variar entre lotes (AURICH, 2005)

\subsubsection{Plasma seminal}

O plasma seminal consiste em um fluido produzido pela rete testis, epidídimo e glândulas sexuais acessórias. A contribuição de cada local de produção varia, e a natureza de todos os componentes ainda não estão bem definidos. Os componentes do plasma seminal participam do desenvolvimento e maturação de espermatozoides no trato reprodutivo masculino (TROEDSSON et al., 2005). Sua participação favorece a locomoção e 
sobrevivência dos espermatozoides, auxiliando no transporte do espermatozoide para o local da fertilização e os protege do ambiente uterino inflamado inibindo a quimiotaxia dos PMN e fagocitose (KATILA, 2001). Porém há relatos que a retirada do plasma seminal, preservou a motilidade espermática, melhorando a qualidade do sêmen refrigerado equino (RAPHAEL, 2007).

As proteínas do plasma seminal protegem os espermatozoides viáveis, não danificados, de se ligarem aos PMN. Este processo tem importância maior quando as éguas são inseminadas com sêmen criopreservado (TROEDSSON, 2005).

Há evidências do plasma seminal ser um fator importante na regulação da endometrite induzida pós-cobertura. A resposta inflamatória teve menor duração quando o plasma seminal foi incluído na dose inseminante, quando comparado com a remoção do plasma seminal e substituição por um diluidor de sêmen comercial (TROEDSSON et al., 2001).

A ausência de plasma seminal associado com alta concentração espermática do sêmen criopreservado causa resposta inflamatória pós-cobertura mais intensa (CARD et al., 2004) e com maior acúmulo de líquido intrauterino, quando comparado com sêmen refrigerado ou cobertura natural (KOTILAINEN; HUHTINEN; KATILA, 1994; TROEDSSON et al., 2001; ROTA et al., 2012). Além de que a remoção do plasma seminal é um dos fatores responsáveis pelas baixas taxas de prenhez que ocorrem em éguas inseminadas com sêmen congelado (KATILA, 2001).

Há evidências que o plasma seminal também desempenha um papel ativo no trato reprodutivo feminino através da ação de hormônios, enzimas, proteínas, lipídeos e metabólitos. A melhora no transporte espermático, o adiantamento do momento da ovulação, e o aumento do fluxo sanguíneo de útero e tubas uterinas de porcas e éguas, tem sido associado à presença de plasma seminal (BOLLWEIN; SOWADE; STOLLA, 2003b). 


\subsection{ANÁLISE ESPERMÁTICA POR SONDAS FLUORESCENTES}

O processo de congelação é responsável por afetar estruturas da célula espermática (ERICSSON et al., 1993), para tanto se faz necessário testes que determinam o grau de comprometimento celular de uma amostra. Testes laboratoriais que avaliam as membranas de forma isolada (membrana plasmática, membrana acrossomal e membrana mitocondrial), não são capazes em predizer a fertilidade de uma amostra de sêmen, no entanto, a combinação de vários testes realizados simultaneamente tem demonstrado melhores resultados (GRAHAM; KUNZE; HAMMERSTEDT, 1990).

A combinação de várias sondas fluorescentes possibilita a avaliação de diversos compartimentos espermáticos, refletindo o estado real de cada estrutura (RODRIGUEZMARTINEZ, 2003; CELEGHINI et al., 2007; ARRUDA et al., 2011).

\subsubsection{Integridade de membrana plasmática}

A membrana plasmática do espermatozoide não é simplesmente uma barreira semipermeável. É uma estrutura dinâmica e complexa composta por lipídeos e fosfolipídios distribuídos em uma bicamada. No interior da membrana há proteínas e glicoproteínas com acesso direto ao meio externo e interno da célula (SIEME; HARRISON; PETRUNKINA, 2008).

Para avaliar a sua integridade pode-se utilizar a sonda fluorescente iodeto de propídeo (PI). Esta sonda é capaz de detectar a proporção de células com membrana plasmática lesada em uma população (PAPAIOANNOU et al., 1997). O PI é um fluoróforo vermelho brilhante, 
com ligação específica ao ácido nucleico e impermeável à membrana plasmática íntegra, corando apenas as células com membrana plasmática rompida (GARNER et al., 1986). Outro corante que apresenta especificidade ao DNA, também utilizado para determinar a integridade de membrana plasmática é o Hoechst 33342 (H342), este quando associado com o corante PI, atua como marcador de membrana plasmática intacta emitindo fluorescência azul (CELEGHINI et al., 2007).

\subsubsection{Integridade de membrana acrossomal}

O acrossomo derivado do complexo de Golgi se encontra sobre a porção anterior do núcleo do espermatozoide. Estudos tem avaliado a perda acrossomal, especialmente na criopreservação espermática, processo este responsável por causar alterações mecânicas nas membranas celulares e afetar sua funcionalidade (CROSS; MEIZEL, 1989).

Para determinar o grau de comprometimento das membranas acrossomais, é utilizada uma sonda fluorescente seletiva específica para o acrossoma, o isotiocianato de fluoresceína (FITC) conjugado com aglutinina de Pisum sativum (PSA) proveniente da ervilha, se liga à glicoconjugados da matriz acrossomal (SUKARDI; CURRY; WATSON, 1997) corando de verde-amarelado os espermatozoides com acrossoma lesado (CROSS; MEIZEL, 1989; ANDRADE et al., 2007; CELEGHINI et al., 2007).

\subsubsection{Potencial de membrana mitocondrial}


A motilidade dos espermatozoides depende do metabolismo energético mitocondrial. Baseado nas alterações das funções mitocondriais, há evidências que o dano mitocondrial causado durante o processo de criopreservação pode ser o principal responsável por diminuir a qualidade do sêmen pós-descongelação (SCHOBER et al., 2007).

A avaliação do potencial de membrana mitocondrial é realizada pela sonda fluorescente 5,5 ,6,6 -tetracloro-1,1,3,3`-tetraetilbenzimidazol carbocyanine iodide (JC-1). O corante de carbocianina fluorescente. O JC-1 indica em laranja as mitocôndrias com alto potencial de membrana e em verde as mitocôndrias com baixo potencial de membrana (REERS et al., 1991; GRAVANCE et al., 2000, ANDRADE et al., 2007).

A associação de PI, H342, FITC-PSA e JC-1 é uma técnica validada e utilizada para avaliar sêmen de touros (GRAVANCE et al., 2000; CELEGHINI et al., 2007) suínos (ANDRADE et al., 2007), carneiros (CELEGHINI et al., 2010b) e equinos (GRAVANCE et al., 2000; NASCIMENTO et al., 2008; CELEGHINI et al., 2010a).

\subsection{INTEGRIDADE DE CROMATINA}

Durante a espermiogênese, as espermátides após terem sofrido meiose, passam por uma série de transformações que resultam em espermatozoides contendo cromatina nuclear condensada (ARAVINDAN et al., 1997; ERENPREISS et al., 2006). A condensação do material nuclear da célula é um evento importante na diferenciação do núcleo espermático, o DNA espermático é compactado devido a substituição de histonas por protaminas (BELETTI; COSTA; GUARDIEIRO, 2005).

A integridade da cromatina espermática é essencial para enviar a informação genética paterna, além de participar no processo de fertilização. A avaliação do DNA espermático 
parece ser uma ferramenta útil para avaliar o potencial de fertilidade masculina (ERENPREISS et al., 2006).

Uma das técnicas utilizadas para esta avaliação é por meio de um corante, o azul de toluidina. Este é um corante catiônico que se liga ao DNA através de interações iônicas com fosfato, apresentando uma coloração violeta-azulada metacromática. Sendo assim os espermatozoides podem ser classificados em três grupos de acordo com o grau de condensação da cromatina: azul claro (negativo, sem descondensação da cromatina), violeta claro (intermediário, com algum grau de descondensação) e violeta azulado escuro (positivo, alto grau de descondensação) (CARRETERO et al., 2011).

Em espermatozoides com cromatina normal, a maior parte do fosfato está bloqueada pelas protaminas e consequentemente poucas moléculas de corante se ligam ao DNA (BELETTI; COSTA; GUARDIEIRO, 2005).

\subsection{MORFOLOGIA ESPERMATICA}

O exame da morfologia espermática isolado, não e capaz de afirmar o potencial de fertilidade de um ejaculado, mas sim pode predizer o baixo potencial de fertilidade quando há alta taxa de espermatozoides apresentando anormalidades. No entanto a morfologia espermática apresenta grande impacto na fertilidade de todas as espécies já estudadas (DOTT, 1975).

Para avaliar a morfologia espermática da espécie equina se faz necessária a remoção do gel, pois este dificulta a visualização dos espermatozoides. A leitura da morfologia 
espermática se faz em câmara úmida, fixadas em formol salino tamponado, sob microscopia de contraste de fase com aumento de 1000x ou mais (BRITO, 2007).

\subsection{PENTOXIFILINA}

A pentoxifilina é um derivado da metilxantina (SAMLASKA; WINFIELD, 1994) que pertence a mesma classe da cafeína, teobromina e teofilina (BAUMGARTNER, 2007).

Tanto na espécie humana como nos animais, a sua absorção é rapidamente realizada pelo trato gastrointestinal (WARD; CLISSOLD, 1987). Seu metabolismo ocorre pelas células vermelhas e pelo fígado. A meia vida é curta com duração aproximada de 3-4 horas. Mais de 90\% da pentoxilifina absorvida é excretada pela urina (SAMLASKA; WINFIELD, 1994).

A terapia com pentoxifilina tem demonstrado resultados em humanos e animais, atuando em uma série de alterações fisiológicas à nível celular, o que a torna importante para o tratamento de diversos tipos de doenças (SAMLASKA; WINFIELD, 1994), isso ocorre devido seu mecanismo de ação que está dividido em dois ramos: agente reológico e agente imunomodulador (BAUMGARTNER, 2007).

Como agente reológico a pentoxifilina atua melhorando o fluxo sanguíneo de tecidos comprometidos (BAUMGARTNER, 2007) através do aumento da capacidade de deformação dos eritrócitos sanguíneos, reduzindo a viscosidade do sangue e diminuindo o potencial de agregação plaquetária e formação de trombos (WARD; CLISSOLD, 1987).

A partir dessas alterações, a pentoxifilina é capaz de tratar doenças vasculares periféricas, doenças cerebrovasculares e outras condições que comprometam a microcirculação de tecidos e órgãos (WARD; CLISSOLD, 1987). Há relatos que a pentoxifilina aumentou a perfusão sanguínea de testículos de Mini-horses no período de 
inverno (POZOR et al., 2011). Geralmente não há efeitos sobre a pressão arterial sistêmica e frequência cardíaca. Há pouca evidência de uma ação vasodilatadora direta após a administração oral de pentoxifilina à pacientes doentes (WARD; CLISSOLD, 1987). Quando foi administrada em doses terapêuticas para éguas prenhes, não alterou o fluxo sanguíneo uterino (BAILEY et al., 2012).

Como agente imunomodulador, ela aumenta a deformabilidade de leucócitos, diminui a agregação e adesão bacteriana nos tecidos do hospedeiro, diminui a degradação de neutrófilos sem afetar o processo de fagocitose, e diminui a liberação de radicais livres,

portanto reduz o dano celular (ARIAS-DIAZ et al., 1997). É também, responsável por estimular a liberação de prostaciclinas, um potente vasodilatador e inibidor de agregação plaquetária (SAMLASKA; WINFIELD, 1994; BAILEY et al., 2012).

\subsubsection{Efeito da pentoxifilina no sêmen}

Vários componentes vem sendo testados para melhorar a motilidade espermática, entre eles está a pentoxifilina. No sêmen sua atuação é diferente, ela inibe a enzima fosfodiesterase e aumenta a concentração de AMPc (adenosina monofosfato cíclico) no interior das células, mantendo a geração de energia que atua diretamente no controle flagelar do espermatozoide, melhorando assim a motilidade dos espermatozoides (CALOGERO et al., 1998, SHEN et al., 1991; GRADIL; BALL, 2000, MARQUES et al., 2002).

A pentoxifilina é conhecida por estimular a motilidade de sêmen humano fresco e criopreservado (CENTOLA; CARTIE; COX, 1995), ela melhora as características cinéticas e o número de espermatozoides exibindo motilidade hiperativada (CALOGERO et al., 1998). 
Vale salientar que em alguns indivíduos as alterações nos parâmetros de motilidade e hiperativação induzidas pela adição de pentoxifilina, nem sempre estiveram acompanhadas por alterações no teor de AMPc intracelular. De fato, algumas amostras de sêmen demonstraram efeito benéfico da pentoxifilina independentemente do aumento ou diminuição do AMPc intracelular. Sugerindo que o aumento do AMPc pode não ser o único mecanismo envolvido (CALOGERO et al., 1998).

\subsubsection{Uso da pentoxifilina in vivo}

Em um estudo, 15 jovens que apresentavam astenozoospermia foram tratados com $1.200 \mathrm{mg}$ de pentoxifilina por dia (alta dosagem), via oral durante quatro meses. Os resultados demonstraram uma melhora significativa na motilidade progressiva. Cinco dos pacientes tiveram sua qualidade espermática normalizada. Portanto, a pentoxifilina parece ser uma alternativa para o tratamento de homens astenozoospérmicos (APARICIO; SCHWARZTEIN; TURNER, 1980).

Nos dois anos seguintes, foi realizado um estudo que tratava dois grupos distintos de homens subférteis: 25 homens com astenozoospermia idiopática e 40 homens com oligozoospermia normogonadotrópica idiopática. Os indivíduos foram tratados com 1,2 g por dia de pentoxifilina durante três meses. O grupo de astenozoospérmicos tiveram aumento significativo na motilidade progressiva, já no grupo de oligozoospérmicos os parâmetros seminais não foram alterados (SCHILL, 1982).

Da mesma forma Shen et al. (1991) observaram que após administração de pentoxifilina durante três meses para pacientes astenozoospérmicos, apesar da motilidade 
espermática ter apresentado aumento significativo, não houve alteração na concentração espermática.

Observou-se aumento tanto na concentração como na motilidade espermática, em um estudo realizado com 22 homens que apresentavam oligoastenozoospermia idiopática que foram tratados com $1.200 \mathrm{mg}$ de pentoxifilina via oral, diariamente durante seis meses (MARRAMA et al., 1985).

Quando foi administrado $400 \mathrm{mg}$ de pentoxifilina, considerada baixa dosagem, em homem apresentando varicocele testicular, via oral duas vezes por semana durante três meses, a motilidade progressiva apresentou um leve aumento quando comparado com o aumento significativo que apresentou quando a pentoxifilina foi aplicada ao sêmen in vitro (MOEIN; KHALILI; DAVOUDI, 2005).

Notou-se que a pentoxifilina é um fármaco seguro, que não deteriorou as características espermáticas como concentração e morfologia. É importante levar isso em consideração, pois não haveria valor se ela melhorasse a motilidade mas prejudicasse outros aspectos do sêmen (MOEIN; KHALILI; DAVOUDI, 2005).

\subsubsection{Uso da pentoxifilina in vitro}

In vitro a pentoxifilina tem sido testada de diversas maneiras a fim de estudar seu efeito nas características espermáticas. Os resultados variam de acordo com a concentração utilizada (CENTOLA; CARTIE; COX, 1995; BLANES et al., 2004), espécie (SHEN et al., 1991; CALOGERO et al., 1998; ORTIGIES et al., 2012), condição que o sêmen se encontra, fresco, refrigerado (GOULART et al., 2004) ou criopreservado (GRADIL; BALL, 2000) e o período de incubação (MARQUES et al., 2002). 
A pentoxifilina parece ter um efeito variável, podendo estar relacionado com a qualidade espermática inicial (CENTOLA; CARTIE; COX, 1995).

Bunge (1973) observou que o sêmen humano quando tratado com solução de cafeína a $4 \mathrm{mM}$ manteve a atividade e viabilidade espermática por mais tempo do que o grupo controle não tratado. Amostras seminais de homens que apresentavam baixa motilidade espermática, tiveram melhora imediata após tratamento com solução de cafeína.

Duas décadas depois, um estudo experimental, comparou o efeito de diferentes doses de pentoxifilina no sêmen fresco e criopreservado de humanos, e demonstrou que o maior efeito benéfico foi alcançado a uma concentração de $2,5 \mathrm{mg} / \mathrm{mL}$ (aproximadamente $9 \mathrm{mM}$ ). Em concentrações acima de $5 \mathrm{mg} / \mathrm{mL}$, a pentoxifilina demonstrou ser prejudicial às células espermáticas, alcançando nível tóxico, sendo que a imobilização total dos espermatozoides ocorreu a uma concentração de 20 mg/mL (CENTOLA; CARTIE; COX, 1995).

Em outro estudo, ainda na espécie humana, foram testadas diferentes concentrações: $1 \mathrm{mM}, 5 \mathrm{mM}, 10 \mathrm{mM}$ e $50 \mathrm{mM}$, no sêmen fresco (controle) e no sêmen congelado com pentoxifilina (tratado), a fim de verificar seu efeito antioxidante. De todos os grupos, só foi observada melhora significativa na motilidade após o processo de congelação e descongelação no grupo de $1 \mathrm{mM}$ de pentoxifilina. Para as concentrações mais altas a qualidade espermática pós-descongelação não melhorou, pelo contrário provocou um efeito negativo. Os autores concluíram então que apenas baixas concentrações de pentoxifilina são capazes de inibir a geração de ânion superóxido e portanto promover a proteção das células durante o processo de congelação (BLANES et al., 2004).

No mesmo ano, outro estudo foi realizado onde foram testados no sêmen refrigerado de garanhões, o efeito da adição de 3,6 mM de pentoxifilina, sendo notado efeito positivo mesmo quando foi adicionada após 48 horas da refrigeração, ela foi capaz de ativar a motilidade espermática até 120 minutos de incubação a $37^{\circ} \mathrm{C}$. A pentoxifilina proporcionou 
além de proteção às células, redução nos radicais livres de oxigênio atuando como fator antioxidante (GOULART et al., 2004).

\subsubsection{Uso da pentoxifilina antes ou após a criopreservação}

A adição de pentoxifilina no sêmen antes de passar pelo processo de criopreservação além de melhorar a motilidade, melhorou a capacidade de reação acrossomal dos espermatozoides, minimizou os danos causados pelo processo de congelação, principalmente a perda acrossomal (ESTEVES et al., 1998).

Brennan e Holden (1995) verificaram que a adição de $1 \mathrm{mM}$ ou $3 \mathrm{mM}$ de pentoxifilina ao meio de congelação, promoveu aumento significativo na motilidade espermática das amostras descongeladas de sêmen humano.

Porém, há estudos que comprovam o contrário. A adição de pentoxifilina $(3 \mathrm{mM}$ ou $7 \mathrm{mM}$ ) ao sêmen equino antes da criopreservação diminuiu significativamente a motilidade total e a progressiva comparada com o grupo controle. Este fato deve ter ocorrido devido uma exaustão do substrato energético disponível no espermatozoide. Já a adição de pentoxifilina (3 mM ou $7 \mathrm{mM}$ ) ao sêmen criopreservado logo após a descongelação melhorou a qualidade espermática quanto a velocidade, linearidade, motilidade total e progressiva (GRADIL; BALL, 2000).

Da mesma forma, um outro estudo experimental demonstrou que a adição de pentoxifilina ao sêmen fresco antes da criopreservação diminuiu significativamente a motilidade total e progressiva. Entretanto, a adição da pentoxifilina ao sêmen criopreservado após descongelação aumentou significativamente a motilidade total e progressiva quando comparado ao grupo controle. Então concluíram que a utilização da pentoxifilina demonstrou 
efeito positivo apenas quando adicionada ao sêmen humano criopreservado pósdescongelação. Nenhuma melhora foi encontrada quando o sêmen foi congelado com pentoxifilina (STANIC; SONICKI; SUCHANEK, 2002).

No sêmen equino, a pentoxifilina aumentou a motilidade progressiva de espermatozoides descongelados após incubação à $37^{\circ} \mathrm{C}$ nos momentos 0 e 120 minutos (MARQUES et al., 2002). Todavia, este efeito não foi observado por Silva et al. (2009), em que a motilidade total e a motilidade progressiva foram menores aos 120 minutos de incubação, quando se utilizou essa substância.

A utilização da pentoxifilina também foi testada em sêmen de epidídimo. Em felinos domésticos, o espermatozoide de epidídimo fresco ou criopreservado, foi incubado com concentrações que variaram de 0,01 à $20 \mathrm{mM}$ de pentoxifilina por 15 minutos à $23^{\circ} \mathrm{C}$. As amostras frescas após a incubação não apresentaram alteração na motilidade espermática, diferente das amostras criopreservadas que apresentaram aumento na motilidade, VSL, VCL e ALH (STACHECKI; GINSBURG; ARMANT 1994).

Recentemente, em um estudo onde o sêmen da cauda de epidídimo de garanhões era colhido, foi demonstrado que, o diluidor contendo pentoxifilina utilizado para a lavagem epididimária por fluxo retrógrado, exerceu influência significativa sobre o padrão de movimento espermático (GUASTI et al., 2013).

\subsection{ENDOMETRITE PÓS-COBERTURA}

A endometrite têm sido relatada como a terceira doença mais comum na clínica de equinos, depois de cólica e desordens do trato respiratório (TROEDSSON, 1999; CARD, 2005). É considerada a principal causa de subfertilidade (WATSON, 2000) e infertilidade na 
+égua (CAUSEY, 2007; COCCHIA et al., 2012). Trazendo grande prejuízo para o mercado equino (CAUSEY, 2006).

De acordo com a etiologia e a fisiopatologia, a endometrite pode ser considerada uma doença multifatorial, causada por pelo menos quatro fatores diferentes: (i) doenças sexualmente transmissíveis, (ii) endometrite infecciosa crônica, (iii) endometrite persistente induzida por cobertura e (iiii) endometriose (endometrite crônica degenerativa) (TROEDSSON, 1997).

A forma mais comum de endometrite é a induzida pela cobertura. Esta endometrite é uma resposta inflamatória transitória e comum após a cobertura (TROEDSSON, 1997; WATSON, 2000; LEBLANC, 2003; DELL'AQUA Jr. et al., 2006) que tem a finalidade de eliminar excesso de sêmen e outros contaminantes do trato reprodutivo feminino, e preparar o útero para a gestação (TROEDSSON, 1999; WATSON, 2000; BRINSKO et al., 2003; ALGHAMDI et al., 2005).

Após a cobertura, células de defesa como os neutrófilos podem ser encontrados no útero dentro de 30 minutos (KOTILAINEN; HUHTINEN; KATILA, 1994), sendo o pico da inflamação endometrial entre 12 e 24 horas após inseminação (CARD, 2005). Entretanto, éguas férteis são capazes de debelar o processo inflamatório dentro de 24 a 36 horas póscobertura (TROEDSSON et al., 2005).

Realizada a remoção dos produtos inflamatórios do lúmen, o ambiente uterino retorna ao estado normal. Após 96 horas do momento da inseminação, a inflamação já deve estar controlada para receber o embrião que descende para o útero com cinco dias e meio após ovulação, permitindo sua sobrevivência e desenvolvimento durante o longo período de gestação característico da espécie equina (MALOUFI et al., 2002; LEBLANC 2003; CARD, 2005). 
Após a cobertura ou inseminação artificial, os espermatozoides são transportados rapidamente até a tuba uterina, sendo visualizados na ponta do corno uterino oito minutos após a cobertura. Os primeiros gametas são identificados na tuba uterina 30 minutos após a inseminação artificial aumentando seu número com o decorrer das horas alcançando sua maior população em aproximadamente quatro horas, independentemente da concentração espermática (FIALA et al., 2007a,b).

Estudos experimentais confirmaram que lavagens uterinas realizadas quatro horas após a inseminação artificial não comprometeram a taxa de fertilidade, ou seja neste momento os espermatozoides capazes de fertilizar já se encontram na tuba uterina (BRINSKO; VARNER; BLANCHARD, 1991).

O transporte espermático é realizado pela combinação da motilidade espermática, motilidade uterina, e atividade ciliar do epitélio, mas apenas uma pequena quantidade de espermatozoides alcança o local da fertilização (TROEDSSON et al., 2005). A maior parte do ejaculado, sendo espermatozoides, proteínas do plasma seminal e bactérias do sêmen e do pênis permanecem no útero (TROEDSSON, 1997; MALSCHITZKY et al., 2007).

Em um estudo experimental as éguas foram avaliadas por eletromiografia. A partir de 30 minutos pós-inseminação com sêmen fresco, houve um aumento na atividade miometrial. As contrações uterinas desta primeira onda eram da cérvix em direção aos cornos uterinos, acredita-se que a mesma esteja relacionada com o transporte dos espermatozoides para a tuba uterina. Entre quatro e 12 horas após a cobertura as éguas apresentaram uma segunda onda de atividade mioelétrica, sendo que as contrações uterinas ocorreram em sentido oposto, indicando que esta onda é provavelmente responsável pela eliminação dos restos celulares e possíveis patógenos do útero (TROEDSSON; LIU; CRABO, 1998).

Para que o excesso seja removido do útero é necessário uma combinação de mecanismos (LEBLANC, 2003). Os mecanismos físicos são constituídos pelas barreiras 
físicas e pela limpeza mecânica, enquanto os celulares se referem à resposta imunológica local (FIALA, 2004).

\subsubsection{Limpeza física do lúmen uterino}

Dentre os mecanismos de limpeza está a contratilidade miometrial, que além de participar no transporte dos espermatozoides em direção à tuba uterina (KATILA, 2001), ela também atua na eliminação rápida do agente agressor e dos subprodutos inflamatórios. A disfunção na atividade miometrial é considerada um defeito primário (LEBLANC, 2003) e muito comum de ser encontrado em éguas susceptíveis à infecção uterina crônica, o que evidencia ser imprescindível para a limpeza física do lúmen uterino (TROEDSSON, 1997; WATSON, 2000; MALSCHITZKY et al., 2007).

Éguas mais velhas apresentam maior predisposição, por ser uma anormalidade funcional fisiológica adquirida com o passar do tempo (LEBLANC et al., 1998; LEBLANC, 2003). As anormalidades funcionais desta doença provém de alterações no útero. Por exemplo, uma anormalidade funcional anatômica muito comum é a posição do útero dentro da cavidade abdominal. Em éguas multíparas, este pode ser o fator responsável por diminuir a capacidade de limpeza do lúmen uterino (ALGHAMDI et al., 2005).

Para auxiliar no processo de limpeza, o sistema linfático entra em ação, tornando-se responsável pela drenagem de subprodutos do processo inflamatório (LEBLANC, 2003).

\subsubsection{Mecanismos celulares e imunológicos}


As reações imunológicas inatas envolvem uma cascata de reações inflamatórias. Este mecanismo não envolve uma resposta imune específica com memória, pois anticorpos contra os espermatozoides, ou uma resposta imune específica mediada por célula, poderia ser prejudicial para a fertilidade nas subsequentes coberturas. Este mecanismo de limpeza inclui a ativação de mediadores inflamatórios e o influxo de células inflamatórias para o lúmen uterino (TROEDSSON et al., 2005).

Ambos os processos de limpeza são importantes e se complementam para realizar a função de forma eficaz, mas segundo Katila (1996) as imunoglobulinas, opsoninas, quimiotaxia, migração de neutrófilos e fagocitose, são importantes na defesa contra invasores bacterianos, porém não forneceram dados suficientes para explicar a susceptibilidade às infecções uterinas. As diferenças entre éguas susceptíveis e resistentes são mais bem explicadas por fatores envolvendo dilatação cervical adequada, contrações miometriais e drenagem linfática intacta. Estes fatores são essenciais para manter a saúde uterina.

\subsubsection{Comprometimento dos mecanismos de limpeza}

Nas primeiras 24 horas após a ovulação as concentrações de progesterona aumentam e a cérvix de relaxada se contrai e se fecha comprometendo em alguns casos os mecanismos de limpeza uterina. Sendo assim algumas éguas não são capazes de debelar a inflamação dentro de 36 horas (HURTGEN, 2006). A infecção uterina pode ser diagnosticada pelo histórico, detecção da inflamação uterina, isolamento do microorganismo (CAUSEY, 2006) e detecção de fluido intrauterino (LEBLANC, 2003) durante o estro ou entre 6 a 48 horas após a cobertura (CAUSEY, 2006). 
O fluido colhido do útero de éguas susceptíveis contém neutrófilos, imunoglobulinas, proteínas, sêmen, bactérias (LEBLANC, 2003), enzimas proteolíticas, radicais livres, e outros produtos tóxicos são altamente prejudiciais à parede do endométrio e geram um ambiente inóspito para o desenvolvimento do embrião (TROEDSSON, 1997). Portanto, se faz necessário lavagens uterinas e tratamento nos casos persistência de endometrite induzida póscobertura, sendo muito frequente recidiva nas éguas de ciclo para ciclo ou de ano para ano (HURTGEN, 2006).

\subsubsection{Interação sêmen-útero}

A introdução de espermatozoides na genitália da fêmea produz resposta inflamatória aguda. A parede uterina apresenta grande quantidade de prostaglandinas, que são responsáveis em estimular a atividade uterina (KATILA, 2001) provocando a migração de neutrófilos (KOTILAINEN; HUHTINEN; KATILA, 1994), imunoglobulinas e complemento para o lúmen uterino (LEBLANC 2003).

A cascata do complemento media uma série de reações biológicas, como o aumento da permeabilidade vascular, quimiotaxia, opsonização antes da fagocitose, ativação das lipases de membrana e lise da célula alvo. A ativação da cascata do complemento resulta na clivagem do fator C5 em C5a e C5b. O fator de complemento C5 media a quimiotaxia de polimorfonucleares, resultando no influxo destes para dentro do lúmen uterino (KOTILAINEN; HUHTINEN; KATILA, 1994; TROEDSSON et al., 2005). Quando os polimorfonucleares (PMN) são ativados eles se ligam ao espermatozoide e o fagocitam liberando $\mathrm{PGF}_{2 \alpha}$ das membranas celulares. Além da $\mathrm{PGF}_{2 \alpha}$ ser um mediador inflamatório, causa contrações do músculo liso, inclusive o miométrio (TROEDSSON et al., 2005). 
A concentração e/ou volume da dose inseminante é que determina a intensidade da reação neutrofílica. Comparando o efeito da inseminação com sêmen congelado e com sêmen fresco foi observado que quanto maior o número total de espermatozoides da dose inseminante mais intensa é a resposta leucocitária (KOTILAINEN; HUHTINEN; KATILA, 1994).

Nikolakopoulos e Watson (2000), compararam a resposta inflamatória gerada em éguas inseminadas com 2 bilhões e infundidas com $40 \mathrm{~mL}$ de PBS com éguas que foram inseminadas com 20 bilhões, e infundidas com $500 \mathrm{~mL}$ de PBS. Observaram que as éguas inseminadas com menor concentração e menor volume, apresentaram maior inflamação uterina residual nas 48 horas após inseminação quando comparadas as éguas inseminadas com maior concentração e maior volume, indicando que a indução de resposta inflamatória mais intensa é capaz de debelar mais rapidamente o processo inflamatório.

Da mesma forma, em um estudo realizado por Fiala et al. (2007b) foi mostrado que a concentração de neutrófilos no lúmen uterino foi maior em éguas inseminadas com um bilhão do que as éguas inseminadas com menor número de espermatozoides duas e quatro horas após a inseminação. Levando à conclusão que uma dose inseminante maior leva à uma maior estimulação dos mecanismos de defesa, favorecendo a recuperação mais rápida do endométrio.

\subsection{ULTRASSONOGRAFIA DOPPLER}

Na medicina veterinária a tecnologia Doppler tem se tornado cada vez mais acessível para os profissionais e pesquisadores da área (BAILEY et al., 2012). 
A ultrassonografia por Doppler foi introduzida como uma técnica não invasiva capaz de fornecer detalhes anatômicos, informações imediatas sobre a fisiologia do fluxo sanguíneo de tecidos e órgãos (BOLLWEIN et al., 1998).

A técnica apresenta três modos de ação: modo B, modo Doppler e modo Espectral. O modo B, utiliza escalas de cinza e é primordialmente empregado para a identificação anatômica. Através do modo Doppler, subdividido em color flow e power flow, é possível estimar a perfusão sanguínea tecidual, levando-se em consideração a porcentagem de tecido coloridos durante o exame. O modo Espectral fornece um espectro que representa a variação de velocidades do fluxo por meio de ciclos cardíacos gerando valores exatos de velocidades do fluxo sanguíneo (GINTHER; MATTHEW, 2004).

Índice de resistência (RI), índice de pulsatilidade (PI), e total do fluxo arterial (TABF) tem sido os mais utilizados para quantificar o fluxo sanguíneo através da ultrassonografia Doppler (BAILEY et al., 2012). Estes índices são uma razão de vários pontos do espectro, e estão relacionados com a hemodinâmica de um tecido. O aumento nos valores de RI e PI indicam aumento na resistência dos vasos e, portanto, a diminuição da perfusão nos tecidos (GINTHER; MATTHEW, 2004).

O RI e PI são índices indiretos que medem o fluxo sanguíneo que irriga um órgão ou tecido, enquanto que o TABF mede o fluxo sanguíneo dentro de um único ciclo cardíaco em um local especifico (BAILEY et al., 2012).

\subsubsection{Ultrassonografia Doppler na reprodução}

Na reprodução a ultrassonografia Doppler é utilizada para avaliar as possíveis alterações fisiológicas e patológicas do suprimento sanguíneo do trato reprodutivo da fêmea. 
Como, por exemplo, permite a avaliação do potencial ovulatório de folículos e do status funcional do corpo lúteo e útero, além de ser uma técnica auxiliar para o diagnóstico de distúrbios na hemodinâmica do sistema reprodutivo. Têm sido uma importante ferramenta para o estudo da viabilidade endometrial, assim como para a interação concepto-maternal (FERREIRA; MEIRA, 2011).

Em humanos, o Doppler transvaginal é utilizado rotineiramente para examinar o fluxo sanguíneo do útero, auxiliando no diagnóstico de infertilidade. Da mesma forma, na espécie equina, estudos experimentais relatam que o fluxo sanguíneo uterino reduzido contribui para a subfertilidade e até infertilidade (BLAICH et al., 1999).

Esta técnica é utilizada também para monitorar as alterações do fluxo sanguíneo em tempo real (BOLLWEIN et al., 1998) em resposta à uma série de intervenções como a inseminação artificial, administração exógena de hormônios e medicação anti-inflamatória (BAILEY et al., 2012).

\subsubsection{Perfusão vascular do endométrio de éguas}

A perfusão vascular do endométrio varia de acordo com uma série de fatores. Entre eles estão idade/paridade do animal, fase do ciclo estral que a égua se encontra, estado de prenhez, condição da dose inseminante, entre outros.

Éguas velhas e pluríparas comumente são afetadas por distúrbios uterinos que podem interferir em sua eficiência reprodutiva. Normalmente elas apresentam menor perfusão sanguínea quando se compara com éguas mais jovens que nunca pariram. Isso pode estar associado com fibrose periglandular do endométrio que ocorre devido à grande distensão 
uterina ao longo da gestação e regressão pós-parto. Esta patologia é considerada a principal causa de perda embrionária e fetal (BOLLWEIN et al., 1998).

A perfusão pode variar quanto à fase do ciclo estral que a égua se encontra, estando parcialmente relacionada com a concentração plasmática hormonal. Na fase de estro há diminuição no índice de pulsatilidade e simultaneamente um aumento na concentração plasmática de estrógeno, ou seja maior perfusão nesta fase. Diferente da progesterona que não apresentou nenhuma correlação com a perfusão vascular. Já na fase de diestro, enquanto houve alterações no fluxo sanguíneo, as concentrações de estrógeno se mantiveram baixas, confirmando que não apenas o estrógeno plasmático, mas outros fatores ainda indeterminados, participam na regulação do fluxo sanguíneo uterino (BOLLWEIN et al., 2002a).

No início da fase luteal (5 dias após a ovulação), o valor de RI se encontra baixo, o que indica maior perfusão uterina. Nesta fase se faz necessário maior suprimento sanguíneo já que é o momento em que o embrião migra da tuba uterina para o útero (BOLLWEIN et al., 1998).

Éguas prenhes apresentam o fluxo sanguíneo das artérias uterinas significativamente maior em relação às éguas vazias. A vesícula embrionária esférica equina se movimenta por todo o lúmen uterino por vários dias até se fixar no segmento caudal do corno uterino aproximadamente 16 dias após a ovulação (SILVA; GINTHER, 2006) isso deve explicar o por que do fluxo sanguíneo de éguas prenhes aumentar em ambas as artérias uterinas, oposto do que ocorre em vacas e ovelhas, em que não há deslocamento do embrião (BOLLWEIN; MAYER; STOLLA, 2003a).

As alterações transitórias da perfusão vascular do endométrio acompanha as mudanças de localização da vesícula embrionária. A perfusão vascular do endométrio é maior em torno da vesícula já fixada do que no corno oposto ou no meio do corno fixado (SILVA et al., 
2005). Do $15^{\circ}$ dia de gestação em diante, o fluxo sanguíneo uterino da artéria ipsolateral ao concepto é significativamente maior do que na artéria uterina contralateral (BOLLWEIN et al., 2003a).

Além de todos estes fatores endógenos que podem influenciar na vascularização do endométrio, foi realizado um estudo por Bollwein et al. (2003b), que consistia em avaliar quais seriam os efeitos da infusão de diluidor de sêmen, plasma seminal e sêmen fresco na vascularização do endométrio. Eles observaram que não houve aumento na perfusão sanguínea quando foi infundido diluidor à base de leite desnatado no útero, mas que houve aumento significativo na perfusão sanguínea de éguas dentro de uma hora após infundir plasma seminal e sêmen fresco. O aumento simultâneo de acúmulo de líquido intrauterino e reação na citologia endometrial sugerem que o aumento na perfusão ocorreu devido a resposta inflamatória do endométrio. 


\section{HIPÓTESES}

As hipóteses propostas no presente estudo são:

1. O diluidor contendo pentoxifilina melhora as características espermáticas.

2. O diluidor contendo pentoxifilina, aumenta o fluxo sanguíneo uterino pós-inseminação devido à sua propriedade vasodilatadora.

3. A pentoxifilina favorece a limpeza uterina pós-cobertura devido sua ação imunomoduladora. 


\section{OBJETIVOS}

Os objetivos do presente estudo foram:

1. Verificar o efeito da utilização de diluidor de sêmen contendo pentoxifilina sobre as características do movimento espermático, integridade das membranas plasmática e acrossomal, potencial de membrana mitocondrial, desnaturação da cromatina e morfologia espermática.

2. Verificar o efeito da pentoxifilina em contato com a parede uterina no período pósinseminação artificial, quanto ao fluxo sanguíneo e resposta leucocitária. 
Para testar as hipóteses formuladas foi proposto um experimento para estudar os efeitos in vitro e in vivo da pentoxifilina, como esquematizados na figura 1. Este experimento está apresentado em dois artigos científicos, intitulados "Pentoxifylline maintains sperm motion characteristics and membranes integrity within two hours of incubation when added after thawed cryopreserved stallion semen" e "The effect of semen extender supplemented with pentoxifylline on post-breeding inflammation response assessed by endometrial cytology and vascular perfusion" (Capitulos 5 e 6 respectivamente).

Figura 1 - Esquema simplificado do projeto de pesquisa

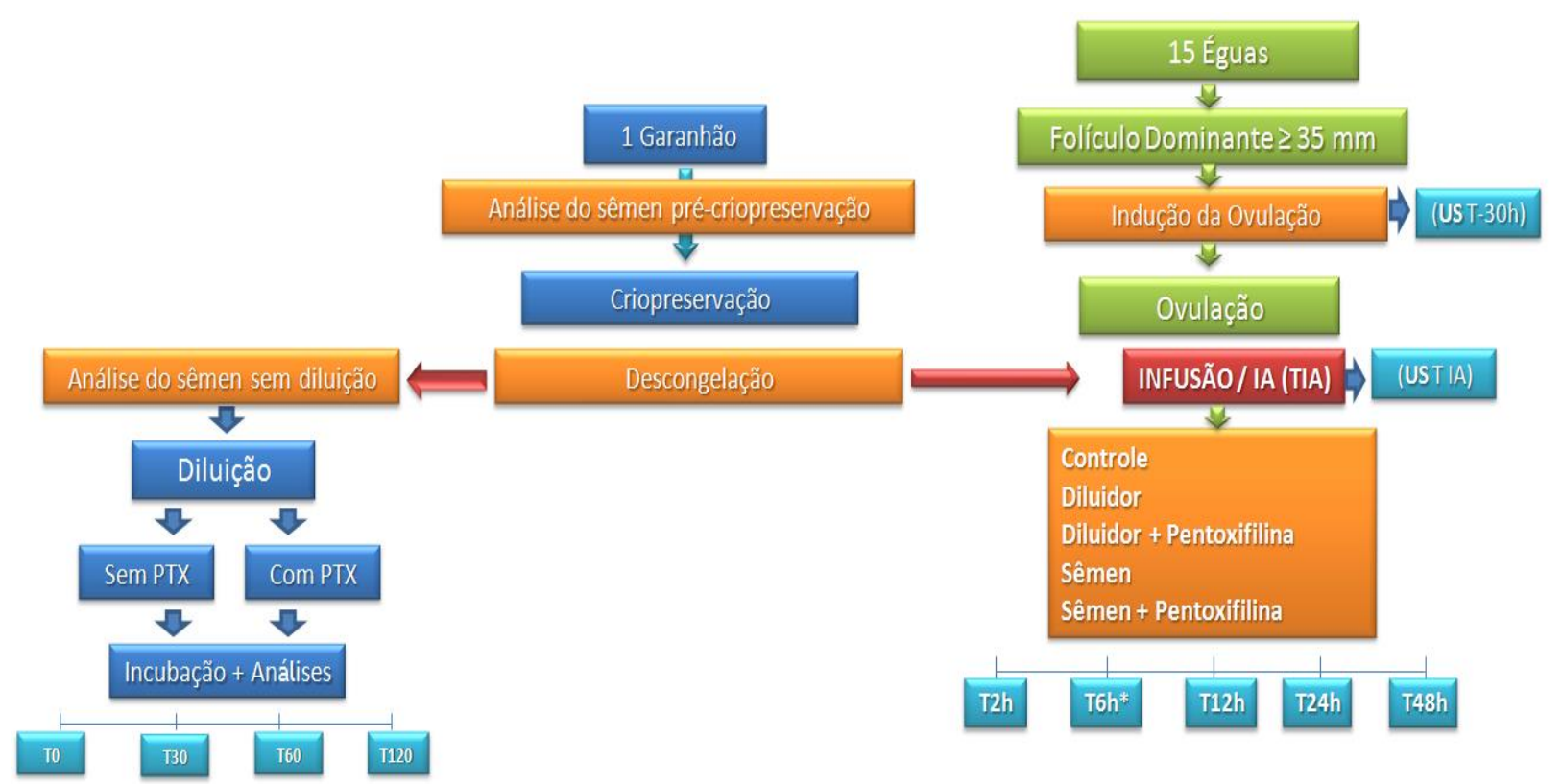

Legenda: * Momento da citologia endometrial. Controle: mimetização do procedimento de IA sem deposição intrauterina; Diluidor: diluidor sem pentoxifilina; Diluidor + Pentoxifilina: diluidor contendo pentoxifilina; Sêmen: sêmen diluído com diluidor sem pentoxifilina; Sêmen + Pentoxifilina: sêmen diluído com diluidor contendo pentoxifilina; T0: 5 minutos; T30: 30 minutos; T60: 60 minutos; T120: 120 minutos após diluição e incubação do sêmen; T-30: ultrassonografia Doppler imediatamente antes da indução da ovulação; TIA: ultrassonografia Doppler imediatamente antes da infusão; T2: duas horas; T6: seis horas; T12: doze horas; T24: vinte e quatro horas e T48: quarenta e oito horas após a infusão. 


\title{
5 -PENTOXIFYLLINE MAINTAINS SPERM MOTION CHARACTERISTICS AND MEMBRANES INTEGRITY WITHIN TWO HOURS OF INCUBATION WHEN ADDED AFTER THAWED CRYOPRESERVED STALLION SEMEN
}

\begin{abstract}
Cryopreservation impairs sperm fertilizing ability by decreasing sperm motility and motion characteristics, therefore pentoxifylline, a phosphodiesterase inhibitor has been used to stimulate the sperm motility. The purpose of this study was to examine the effects induced by adding pentoxifylline to seminal extender on cryopreserved equine semen after thawing and examine sperm motion characteristics, membranes and chromatin integrity until two hours of incubation at $37^{\circ} \mathrm{C}$. Eight batches from a unique stallion were cryopreserved $\left(100 \times 10^{6}\right.$ spermatozoa/0.5 mL straw). Two frozen semen straws were thawed evaluated and divided in two aliquots. One of the aliquots was diluted in skim milk extender, and the other aliquot was diluted in the same skim milk extender plus pentoxifylline $(7.18 \mathrm{mM})$. Aliquots of each treatment were warmed in water bath at $37^{\circ} \mathrm{C}$ and analyzed at 5 (T0), 30 (T30), 60 (T60) and 120 (T120) minutes after dilution and incubation. The sperm movement was evaluated using the Computer-Assisted Sperm Analysis (CASA), integrity of plasma and acrosomal membranes and mitochondrial membrane potential, using association of fluorescent probes (PI, H342, FITC-PSA and JC-1) and chromatin denaturation assessed by Toluidine blue. To all variables was utilized the analysis of variance (ANOVA), and the range was compared by LSD test (SAS 9.3 version, 2010). For statistical analyses, it was considered effect of treatment, time and treatment $\mathrm{x}$ time interaction. Diluted samples using skim milk extender without $(31.00 \pm 1.75 \%)$ or with pentoxifylline $(33.77 \pm 1.65 \%)$ showed better progressive motility than non diluted samples $(23.20 \pm 3.88 \%)$ at $5 \mathrm{~min}$ after dilution, but the addition of pentoxifylline did not changed progressive motility $(\mathrm{p}>0.05)$. Pentoxifylline increased
\end{abstract}


$(\mathrm{p}<0.05)$ path velocity (VAP, $71.68 \pm 1.52 \times 65.71 \pm 0.89 \mu \mathrm{m} / \mathrm{s})$, progressive velocity (VSL, $63.63 \pm 1.2 \times 59.20 \pm 0.80 \mu \mathrm{m} / \mathrm{s}$ ) and curvilinear velocity (VCL, 131.24 $\pm 2.51 \times 118.50 \pm 1.57$ $\mu \mathrm{m} / \mathrm{s}$ ) when compared to control, respectively. There were no significant differences ( $\mathrm{p}>$ 0.05) between the two treatments at the four times on percentage of cells presenting intact plasma membrane, intact acrosome and high mitochondrial membrane potential (IPIAH). This suggests that the protective behavior of the extender, maintaining the integrity of membranes for two hours safely. Chromatin integrity was not affected by extender, neither the time of incubation. In conclusion, dilution only and dilution containing pentoxifylline, increase velocity characteristics, do not affect, but maintain cellular and chromatin membranes.

Keywords: Pentoxifylline. Stallion. Cryopreservation. Extender. Semen. 


\subsection{INTRODUCTION}

The storage of reproductive cells and tissues in cryobanks is a crucial step on modern science and clinical service in reproductive medicine and biotechnology. Therefore, the improvement of gamete cryopreservation systems is essential for genetic resource banking, agriculture and human reproduction (WATSON, 2000; PETRUNKINA, 2007). However, severe limitations are observed in the methods currently used for gamete cryopreservation, resulting in sub-optimal maintenance of gametes viability after the freezing-thawing procedures. The manipulation of male gametes for preservation and storage for long periods is known to lead to damages to the sperm structure, compromising their biological function (SILVA; GERRA, 2011). The ability to cryopreserve spermatozoa from all of the domestic species is challenging. Despite the similar physical stresses that all cells must endure due to the cryopreservation process, sperm from different species are very different in size, shape, and lipid composition, which may differently affect cryosurvival (PURDY, 2006).

Stallion semen, when compared to other species, is one of the most impaired during this process. It is generally believed that the key to cryopreservation success of stallion semen is the individual stallion itself. Stallions have shown a particularly high degree of individual variation. Previous studies indicate that while approximately $20 \%$ of stallions produce semen that freeze well, $60 \%$ and $20 \%$ of the stallions show acceptable and poor freezability, respectively (VIDAMENT et al., 1997).

Many factors must be considered, when freezing stallion semen; exposure of spermatozoa to cooling, ice crystal damage and intracellular changes brought about by dehydration (AMANN; PICKETT, 1987). 
During freezing, cells become dehydrated and shrink; during thawing, as water promote re-equilibration, a hypotonic challenge takes place, a process which is associated with a volume expansion. Damage will occur beyond certain levels of shrinkage or swelling (the overall range between these levels is known as the maximal cell volume excursion). The optimal equilibrium freezing rate is not related to the loss of membrane integrity and impaired cell function (PETRUNKINA, 2007; SIEME; HARRISON; PETRUNKINA, 2008; SILVA; GUERRA, 2011).

Components of the extender, alter the environment, the spermatozoa and the responses of spermatozoa to freezing and thawing process (AMANN; PICKETT, 1987). Various compounds have been used in the attempt to improve sperm motility, including procaine (ORTGIES et al., 2012) antioxidant trolox (SILVA et al., 2009) and ascorbic acid (MARQUES et al., 2002) and methylxanthine derivative as caffeine (BUNGE, 1973; STACHECKI; GINSBURG; ARMANT, 1994) and pentoxifylline (SHEN et al., 1991; CENTOLA; CARTIE; COX, 1995; MARQUES et al., 2002; ORTGIES et al., 2012).

Pentoxifylline is a phosphodiesterase inhibitor which increases sperm kinetic characteristics and the number of spermatozoa exhibiting hyperactivated motility by raising the intracellular content of cAMP, a molecule involved in the generation of sperm energy (CENTOLA; CARTIE; COX, 1995; CALOGERO et al., 1998; ESTEVES et al., 1998; GRADIL; BALL, 2000; STANIC; SONICKI; SUCHANEK, 2002; GOULART et al., 2004; ORTGIES et al., 2012).

Studies analyzing the effects of pentoxifylline treatment before freezing may be useful for cryopreservation purposes, improving fertilization rates with assisted reproductive procedures such as intrauterine insemination or in vitro fertilization (BRENNAN; HOLDEN, 1995; ESTEVES et al., 1998). 
However, others have reported that the addition of pentoxifylline to semen before cryopreservation significantly decreased velocity, linearity, and motility of spermatozoa. Such a decrease may be due to an exhaustion of spermatozoa energy substrate available. Therefore it is advisable to add pentoxifylline to cryopreserved equine semen after thawing (GRADIL; BALL, 2000; STANIC; SONICKI; SUCHANEK, 2002).

The purpose of this study was to examine the effects of pentoxifylline added after the freezing-thawing process on sperm motion characteristics, membranes, chromatin integrity and spermatic morphology until two hours of incubation at $37^{\circ} \mathrm{C}$.

\subsection{MATERIALS AND METHODS}

\subsubsection{Location and Experimental Period}

This study was conducted in two different locations at São Paulo state, Brazil. Semen collection, sperm processing and cryopreservation procedures were performed at "Estância Sonho Meu" located in Piedade city, at $23^{\circ} \mathrm{C}$ latitude south and $47^{\circ} \mathrm{C}$ longitude west, altitude between 750-1227 meters over the sea level. Sperm thawing, incubation, and sperm analysis was performed at the Laboratory of Semen Biotechnology and Andrology, Center of Biotechnology in Animal Reproduction, Department of Animal Reproduction, College of Veterinary Medicine and Animal Science of the University of São Paulo, Pirassununga city. Experimental period occurred between October 2012 to February 2013. 


\subsubsection{Stallion selection}

For this experiment only one stallion Margalarga Marchador, with 4 years old, was selected to minimize individual variation. The stallion was selected based on the reproductive history, clinic examination, assessment of sexual behavior, scrotal circumference, measurements of size and consistency of the testes and semen analysis.

\subsubsection{Semen collection and cryopreservation}

Eight ejaculates were collected using an artificial vagina Botucatu model (Botupharma - SP- Brazil). Semen was collected twice a week. Each ejaculate was extended 1:1 with skim milk commercial extender Botusemen ${ }^{\circledR}$ (Botupharma - Botucatu SP - Brazil), and centrifuged in $15 \mathrm{~mL}$ tubes at $1.100 \mathrm{rpm}$ during 15 minutes. The supernatant was removed, and spermatozoa were resuspended in egg yolk freezing extender Botucrio ${ }^{\circledR}$ (Botupharma Botucatu SP - Brazil). This semen was packaged in properly identified $0.5 \mathrm{~mL}$ straws, containing $100 \times 10^{6}$ spermatozoa/straw.

Semen was frozen in automated system, using a portable semen freezer Tetakon® (TK 3000; Uberaba, Brazil). The cooling rate was $0.25^{\circ} \mathrm{C} / \mathrm{min}$ until reaching $5^{\circ} \mathrm{C}$ during approximately one hour. The cooling tube containing all straws was placed in an isothermal box. Freezing rate consisted on lowering the temperature $-15^{\circ} \mathrm{C} /$ minute, from 5 to $-80^{\circ} \mathrm{C}$, and then decreasing $-10^{\circ} \mathrm{C} /$ minute until it reached $-120^{\circ} \mathrm{C}$, during 7 minutes. The final step of the process consisted of removing the straws from the tube and immersing in liquid nitrogen $\left(-196^{\circ} \mathrm{C}\right)$. All straws were stored in racks in cryogenic cylinder. 


\subsubsection{Semen thawing, dilution and incubation}

Two semen straws, $1 \mathrm{ml}$ total volume with $200 \times 10^{6}$ spermatozoa, were thawed at $37^{\circ} \mathrm{C}$ for 30 seconds in water bath. Samples were divided in two equal aliquots and diluted following two treatments: the first aliquot was treated by adding skim milk extender and the second aliquot received the same skim milk extender plus $0.119 \mathrm{~g}$ of Pentoxifylline (Pentoxifylline P 1784-10g Sigma-Aldrich), reaching final concentration of $7.18 \mathrm{mM}$. All semen samples were placed in $1.5 \mathrm{~mL}$ microcentrifuge tubes and maintained in water bath until 120 minutes. For semen analysis, aliquots were taken in four periods: 5 minutes after dilution (T0), 30 (T30), 60 (T60) and 120 (T120) minutes after in vitro incubation at $37^{\circ} \mathrm{C}$.

The concentration of pentoxifylline used in the present study as well as the length of incubation were performed according previous studies (CALOGERO et al., 1998; GRADIL; BALL, 2000; MARQUES et al., 2002; GUASTI et al., 2010).

\subsubsection{Semen Analysis}

\subsubsection{Computer-Assisted Sperm Analysis (CASA)}

In order to assess sperm motion characteristics, an aliquot of thawed semen was taken from the microcentrifuge tube heated at $37^{\circ} \mathrm{C}$ in water bath, and diluted in TALP sperm adjusting concentration to $25 \times 10^{6}$ spermatozoa/mL. Ten microliters were placed in Makler Counting Chamber (Sefi Medical Instruments Ltd.), which was then inserted into the Computer-Assisted Sperm Analysis (CASA, Hamilton Thorne Biosciences equipment, 12.3 
version). The equipment consisted of a microscope coupled to a computer. Equipment settings were adjusted for stallion semen according to manufactures recommendations. Five fields were selected and considered for analysis.

The sperm parameters analyzed were: total motility (TMOT, \%); progressive motility (PMOT, \%); average path velocity (VAP, $\mu \mathrm{m} / \mathrm{s}$ ); straight line velocity (VSL, $\mu \mathrm{m} / \mathrm{s}$ ) curvilinear velocity (VCL, $\mu \mathrm{m} / \mathrm{s})$; amplitude of lateral head displacement (ALH, $\mu \mathrm{m})$; beatcross frequency $(\mathrm{BCF}, \mathrm{Hz})$; straightness (STR, \%); linearity (LIN, \%) and percentage of rapid cells (VRAP, \%). This analysis was repeated in all the four moments: T0, T30, T60, and T120.

\subsubsection{Membranes Analysis}

The protocol used to evaluate integrity of both plasma and acrosomal membranes and mitochondrial membrane potential consisted on diluting an aliquot of thawed semen from the micro centrifuge tube heated at $37^{\circ} \mathrm{C}$ in TALP sperm, and adjusting the concentration to $25 \times 10^{6}$ spermatozoa $/ \mathrm{mL}$. A $150-\mu \mathrm{L}$ aliquot of diluted semen was placed in another prewarmed micro centrifuge tube the fluorescent probes were subsequently added as follows: $3 \mu \mathrm{L}$ of Propidium Iodide (PI-0.5 mg/mL, P4170, Sigma-Aldrich Co., Saint Louis, Missouri, EUA), $2 \mu \mathrm{L}$ of Hoechst 33342 (H342 5mg/mL, Molecular probes Inc., Eugene, Oregon, EUA), $5 \mu \mathrm{L}$ of $5,5^{\prime}, 6,6^{\prime}$-tetrachloro-1,1',3,3'-tetraethylbenzimidazolyl carbocyanine iodide (JC-1, $153 \mu \mathrm{M}, \mathrm{T}-3168$, Molecular Probes Inc., Eugene, Oregon, EUA), and $80 \mu \mathrm{L}$ of fluorescein isothiocyanate-conjugated Pisum sativum agglutinin (FITC-PSA-100 $\mu \mathrm{g} / \mathrm{mL}$, L0770, Sigma-Aldrich Co., Saint Louis, Missouri, EUA). This protocol was adapted from Nascimento et al. (2008) and Celeghini et al. (2010b). 
The sample was incubated for 8 minutes at $37^{\circ} \mathrm{C}$. An $8 \mu \mathrm{L}$ aliquot was placed between a slide and coverslipped and evaluated immediately by epifluorescent microscopy (Nikon, Eclipse 80i, Melville, NY, USA) in a triple filter (D/F/R, C58420), showing a set: UV-2E/C (excitation 340-380 $\mathrm{nm}$ and emission 435-485 nm), B-2E/C (excitation 465-495 $\mathrm{nm}$ and emission 515-555 nm), and G-2E/C (excitation 540-525 nm and emission 605-655 nm), at 1000x magnification. Two hundred sperm cells per slide were examined and classified in eight different groups based on the fluorescence emitted from each probe (Table 1), according to Celeghini et al. (2007).

Table 1 - Sperm cells classification in eight groups, according to fluorescence emitted by different probes Pirassununga - São Paulo - 2013

\begin{tabular}{|c|c|}
\hline & Classification \\
\hline IPIAH & Intact plasma membrane, intact acrosome and high mitochondrial membrane potential \\
\hline IPIAL & Intact plasma membrane, intact acrosome and low mitochondrial membrane potential \\
\hline IPDAH & Intact plasma membrane, damaged acrosome and high mitochondrial membrane potential \\
\hline IPDAL & Intact plasma membrane, damaged acrosome and low mitochondrial membrane potential \\
\hline DPIAH & Damaged plasma membrane, intact acrosome and high mitochondrial membrane potential \\
\hline DPIAL & Damaged plasma membrane, intact acrosome and low mitochondrial membrane potential \\
\hline DPDAH & Damaged plasma membrane, damaged acrosome and high mitochondrial membrane potential \\
\hline DPDAL & Damaged plasma membrane, damaged acrosome and low mitochondrial membrane potential \\
\hline
\end{tabular}

Besides the eight groups there are three more groups that represent the percentage of cells of the hole sample containing plasma membrane integrity (PMI, \%), acrosomal membrane integrity (AMI, \%) and high mitochondrial membrane integrity (HMMP, \%). This analysis was performed in all the four moments after in vitro incubation: T0, T30, T60, and T120. 


\subsubsection{Chromatin Denaturation Analysis}

An aliquot of thawed semen from the microcentrifuge tube heated at $37^{\circ} \mathrm{C}$ in water bath was smeared in a glass slide. Smears were fixed with ethanol acetic acid (3:1, V/V) for 1 min and then in $70 \%$ ethanol for $3 \mathrm{~min}$. The smears were hydrolyzed for $5 \mathrm{~min}$ in $4 \mathrm{mM} \mathrm{HCl}$, washed in distilled water and air-dried. One droplet of $0.025 \%$ Toluidine Blue in McIlvaine buffer solution (sodium citrate-phosphate), $\mathrm{pH} 4.0$, was placed over each smear and then coverslipped according to Belleti; Costa and Guardieiro (2005).

The slides were examined using light microscopy (Nikon, Eclipse E200 Tokio, Japan) not more than 3 and not less than 20 minutes after adding Toluidine Blue on the slides. The analysis was performed at 1000x magnification, five hundred cells per slide were examined and classified in three groups: colored in light blue, for those cells without chromatin decondensation (ATI), colored in violet-blue, intermediate decondensation (ATII), and colored dark violet-blue indicating high decondensation (ATIII). This analysis was performed only in two moments after in vitro incubation: T30 and T120.

\subsubsection{Sperm Morphology}

To evaluate the morphology, an aliquot of semen was diluted in saline buffered formalin and placed between slide and cover slip. Two hundreds of spermatic cells were counted using differential interference contrast micoscopy (Model Eclipse 80i, Nikon), in 1000x magnitude on immersion. Classification of cells were made according with definitions described by Brito (2007). 


\subsection{STATISTICAL ANALYSIS}

All data were evaluated using 9.3 SAS System for Windows (SAS Institute Inc., Cary, NC, USA). The effect of Pentoxifylline treatment (SM Extender, and SM Extender+Pentoxifylline) in the different moments of evaluation (T0, T30, T60 and T120) and the effect incubation periods in the different treatments were determined using parametric (Student $\mathrm{t}$ test and General Linear Model procedure-PROC GLM, respectively) and nonparametric (Mann Whitney $\mathrm{U}$ and Kruskall Wallis, respectively) tests, according to the residue normality (Gaussian distribution) and variance homogeneity of each variable. A probability value of $\mathrm{P}<0.05$ was considered statistically significant. Results are reported as untransformed means \pm S.E.M.

\subsection{RESULTS}

\subsubsection{Effect of equine thawed sperm dilution using skim milk extender with pentoxifyline on sperm motion and membranes}

The results of sperm motion obtained by CASA are shown on table 2. Comparing total motility of not diluted semen and diluted using skim milk extender with or without pentoxifylline, no statistical differences was found between treatments at T0. But, diluted samples using skim milk extender without $(31.00 \pm 1.75 \%)$ or with pentoxifylline $(33.77 \pm 1.65 \%)$ showed better $(\mathrm{p}<0.05)$ progressive motility than non diluted samples $(23.20 \pm 3.88 \%)$. However, the addition of pentoxifylline to the extender did not change progressive motility $(\mathrm{p}>0.05)$. Rapid cells also improved $(\mathrm{p}<0.05)$ by dilution, but was not affected by pentoxifylline addition. 
Interestingly a positive effect was observed when pentoxifylline was added on semen extender for velocity characteristics. The data shows that VAP, VSL, and VCL were significantly higher $(\mathrm{p}<0.05)$ for these samples than the samples non diluted and those diluted to ordinary skim milk extender. Amplitude of lateral head displacement was higher $(\mathrm{p}<0.05)$ in non diluted samples $(5.09 \pm 0.26 \mu \mathrm{m})$ and diluted to extender plus pentoxifylline $(5.17 \pm 0.09 \mu \mathrm{m})$ than samples diluted to extender without PTX $(4.69 \pm 0.07 \mu \mathrm{m})$. Diluted samples increased BCF and STR of the sperm movement. Addition of pentoxifylline exerted significant effect $(\mathrm{p}<0.05)$ decreasing LIN.

Table 2 - Mean \pm standard error of motion characteristics obtained by CASA of frozen-thawed equine sperm not diluted (No dilution) and diluted using skim milk extender (SM Extender) or skim milk extender plus pentoxifylline (SM Extender + PTX, at 7.18 mM) - Pirassununga - SP - 2013

\section{Characteristics of} sperm motion

\section{No dilution $\quad$ SM Extender $\quad$ SM Extender+PTX}

\begin{tabular}{cccc|} 
TMOT $(\%)$ & $42.80 \pm 4.36$ & $45.48 \pm 2.32$ & $46.87 \pm 1.93$ \\
PMOT $(\%)$ & $23.20 \pm 3.88^{\mathrm{b}}$ & $31.00 \pm 1.75^{\mathrm{a}}$ & $33.77 \pm 1.65^{\mathrm{a}}$ \\
\cline { 3 - 4 } RAP $(\%)$ & $25.90 \pm 4.00^{\mathrm{b}}$ & $32.64 \pm 1.91^{\mathrm{ab}}$ & $36.25 \pm 1.79^{\mathrm{a}}$ \\
\cline { 3 - 4 } VAP $(\mu \mathrm{m} / \mathrm{s})$ & $64.78 \pm 2.61^{\mathrm{b}}$ & $65.71 \pm 0.89^{\mathrm{b}}$ & $71.68 \pm 1.52^{\mathrm{a}}$ \\
\cline { 3 - 4 } VSL $(\mu \mathrm{m} / \mathrm{s})$ & $55.74 \pm 2.76^{\mathrm{b}}$ & $59.20 \pm 0.80^{\mathrm{b}}$ & $63.63 \pm 1.29^{\mathrm{a}}$ \\
\cline { 3 - 4 } VCL $(\mu \mathrm{m} / \mathrm{s})$ & $111.34 \pm 4.03^{\mathrm{b}}$ & $118.50 \pm 1.57^{\mathrm{b}}$ & $131.24 \pm 2.51^{\mathrm{a}}$ \\
ALH $(\mu \mathrm{m})$ & $5.09 \pm 0.26^{\mathrm{a}}$ & $4.69 \pm 0.07^{\mathrm{b}}$ & $5.17 \pm 0.09^{\mathrm{a}}$ \\
BCF $(\mathrm{Hz})$ & $35.13 \pm 0.90^{\mathrm{b}}$ & $39.66 \pm 0.45^{\mathrm{a}}$ & $39.19 \pm 0.63^{\mathrm{a}}$ \\
STR $(\%)$ & $83.80 \pm 1.37^{\mathrm{b}}$ & $89.67 \pm 0.27^{\mathrm{a}}$ & $88.61 \pm 0.40^{\mathrm{a}}$ \\
\cline { 3 - 4 } $\operatorname{LIN~}(\%)$ & $52.80 \pm 1.74^{\mathrm{a}}$ & $53.45 \pm 0.45^{\mathrm{a}}$ & $36.25 \pm 1.79^{\mathrm{b}}$
\end{tabular}

${ }^{\mathrm{a}, \mathrm{b}}$ Means within rows with different superscripts differ significantly ( $\mathrm{p}<0.05$ ). TMOT: total motility; PMOT: progressive motility; RAP: percentage of rapid cells; VAP: average path velocity; VSL: straight line velocity; VCL: curvilinear velocity; ALH: amplitude of lateral head displacement; BCF: beat-cross frequency; STR: straightness; LIN: linearity

For the intact plasma membrane, intact acrosome and high mitochondrial membrane potential (IPIAH) category of cells analyzed by association of fluorescent probes no significant effects was found between the two diluted semen, they behaved similarly, but both was statistically different $(\mathrm{p}<0.05)$ from the samples that was not diluted (Table 3 ). 
No significant effects were found on the percentage of cells presenting plasma membrane integrity among treatments. But it was observed significant improvement $(\mathrm{p}<0.05)$ on acrosomal membrane integrity, when both extenders, skim milk $(94.81 \pm 0.68 \%)$ and skim milk plus pentoxifylline $(95.72 \pm 0.52 \%)$ was added, different from samples non diluted $(71.25 \pm 1.71 \%)$. Similarly both extenders also induced high mitochondrial membrane potential percentage $(61.48 \pm 2.16 \%$ to $\mathrm{SM}$ and $61.44 \pm 2.03 \%$ to $\mathrm{SM}+\mathrm{PTX})$ different from samples non diluted $(36.35 \pm 2.99 \%)$.

Table 3 - Mean \pm standard error of plasma and acrosomal membranes integrity and mitochondrial membrane potential of frozen-thawed equine sperm not diluted (No dilution) and diluted using skim milk extender (SM Extender) or skim milk extender plus pentoxifylline (SM Extender + PTX, at 7.18 mM) - Pirassununga - SP - 2013

\begin{tabular}{cccc} 
Membranes status & No dilution & SM Extender & SM Extender+PTX \\
\hline IPIAH (\%) & $29,65 \pm 1,99^{\mathrm{b}}$ & $41,03 \pm 1,51^{\mathrm{a}}$ & $40,32 \pm 1,48^{\mathrm{a}}$ \\
PMI (\%) & $43.75 \pm 4.50$ & $41.37 \pm 1.50$ & $41.10 \pm 1.48$ \\
AMI (\%) & $71.25 \pm 1.71^{\mathrm{b}}$ & $95.72 \pm 0.52^{\mathrm{a}}$ & $94.81 \pm 0.68^{\mathrm{a}}$ \\
HMMP (\%) & $36.35 \pm 2.99^{\mathrm{b}}$ & $61.48 \pm 2.16^{\mathrm{a}}$ & $61.44 \pm 2.03^{\mathrm{a}}$ \\
\hline
\end{tabular}

${ }^{a, b}$ Means within rows with different superscripts differ significantly ( $\left.p<0.05\right)$. IPIAH: intact plasma membrane, intact acrosome and high mitochondrial membrane potential; PMI: plasma membrane integrity; AMI: acrosome membrane integrity; HMMP: high mitochondrial membrane potential

\subsubsection{Effect of pentoxifylline addition to skim milk extender to equine frozen-thawed sperm in vitro incubated at $37^{\circ} \mathrm{C}$ has on sperm motion, membranes, chromatin and morphology}

After in vitro incubation at $37^{\circ} \mathrm{C}$ until 120 minutes, total and progressive motility of diluted frozen-thawed equine sperm using skim milk extender with or without pentoxifylline did not show effects of treatment $(p<0.05)$, time $(p<0.05)$, neither interaction time $\mathrm{x}$ treatment $(\mathrm{p}<0.05)($ Table 4$)$. 
Table 4 - Mean \pm standard error of total and progressive motility of frozen-thawed equine sperm diluted using skim milk extender (SM Extender) or skim milk extender containing pentoxifylline (SM Extender+PTX, at $7.18 \mathrm{mM}$ ). Incubated in vitro at $37^{\circ} \mathrm{C}$ during 5 (T0), 30 (T30), 60 (T60), and 120 (T120) minutes - Pirassununga - SP - 2013

\begin{tabular}{lccccc}
\hline \multirow{2}{*}{ Motility } & Treatment & \multicolumn{4}{c}{ Time after in vitro incubation at $3^{\circ} \mathbf{C}$} \\
\cline { 3 - 6 } & & T0 & T30 & T60 & T120 \\
\hline \multirow{2}{*}{ TMOT (\%) } & SM Extender & $44.62 \pm 4.30$ & $47.37 \pm 5.63$ & $42.57 \pm 3.89$ & $47.00 \pm 5.11$ \\
& SM Extender+PTX & $46.00 \pm 2.40$ & $46.75 \pm 3.13$ & $52.71 \pm 4.26$ & $42.75 \pm 5.10$ \\
\hline \multirow{2}{*}{ PMOT (\%) } & SM Extender & $31.75 \pm 3.44$ & $30.75 \pm 4.19$ & $28.28 \pm 2.71$ & $32.87 \pm 3.83$ \\
& SM Extender+PTX & $34.37 \pm 2.23$ & $32.50 \pm 2.26$ & $36.85 \pm 4.07$ & $31.75 \pm 4.57$ \\
\hline
\end{tabular}

TMOT: total motility; PMOT: progressive motility. No statistical difference was found ( $\mathrm{p}>0.05)$.

The effects of the addition of pentoxifylline on semen extender related to velocity parameters are demonstrated on tables 5, 6 and 7. It was observed a significant $(\mathrm{p}<0.05)$ improvement on sperm velocity only at T0. For the other moments there was no improvement, but maintained same velocity characteristics from 30 to 120 minutes.

Table 5 - Mean \pm standard error of motion characteristics of frozen-thawed equine sperm after dilution (with or without pentoxifylline) and in vitro incubation at $37^{\circ} \mathrm{C}$ during 5 (T0), 30 (T30), 60 (T60), and 120 (T120) minutes, regardless on the treatment - Pirassununga - SP - 2013

\begin{tabular}{|c|c|c|c|c|c|}
\hline \multirow{2}{*}{ Sperm velocity } & \multicolumn{4}{|c|}{ Time after in vitro incubation at $37^{\circ} \mathrm{C}$} & \multirow[t]{2}{*}{$\mathbf{p}$} \\
\hline & T0 & T30 & T60 & T120 & \\
\hline $\mathrm{VAP}(\mu \mathrm{m} / \mathrm{s})$ & $73.35 \pm 2.15^{\mathrm{a}}$ & $66.52 \pm 1.53^{\mathrm{b}}$ & $67.12 \pm 2.01^{\mathrm{b}}$ & $67.58 \pm 1.53^{b}$ & 0.0368 \\
\hline $\operatorname{VSL}(\mu \mathrm{m} / \mathrm{s})$ & $65.31 \pm 1.66^{\mathrm{a}}$ & $59.22 \pm 1.38^{\mathrm{b}}$ & $59.92 \pm 1.79^{b}$ & $61.02 \pm 1.31^{\mathrm{b}}$ & 0.0290 \\
\hline $\operatorname{VCL}(\mu \mathrm{m} / \mathrm{s})$ & $132.76 \pm 3.50^{\mathrm{a}}$ & $121.88 \pm 2.79^{b}$ & $123.02 \pm 3.40^{\mathrm{b}}$ & $121.58 \pm 3.16^{\mathrm{b}}$ & 0.0470 \\
\hline $\operatorname{RAP}(\%)$ & $35.68 \pm 2.16$ & $33.68 \pm 2.57$ & $34.78 \pm 2.93$ & $33.68 \pm 3.07$ & 0.9409 \\
\hline
\end{tabular}

a,b Means within rows with different superscripts differ significantly $(\mathrm{p}<0.05)$. VAP: average path velocity; VSL: straight line velocity; VCL: curvilinear velocity; RAP: percentage of rapid cells.

Table 6 - Mean \pm standard error of motion characteristics of frozen-thawed equine sperm dilution with skim milk extender (SM Extender) and skim milk extender plus pentoxifylline (SM Extender + PTX, at 7.18 mM), regardless on the time of analysis - Pirassununga - SP - 2013

\begin{tabular}{cccc}
\hline Sperm velocity & SM Extender & SM Extender+PTX & p \\
\hline VAP $(\mu \mathrm{m})$ & $65.71 \pm 0.89$ & $71.68 \pm 1.52$ & 0.0017 \\
VSL $(\mu \mathrm{m})$ & $59.20 \pm 0.80$ & $63.63 \pm 1.29$ & 0.0055 \\
VCL $(\mu \mathrm{m})$ & $118.50 \pm 1.57$ & $131.24 \pm 2.51$ & $<0.0001$ \\
RAP $(\%)$ & $32.64 \pm 1.91$ & $36.25 \pm 1.79$ & 0.1737
\end{tabular}

Statistical difference $(\mathrm{p}<0.05)$. VAP: average path velocity; VSL: straight line velocity; VCL: curvilinear ${ }^{-}$ velocity; RAP: percentage of rapid cells. 
For the velocities characteristics mentioned above, the only one which had no statistical difference ( $p>0.05$ ) was percentage of rapid cells (RAP). However, pentoxifylline did increase $(p>0.05)$ velocity characteristics significantly.

Table 7 - Mean \pm standard error of motion characteristics of frozen-thawed equine sperm dilution with skim milk extender (SM Extender) and skim milk extender plus pentoxifylline (SM Extender + PTX, at $7.18 \mathrm{mM}$ ). Incubated in vitro at $37^{\circ} \mathrm{C}$ during 5 (T0), 30 (T30), 60 (T60), and 120 (T120) minutes - Pirassununga $\mathrm{SP}-2013$

\begin{tabular}{|c|c|c|c|c|c|}
\hline \multirow{2}{*}{$\begin{array}{l}\text { Sperm } \\
\text { velocity }\end{array}$} & \multirow{2}{*}{ Treatment } & \multicolumn{4}{|c|}{ Time after in vitro incubation at $37^{\circ} \mathrm{C}$} \\
\hline & & T0 & T30 & T60 & T120 \\
\hline \multirow{2}{*}{$\operatorname{VAP}(\mu \mathrm{m} / \mathrm{s})$} & SM Extender & $69.43 \pm 1.73^{\mathrm{A}}$ & $63.37 \pm 1.65^{\mathrm{B} \mathrm{b}}$ & $64.38 \pm 1.80^{\mathrm{B}}$ & $\underset{\mathrm{B}}{65.48 \pm 1.49^{\mathrm{A}}}$ \\
\hline & $\begin{array}{c}\text { SM } \\
\text { Extender+PTX }\end{array}$ & $77.27 \pm 3.52$ & $69.67 \pm 2.13^{\mathrm{a}}$ & $69.87 \pm 3.42$ & $69.68 \pm 2.57$ \\
\hline \multirow{2}{*}{$\operatorname{VSL}(\mu \mathrm{m} / \mathrm{s})$} & SM Extender & $62.83 \pm 1.50^{\mathrm{A}}$ & $56.81 \pm 1.32^{\mathrm{B}}$ & $57.57 \pm 1.70^{\mathrm{B}}$ & $59.38 \pm 1.24^{\mathrm{A}}$ \\
\hline & $\begin{array}{c}\text { SM } \\
\text { Extender+PTX }\end{array}$ & $67.80 \pm 2.79$ & $61.63 \pm 2.19$ & $62.27 \pm 3.02$ & $62.66 \pm 2.26$ \\
\hline \multirow[b]{2}{*}{ VCL $(\mu \mathrm{m} / \mathrm{s})$} & SM Extender & $124.10 \pm 2.92^{b}$ & $115.50 \pm 2.82^{\mathrm{b}}$ & $118.70 \pm 3.01$ & $115.72 \pm 3.33$ \\
\hline & $\begin{array}{c}\text { SM } \\
\text { Extender+PTX }\end{array}$ & $\frac{141.42 \pm 4.75^{\mathrm{A}}}{\mathrm{a}}$ & $\underset{\mathrm{a}}{128.27 \pm 3.70^{\mathrm{A}, \mathrm{B}}}$ & $\underset{\mathrm{B}}{127.35 \pm 5.91}$ & $\underset{B}{127.43 \pm 4.69}$ \\
\hline \multirow{2}{*}{$\operatorname{RAP}(\%)$} & SM Extender & $33.75 \pm 3.69$ & $32.62 \pm 4.69$ & $29.85 \pm 3.12$ & $34.00 \pm 4.02$ \\
\hline & $\begin{array}{c}\text { SM } \\
\text { Extender+PTX }\end{array}$ & $37.62 \pm 2.32$ & $34.75 \pm 2.45$ & $39.71 \pm 4.42$ & $33.37 \pm 4.93$ \\
\hline
\end{tabular}

At this point of view, pentoxifylline exert positive effects only on VAP at 30 minutes after incubation and VCL at 0 and 30 minutes after incubation. Comparing between time of analysis, VAP and VSL on skim milk extender only, presented higher values at T0 and T120 than at T30 and T60. For VCL on skim milk extender plus pentoxifylline it was significantly different $(\mathrm{p}<0.05)$ higher at time T0 and T30 than for times T6 and T120.

Pentoxifylline was statistical different $(\mathrm{p}<0.05)$ for ALH, BCF and STR. LIN was not significantly $(\mathrm{p}>0.05)$ affected by pentoxifylline addition. Data are shown in tables 8 and 9 . 
Table 8 - Mean \pm standard error of motion characteristics of frozen-thawed equine sperm dilution with skim milk extender (SM Extender) and skim milk extender plus pentoxifylline (SM Extender + PTX, at $7.18 \mathrm{mM})$, regardless on the time of analysis - Pirassununga - SP - 2013

\begin{tabular}{cccc} 
Motion characteristics & SM Extender & SM Extender+PTX & p \\
\hline ALH $(\mu \mathrm{m})$ & $4.69 \pm 0.07$ & $5.17 \pm 0.09$ & 0.0001 \\
BCF $(\mathrm{Hz})$ & $39.66 \pm 0.45$ & $39.19 \pm 0.63$ & 0.5563 \\
STR $(\%)$ & $89.67 \pm 0.27$ & $88.61 \pm 0.40$ & 0.0347 \\
LIN (\%) & $53.45 \pm 0.45$ & $51.45 \pm 0.49$ & 0.0040
\end{tabular}

ALH: lateral head displacement, BCF: beat-cross frequency, STR: straightness, LIN: linearity. Statistical difference $(\mathrm{p}<0.05)$.

Table 9 - Mean \pm standard error of motion characteristics of frozen-thawed equine sperm dilution with skim milk extender (SM Extender) and skim milk extender plus pentoxifylline (SM Extender + PTX, at $7.18 \mathrm{mM}$ ). Incubated in vitro at $37^{\circ} \mathrm{C}$ during 5 (T0), 30 (T30), 60 (T60), and 120 (T120) minutes Pirassununga - SP - 2013

\begin{tabular}{cccccc}
\multirow{2}{*}{$\begin{array}{c}\text { Motion } \\
\text { Characteristics }\end{array}$} & Treatments & \multicolumn{4}{c}{ Time after in vitro incubation at $37^{\circ} \mathrm{C}$} \\
\cline { 3 - 6 } & & T0 & T30 & T60 & T120 \\
\hline \multirow{2}{*}{ ALH $(\mu \mathrm{m})$} & SM Extender & $4.76 \pm 0.13^{\mathrm{b}}$ & $4.81 \pm 0.10^{\mathrm{b}}$ & $4.81 \pm 0.18$ & $4.41 \pm 0.14^{\mathrm{b}}$ \\
& SM Extender+PTX & $5.53 \pm 0.10^{\mathrm{A} a}$ & $5.35 \pm 0.18^{\mathrm{A}, \mathrm{Ba}}$ & $4.90 \pm 0.14^{\mathrm{B}, \mathrm{C}}$ & $4.87 \pm 0.17^{\mathrm{C} \text { a }}$ \\
\hline \multirow{2}{*}{ BCF $(\mathrm{Hz})$} & SM Extender & $39.30 \pm 0.63$ & $39.17 \pm 0.90$ & $39.80 \pm 1.46$ & $40.38 \pm 0.74$ \\
& SM Extender+PTX & $37.88 \pm 0.77^{\mathrm{B}}$ & $37.47 \pm 1.74^{\mathrm{B}}$ & $39.84 \pm 1.12^{\mathrm{A}, \mathrm{B}}$ & $41.66 \pm 0.74^{\mathrm{A}}$ \\
\hline \multirow{2}{*}{ STR $(\%)$} & SM Extender & $90.00 \pm 0.53^{\mathrm{a}}$ & $89.12 \pm 0.66$ & $89.14 \pm 0.40$ & $90.37 \pm 0.49$ \\
& SM Extender+PTX & $87.25 \pm 0.84^{\mathrm{B} \mathrm{b}}$ & $88.12 \pm 0.97^{\mathrm{A}, \mathrm{B}}$ & $89.14 \pm 0.67^{\mathrm{A}, \mathrm{B}}$ & $90.00 \pm 0.37^{\mathrm{A}}$ \\
\hline \multirow{2}{*}{ LIN $(\%)$} & SM Extender & $54.00 \pm 0.77^{\mathrm{A}, \mathrm{B}}$ & $52.62 \pm 0.77^{\mathrm{B}, \mathrm{C}}$ & $51.57 \pm 0.57^{\mathrm{C}}$ & $55.37 \pm 0.90^{\mathrm{A} \mathrm{a}}$ \\
& SM Extender+PTX & $50.62 \pm 0.56^{\mathrm{b}}$ & $50.75 \pm 1.53$ & $51.85 \pm 0.80$ & $52.62 \pm 0.70^{\mathrm{b}}$ \\
\hline
\end{tabular}

${ }^{\mathrm{a}, \mathrm{b}}$ Means in the column within treatment with different superscripts differ significantly (p<0.05). ${ }^{\mathrm{A}, \mathrm{B}}$ Means in the line with different superscripts differ significantly $(\mathrm{p}<0.05)$. ALH: lateral head displacement, BCF: beatcross frequency, STR: straightness, LIN: linearity.

Pentoxifylline increased ( $\mathrm{p}<0.05)$ ALH at 5, 30 and 120 minutes after incubation. Whereas decreased $(\mathrm{p}<0.05)$ STR and LIN at T0 and LIN at 120 minutes after incubation. Comparing between time of analysis ALH on skim milk plus pentoxifylline was higher at T0 and T30. BCF on skim milk plus pentoxifylline was higher at T60 and T120. For STR on skim milk plus pentoxifylline was lower at T0 than for the other moments. For LIN on skim milk extender only was higher at T0 and T120 than for T30 and T60 moments. 
The results referent to how time and treatment affected percentage of cells with membrane integrity are described in table 10.

Table 10 - Mean \pm standard error of membranes status of frozen-thawed equine sperm dilution with skim milk extender (SM Extender) or skim milk extender plus pentoxifylline (SM Extender+PTX, at 7.18 $\mathrm{mM}$ ). Incubated in vitro at $37^{\circ} \mathrm{C}$ during 5 (T0), 30 (T30), 60 (T60), and 120 (T120) minutes Pirassununga - SP - 2013

\begin{tabular}{cccccc}
\multirow{2}{*}{$\begin{array}{c}\text { Membranes } \\
\text { status }\end{array}$} & Treatments & \multicolumn{4}{c}{ Time after in vitro incubation at $3^{\circ} \mathbf{C}$} \\
\cline { 3 - 6 } & & T0 & T30 & T60 & T120 \\
\hline \multirow{2}{*}{ IPIAH (\%) } & SM Extender & $40.30 \pm 3.03$ & $42.47 \pm 3.99$ & $42.02 \pm 2.68$ & $39.32 \pm 2.70$ \\
& SM Extender+PTX & $40.65 \pm 3.13$ & $42.00 \pm 3.95$ & $37.91 \pm 2.42$ & $40.72 \pm 2.58$ \\
\hline \multirow{2}{*}{ PMI (\%) } & SM Extender & $40.59 \pm 3.07$ & $43.03 \pm 3.91$ & $42.33 \pm 2.60$ & $39.52 \pm 2.75$ \\
& SM Extender+PTX & $41.28 \pm 3.29$ & $42.50 \pm 3.80$ & $39.15 \pm 2.93$ & $41.47 \pm 2.10$ \\
\hline \multirow{2}{*}{ AMI (\%) } & SM Extender & $95.19 \pm 1.22$ & $95.24 \pm 1.16$ & $96.29 \pm 0.95$ & $96.14 \pm 0.99$ \\
& SM Extender+PTX & $93.69 \pm 1.34$ & $95.87 \pm 1.32$ & $93.25 \pm 1.80$ & $96.43 \pm 0.64$ \\
\hline \multirow{2}{*}{ HMMP (\%) } & SM Extender & $61.49 \pm 4.06$ & $65.48 \pm 4.96$ & $61.81 \pm 4.29$ & $57.12 \pm 4.26$ \\
& SM Extender+PTX & $61.40 \pm 3.17$ & $63.68 \pm 4.33$ & $59.34 \pm 4.01$ & $61.33 \pm 5.17$ \\
\hline
\end{tabular}

IPIAH: intact plasma membrane, intact acrosome and high mitochondrial membrane potential; PMI: plasmatic membrane integrity; AMI: acrosome membrane integrity; HMMP: high mitochondrial membrane potential. No statistical difference was found $(\mathrm{p}>0.05)$.

Analyzing the percentage of cells presenting plasma membrane integrity, intact acrosome and high mitochondrial membrane potential (IPIAH) regardless on the time of analysis, there was no statistical difference $(\mathrm{p}>0.05)$ between skim milk extender and skim milk extender containing pentoxifylline ( $41.03 \pm 1.51$ and $40.32 \pm 1.48 \%$, respectively).

There were no significant differences $(\mathrm{p}>0.05)$ between the two treatments at T0, T30, T60 and T120. This suggests the protective behavior of both extenders, maintain the integrity of membranes for two hours safely.

No statistical difference $(p>0.05)$ was found neither for the time nor for the treatments on DNA decondensation after addition of pentoxifylline (tables 11 and 12). 
Table 11 - Mean \pm standard error of chromatin decondensation classification of frozen-thawed equine sperm diluted with skim milk extender (SM Extender) and skim milk extender plus pentoxifylline (SM Extender + PTX, at $7.18 \mathrm{mM}$ ), regardless on the time of analysis - Pirassununga - SP - 2013

\begin{tabular}{cccc}
\hline $\begin{array}{c}\text { Chromatin } \\
\text { decondensation }\end{array}$ & SM Extender & SM Extender + PTX & p \\
\hline AT I (\%) & $94.11 \pm 0.54$ & $94.07 \pm 0.60$ & 0.9641 \\
AT II (\%) & $5.09 \pm 0.50$ & $5.06 \pm 0.57$ & 0.9689 \\
AT III (\%) & $0.79 \pm 0.10$ & $0.86 \pm 0.09$ & 0.6434 \\
\hline
\end{tabular}

ATI: cells without chromatin decondensation; ATII: intermediate decondensation; ATIII: high decondensation. No statistical difference was found $(\mathrm{p}>0.05)$.

Table 12 - Mean \pm standard error of chromatin decondensation classification of frozen-thawed equine sperm incubated in vitro at $37^{\circ} \mathrm{C}$ during T30 (30 minutes after incubation) and T120 (120 minutes after incubation), regardless on treatment - Pirassununga - SP - 2013

\begin{tabular}{cccc}
\hline \multirow{2}{*}{$\begin{array}{c}\text { Chromatin } \\
\text { decondensation }\end{array}$} & \multicolumn{2}{c}{ Time after in vitro incubation at 37 $\mathbf{C}$} & \multirow{2}{*}{$\mathbf{p}$} \\
\cline { 2 - 3 } & $\mathbf{T 3 0}$ & $\mathbf{T 1 2 0}$ & \\
\hline AT I (\%) & $94.42 \pm 0.59$ & $93.74 \pm 0.52$ & 0.3975 \\
AT II (\%) & $4.68 \pm 0.53$ & $5.50 \pm 0.52$ & 0.2846 \\
AT III (\%) & $0.88 \pm 0.10$ & $0.76 \pm 0.08$ & 0.3732 \\
\hline
\end{tabular}

ATI: cells without chromatin decondensation; ATII: intermediate decondensation; ATIII: high decondensation. No statistical difference was found $(\mathrm{p}>0.05)$.

No statistical difference $(\mathrm{p}>0.05)$ was found on spermatic morphology, between treatment skim milk extender and skim milk extender containing pentoxifylline, neither between moments of analysis 5 (T0) and 120 (T120) minutes after dilution (Table 13).

Table 13 - Mean \pm standard error of spermatic morphology of frozen-thawed equine sperm dilution with skim milk extender (SM Extender) or skim milk extender plus pentoxifyliine (SM Extender + PTX, at $7,18 \mathrm{mM}$ ). Incubated in vitro at $37^{\circ} \mathrm{C}$ during T0 (5 minutes after incubation) and T120 (120 minutes after incubation) - Pirassununga - SP - 2013

\begin{tabular}{ccccc}
\hline & Morphology & Major Defects & Minor Defects & Total Defects \\
\hline \multirow{2}{*}{ T0 } & SM Extender & $7.06 \pm 0.81$ & $5.81 \pm 1.13$ & $12.87 \pm 1.15$ \\
& SM Extender + PTX & $6.93 \pm 0.59$ & $4.68 \pm 0.71$ & $11.62 \pm 0.71$ \\
\hline \multirow{2}{*}{ T120 } & SM Extender & $8.43 \pm 0.75$ & $5.18 \pm 1.42$ & $13.62 \pm 1.67$ \\
& SM Extender + PTX & $7.92 \pm 0.71$ & $5.78 \pm 1.29$ & $13.71 \pm 1.55$ \\
\hline
\end{tabular}

No statistical difference was found $(\mathrm{p}>0.05)$. 


\subsection{DISCUSSION}

In this experiment, we determined the effect of skim milk extender supplemented with pentoxifylline $(7.18 \mathrm{mM})$ on the physiology of stallion cryopreserved spermatozoa, in order to characterize its resistance through two hours of incubation at $37^{\circ} \mathrm{C}$ and also investigate potential mechanisms of sperm damage.

\subsubsection{Effect of equine thawed sperm dilution using skim milk extender with pentoxifyline on sperm motion and membranes}

Various compounds have been used in the attempt to improve sperm motility, including pentoxifylline, a methylxantine derivative. It has been postulated that pentoxifylline, being a phosphodiesterase inhibitor, increases sperm kinetic characteristics and the number of spermatozoa exhibiting hyperactived motility (CALOGERO et al., 1998).

However, the results of the effect of pentoxifylline change according to the moment of addition, before (ESTEVES et al., 1998; ESTEVES; SPAINE; CEDENHO, 2007) or after cryopreservation, where the best post-thaw motility was obtained from groups treated after thawing (GRADIL; BALL, 2000; STANIC; SONICKI;SUCHANEK, 2002; MARQUES et al., 2002), in contrast to Ortigies et al. (2012) and this experiment, where results indicate that pentoxifylline did not exert the expected effect on increasing sperm motility.

Therefore, Calogero et al. (1998) examined the intracellular cAMP content. In some individuals pentoxifylline induced changes in sperm kinetic characteristics and hyperactivation were not always accompanied by an equivalent change in the intracellular cAMP content. Indeed, some semen samples showed a beneficial effect of pentoxifylline, 
despite no increment, or even a decrease, in the intracelular sperm cAMP content, suggesting that the increasing cAMP may not be the only mechanism involved. This implies that, other mechanisms may play a role in the stimulation of sperm motility induced by pentoxifylline (WANG et al., 1993).

Our results revealed that cryopreserved semen diluted in skimmed milk-based extender and skimmed milk-based extender containing pentoxifylline immediately after dilution (T0), had similar behavior. Whereas Pentoxifylline just exert positive effect in some of the characteristics analyzed, as VAP, VSL and VCL. Pentoxifylline did not exert any effect on progressive motility, beat cross frequency, and straightness, were improvement occurred due to dilution on skim milk based extender.

Sperm protection by milk, contain active components as casein micelles, which interact with membrane plasma proteins and protect against the removal of phospholipids and cholesterol from the plasma membrane (BERGERON; MANJUNATH, 2006).

Despite advances in the development of extenders, and until nowadays skim milk based extender presents as good performance as others more complex and modern extenders. Besides dilution, extender media and their ingredients protect the sperm plasma membrane against environmental influences by controlling $\mathrm{pH}$ and osmolarity (AURICH, 2005).

Different extenders interact with semen and provide protection of various cells compartments during the cooling, freezing and thawing processes (HOLT, 2000). Rams presented the highest post-thawing sperm membrane integrity when the semen was frozen in skim milk extender in comparison to tris-yolk and tris-yolk/skim milk extenders (CARVALHO et al., 2008).

Extenders of different formulations protect the various cells compartments during cryopreservation. Celeghini et al. (2008) found that egg yolk based extender have more advantages in term of cell preservation than soy lecithin based extender in bovine semen. In 
contrast, for equine cooled semen after 24 hours at $6-8^{\circ} \mathrm{C}$, plasma membrane integrity by HOST was higher $(\mathrm{p}<0.05)$ in glycine egg yolk extender compared with that of skim milk extender (PUGLIESI et al., 2012).

On the other hand, the major problem in semen extenders based on milk or egg yolk exists by the fact that these biological substances are composed of a variety of different molecules and may differ between batches. Besides components with beneficial effects on sperm plasma membranes, also detrimental or even toxic components can be included (AURICH, 2005).

For the percentage of cells with plasma membrane integrity, we observed no statistical difference, between groups diluted to not diluted. Whereas cells with acrosomal membrane integrity and cells with high mitochondrial membrane potential differed statistically from not diluted to diluted. Semen samples diluted presented higher membranes integrity. This may suggest that cryoprotectant may be more toxic for acrosomal and mitochondrial membranes than for plasma membrane.

The extender of cryopreservation utilized for this experiment, Botucrio ${ }^{\circledR}$ (Botupharma - Botucatu SP- Brazil) contain sugars, amino acids, egg yolk, glycerol and dimethilformamide (TERRACIANO et al., 2008).

Glycerol is such a cryoprotectant, which exerts its action retaining water within the cell, thus avoiding excessive dehydration due to the exposure to concentrated solutions. On the other hand, glycerol are considered toxic, a toxicity that has been claimed as being the single most limiting factor for the success of cryopreservation. Glycerol is, to date, the most widely used cryoprotectant to freeze stallion spermatozoa at concentrations between 2 and 5\% (MACIAS GARCIA et al., 2012). 


\subsubsection{Effect of pentoxifyline addition to skim milk extender to frozen-thawed equine sperm in vitro incubated at $37^{\circ} \mathrm{C}$ has on sperm motion, membranes, chromatin and morphology}

Related to time of incubation, we observed that total motility and progressive motility behaved the same way since immediately after dilution (T0) until 120 minutes from dilution and incubation, suggesting that both extenders maintained motility for two hours, safely. Different from what was found in other study, where the total motility and progressive motility were lower at $120 \mathrm{~min}$, than 0 and $60 \mathrm{~min}$ of incubation (SILVA et al., 2009). Marques et al. (2002) observed that the progressive motility increased when pentoxifylline was added alone or in combination with ascorbic acid to frozen-thawed stallion semen just at time 0 or 120 minutes of in vitro incubation, but there was no significant difference at time 60 minutes.

However, pentoxifylline did exert an increase on velocities characteristics VAP, VSL, VCL and also on others sperm motion, characteristics such as ALH, BCF and STR within two hours of incubation. In agreement, Calogero et al. (1998) also observed an increase on BCF after 1 and 2 hours and Gradil and Ball (2000) found significant effects on ALH, BCF, and LIN, but not in progressive motility.

Stacheki, Ginsburg and Armant (1994), examined the stimulation of cryopreserved epididymal feline sperm and also noticed that the addition of pentoxifylline had a profound stimulatory effect, increasing motility, VCL, VSL and ALH at the majority of concentrations tested. In contrast, Esteves et al. (1998) did not found any improvement in VCL or VAP, and found a significantly decrease on VSL and LIN.

High mitochondrial membrane potential was the characteristic most expected for semen diluted with pentoxifylline because its relation to high motility (SHEN et al., 1991; 
CENTOLA; CARTIE; COX, 1995; CALOGERO et al., 1998; GRADIL; BALL, 2000; MARQUES et al., 2002) even after $120 \mathrm{~min}$ incubation at $37^{\circ} \mathrm{C}$ (GOULART et al., 2004). In addition, another study a positive correlation between sperm motility and the addition of pentoxifylline in cryopreserved stallion semen (GRADIL; BALL, 2000) and human semen (STANIC; SONICKI, SUCHANEK, 2002) after thawing was observed. In contrast, with the present study, where an association between pentoxifylline and high mitochondrial membrane potential was not found.

Silva et al. (2009) observed on samples treated with pentoxifylline, a significant reduction in percentage of cells with intact acrosome as a result of the incubation time, more markedly after 120 minutes of incubation. Tesarik, Thebault and Testart (1992), suggested pentoxifylline as a potential drug for the treatment of anomalies in the acrosome reaction.

As seen in the present study, acrosomal and mitochondrial membrane, when in contact for long period after thawing to the cryoprotectant, needs to be diluted and diminish its toxic effect (AMANN; PICKETT, 1987).

Acrosome integrity did not differ between control and treated groups before freezing. The freeze-thaw process significantly decreased the percentages of live-sperm with intact acrosomes in both the control and pentoxifylline groups. Pre-freeze treatment of poor quality human sperm with pentoxifylline improved the ability of thawed spermatozoa to undergo the acrosome reaction in response to calcium ionophore (ESTEVES; SPAINE; CEDENHO, 2007).

Low quality of chromatin detected in morphologically abnormal sperm may represent one of the major factors limiting the fertilizing ability of the sperm. As in this experiment, the analysis of sperm DNA integrity showed no difference between treatments and the time of incubation, demonstrating that the cryopreservation process did not damaged genetic material. 
This fact indicates that when sperm cells are in favorable conditions maintaining the DNA integrity, the addition of antioxidant are not required (SILVA et al., 2009).

There is a wide variation in sperm morphology among breeding stallion. Sperm morphology can vary considerably during the breeding season, and routine evaluation are necessary to determine sperm morphology characteristics of a particular stallion (BRITO, 2007).

Reduced number of sperm, large percentage of immotile sperm, a high proportion of abnormal shaped sperm, or combination of these findings may reduce male fertility. Among semen parameters, sperm number and morphology are closely related to spermatogenesis and thus difficult to be modified once sperm is formed (SHEN et al., 1991).

As we expected, spermatic morphology was not affected by the addition of pentoxifylline on semen extender, neither after 2 hours after incubation.

\subsection{CONCLUSION}

Pentoxifylline increased sperm velocity, lateral head displacement, beat-cross frequency and straightness trough the incubation period and was able to maintaining total and progressive sperm motility and membranes integrity for at least two hours. However, did not exert any effect on sperm motility or protecting membranes. 


\title{
6 THE EFFECT OF SEMEN EXTENDER SUPPLEMENTED WITH PENTOXIFYLLINE ON POST-BREEDING INFLAMMATION RESPONSE ASSESSED BY ENDOMETRIAL CYTOLOGY AND VASCULAR PERFUSION
}

\begin{abstract}
The aim of this study was to examine, through color and spectral mode ultrasonography Doppler and cytology, the uterine inflammatory response caused by pentoxifylline added to skim milk extender. Fifteen mares in estrous were examined daily via transrectal palpation and ultrasound examination, when the dominant follicle reach $\geq 35 \mathrm{~mm}$ in diameter, $2500 \mathrm{IU}$ of hCG (Vetecor®) intravenously, was administered. After 30 hours, ultrasound examinations were made every 6 hours, in order to inseminate mares post ovulation. For artificial insemination, mares were randomly divided into 5 groups: Group C (control): no deposition of semen, or extender, just mimicking the AI procedure; Group Extender: deposition of skim milk based extender (Botusemen ${ }^{\circledR}$, Botupharma); Group Extender+PTX: deposition of skim milk based extender plus Pentoxifylline $(7.18 \mathrm{mM}, \mathrm{P}-1784$ Sigma-Aldrich, as described by Guasti et al., 2013); Group Semen: deposition of semen diluted with extender without Pentoxifylline; Group Semen+PTX: deposition of semen diluted with extender containing Pentoxifylline. The inseminantion dose showed a total of $1 \times 10^{9}$ sperm. Uterine hemodynamics were examined through color flow mode of the left and right horns and spectral mode of the left and right uterine arteries on seven predetermined times: immediately before ovulation induction (T-30), immediately before insemination (TAI), 2 hours after insemination (T2), 6 hours after insemination (T6), 12 hours after insemination (T12), 24 hours after insemination (T24) and 48 hours after insemination (T48). Endometrial samples were collected at six hours after insemination. Samples were collected rotating the cytobrush, in contact with the uterine wall. Slides for cytology were prepared by rolling the cytobrush
\end{abstract}


onto a glass microscope slide and air-dried, stained using Panótico Rapido ${ }^{\circledR}$ (Laborclin Ltda.), air-dried and examined by light microscopy (Nikon, Eclipse E200, Tokio, Japan) at 400x magnification. Three hundred cells per slide were examined and classified as endometrial epithelial cells and PMNs. To all variables was utilized the analysis of variance (ANOVA), and the range was compared by $L S D$ test, SAS 9.3 version (2010). Pentoxifylline had no additional effect on vascular perfusion, since no statistical difference was found between analyzed moments on uterine blood flow of mares neither between treatments. However, results of endometrial cytology clearly shows a major $(\mathrm{p}<0.05)$ inflammatory response on groups containing Pentoxifylline when compared to controls. Group extender plus pentoxifylline considered mild inflammation $(57.98 \pm 9.42 \%$ of inflammatory cells), induced 2.87 times more inflammatory response, than group extender only, considered slight inflammation $(20.20 \pm 6.63 \%$ of inflammatory cells). The same happened to groups of semen diluted in extender containing or not pentoxifyline, the one which contain pentoxifylline, considered severe inflammation $(82.84 \pm 5.71 \%$ of inflammatory cells), inducing 1.7 times higher inflammatory degree than semen without pentoxifylline, considered slight inflammation $(47.83 \pm 10.61 \%$ of inflammatory cells). This suggests that the addition of pentoxifyline induce a intense inflammatory response. In conclusion pentoxifylline does not stimulate blood flow however, induce a greater mechanisms defense, since increased neutrophils migration to uterine lumen whereas may promote faster endometrial recovery.

Keywords: Endometritis. Pentoxifylline. Doppler. Cytology. 


\subsection{INTRODUCTION}

Uterine infection induce major losses on the equine industry (CAUSEY, 2006) and has been reported to be the third most common clinical condition of horses (CARD, 2005; LIU; TROEDSSON, 2008). Fertility varies markedly among mares. Apart from poor management and incorrect time of mating, probably one of the most important reasons for low pregnancy rates is endometritis (WATSON, 2000).

In mares, spermatozoa are deposited directly into the uterus, however only a small number of spermatozoa ever reach the site of fertilization in the uterine tube. The majority of the ejaculate remains in the uterus and is cleared by two mechanisms: uterine contractions and acute uterine inflammatory response (LEBLANC, 2003).

The post breeding inflammatory response are usually physiological, transient, lasting less than 48 hours in those mares known as "resistant" (CAUSEY, 2006; TROEDSSON, 2006). However, delayed uterine clearance of spermatozoa and contaminants has been identified as the underlying cause of persistent uterine inflammation (TROEDSSON, 1997; CARD et al., 2004; MALSCHITZKY et al., 2007).

Mares termed "susceptible" to endometritis are unable to clear within 96 hours. This mares presenting persistent inflammation typically have a number of predisposing factors (MALOUFI et al., 2002; FUMUSO et al., 2007), such as poor perineal conformation, a dependent uterine location and delayed uterine clearance due to suboptimal myometrial contractility, being incapable of supporting pregnancy (RIGBY et al., 2001; CARD, 2005).

Besides pentoxifylline is a phosphodiesterase inhibitor and increases sperm kinetic characteristics and the number of spermatozoa exhibiting hyperactivated motility (CALOGERO et al., 1998; ESTEVES; SPAINE; CEDENHO, 2007) appears to participate 
from two concurrent methods of action: it acts as a rheological agent, improving blood flow to compromised tissues, and it acts as an immunomodulatory agent (BAUMGARTNER, 2007).

Pentoxifylline has been shown to improve bacterial clearance significantly decreasing bacterial colonization, thereby potentially decreasing tissue damage caused by neutrophils (SAMLASKA; WINFIELD, 1994; BAUMGARTNER, 2007). There are also some studies of the relation between pentoxifylline and blood flow. Short-term pentoxifylline oral administration increased testicular blood flow (POZOR et al., 2011), but when therapeutic dose was orally administered to pregnant mares, did not alter uterine artery blood flow parameters (BAILEY et al., 2012).

Endometrial inflammation cause changes in uterine perfusion, and can be assessed by ultrasound Doppler (BOLLWEIN; SOWADE; STOLLA, 2003b). Specifically, three measures of blood flow - the Resistance Index (RI), Pulsatility Index (PI), and Total Arterial Blood Flow (TABF) have been most commonly applied to quantify blood flow via Doppler ultrasonography. RI and PI are ratios that are computed from various points on the spectrum.

The indices are relatable to the hemodynamics of the tissue supplied by the artery. Increasing RI or PI values indicate increasing resistance and decreasing perfusion of the distal tissues (GINTHER; MATTHEW, 2004).

Other technique often used to evaluate endometrial inflammation, is through the detection of neutrophils on exfoliative endometrial cytology (CARD, 2005). Uterine cytology provides direct evidence of uterine inflammation (CAUSEY, 2006). Even though the cytobrush technique requires specialized equipment, sample collection by this method was easier, more consistent, and quicker than the lavage method, indicating that the cytobrush would be the preferred collection method for use on field in the mare (COCCHIA et al., 2012). 
The purpose of this study was examines the inflammatory response of the uterus caused by the addition of pentoxifylline on semen extender, trough both techniques: ultrasound Doppler and exfoliative endometrial cytology.

\subsection{MATERIALS AND METHODS}

\subsubsection{Location and Experimental Period}

This experiment was conducted in "Estância Sonho Meu" located in Piedade city, São Paulo state, at $23^{\circ} \mathrm{C}$ south latitude and $47^{\circ} \mathrm{C}$ west longitude, altitude between $750-1227$ meters over the sea level. Sperm analysis and cytology were performed at the Laboratory of Semen Biotechnology and Andrology, Center of Biotechnology in Animal Reproduction, Department of Animal Reproduction, College of Veterinary Medicine and Animal Science of the University of São Paulo, Pirassununga city. Experimental period occurred from October 2012 to February 2013.

\subsubsection{Management and Animal selection}

For this experiment were used 15 mares, presenting between 4 and 12 years old. Mares lived randomly distributed in paddocks. Animals were fed twice daily with hay (Lolium multiflorum), mineral supplementation and water ad libidum. Candidate mares were examined for reproductive soundness, including evaluation of perineal conformation, transrectal 
palpation and ultrasound examination of the genital tract, a vaginal speculum examination and cytological evaluation. All mares were clinically healthy and had normal estrous cycles.

\subsubsection{Follicular development and ovulation detection}

Mares in estrous were examined daily, via transrectal palpation and ultrasound examination, until a dominant softening follicle that measured $\geq 35 \mathrm{~mm}$ and prominent endometrial folds were detected. At this time $2500 \mathrm{IU}$ of human chorionic gonadotrophin $\left(\mathrm{hCG}\right.$, Vetecor $\left.^{\circledR}\right)$ was administered intravenously.

Mares were examined more frequently after 30 hours of ovulation induction, ultrasound examinations were made every six hours, in order to inseminate mares as close as possible to post-ovulation moment. The ultrasound used to perform all the evaluations was Doppler Ultrasound (M5Vet, Mindray Medical International Limited, China) with transrectal linear probe $(6.5 \mathrm{MHz})$.

\subsubsection{Semen analysis}

Ten semen batches previously cryopreserved $\left(100 \times 10^{6}\right.$ spermatozoa/0.5 mL straw) from a unique stallion was analyzed to use in the experiment. Two frozen semen straws were thawed $\left(37^{\circ} \mathrm{C} / 30\right.$ seconds) hold in a microcentrifuge tube (heated at $\left.37^{\circ} \mathrm{C}\right)$ and homogenized. The sperm movement was evaluated using the Computer-Assisted Sperm Analysis (CASA), as described by Nascimento et al. (2008). Integrity of plasma and acrosomal membranes and 
mitochondrial membrane potential, using the fluorescent probes association Propidium Iodide (PI), Hoechst 33342 (H342), 5,5',6,6'-tetrachloro-1,1',3,3'-tetraethylbenzimidazolyl carbocyanine iodide (JC-1) and fluorescein isothiocyanate-conjugated Pisum sativum agglutinin (FITC-PSA) adapted from Nascimento et al. (2008) and Celeghini et al. (2010a). Sperm morphology was analyzed using a differential interference contrast (DIC) microscopy. Chromatin denaturation assessed by Toluidine blue, (BELLETI; COSTA; GUARDIEIRO, 2005).

\subsubsection{Extenders and Artificial Insemination}

It was used two different extenders: (Extender) skim milk based extender commercial extender Botusemen $^{\circledR}$ (Botupharma- Botucatu - SP) and (Extender+PTX) skim milk based extender (the same commercial extender, Botusemen ${ }^{\circledR}$ ) addicting $0.119 \mathrm{~g}$ of Pentoxifylline (P-1784, Sigma-Aldrich) in $100 \mathrm{ml}$ of extender, obtaining final concentration of $7.18 \mathrm{mM}$ pentoxifylline, according to Guasti (2010). Both extenders were preheated at $37^{\circ} \mathrm{C}$ to prevent cold shock injuries in sperm cells.

After extenders preparations, ten semen straws were thawed in water bath at $37^{\circ} \mathrm{C}$ during 30 seconds and then diluted with $25 \mathrm{~mL}$ of extender obtaining final volume of $30 \mathrm{~mL}$, referent to inseminate dose.

For artificial insemination, mares were randomly divided into 5 groups according to semen extenders used: Group Control (control): no deposition of semen, or extender, just mimicking the AI procedure; Group SM Extender: deposition of skim milk based extender; Group SM Extender+PTX: deposition of skim milk based extender plus Pentoxifylline; Group 
Semen: deposition of semen diluted with extender without Pentoxifylline; Group Semen+PTX: deposition of semen diluted with extender containing Pentoxifylline.

\subsubsection{Assessment of endometrial inflammatory response}

\subsubsection{Vascular perfusion of the endometrium}

The identification of the uterine artery was carried out by visualizing its branching from the external iliac artery and following its course to the crossing point with the arteria circumflexa ilium profunda. This area was defined as the region of interest and a pulsed Doppler range gate was placed across the vessel.

The examination was performed until it was obtained at least nine similar waves of the cardiac cycle. The data was saved and later evaluation of these waves was peformed, so that every three similar waves formed, the RI value of the medium wave was selected and added to the other two medium waves of the next cycle obtained. For statistical analysis we used the average of the three selected waves.

The extent of local perfusion or blood flow of the uterine horn was estimated subjectively using the color-flow images. The evaluation of vascular score (VS) was made by scoring system quantification from 1 (less perfusion) to 4 (higher perfusion) according to Ginther (2007). This approach to color Doppler evaluation has appeal for both clinical and research purposes because it focuses directly on the tissue or structure of interest, shown in figure 2 . 
Figure 2 - The sonograms of equine uterine horn in transversal section, by color Doppler equipment (M5Vet, Mindray)
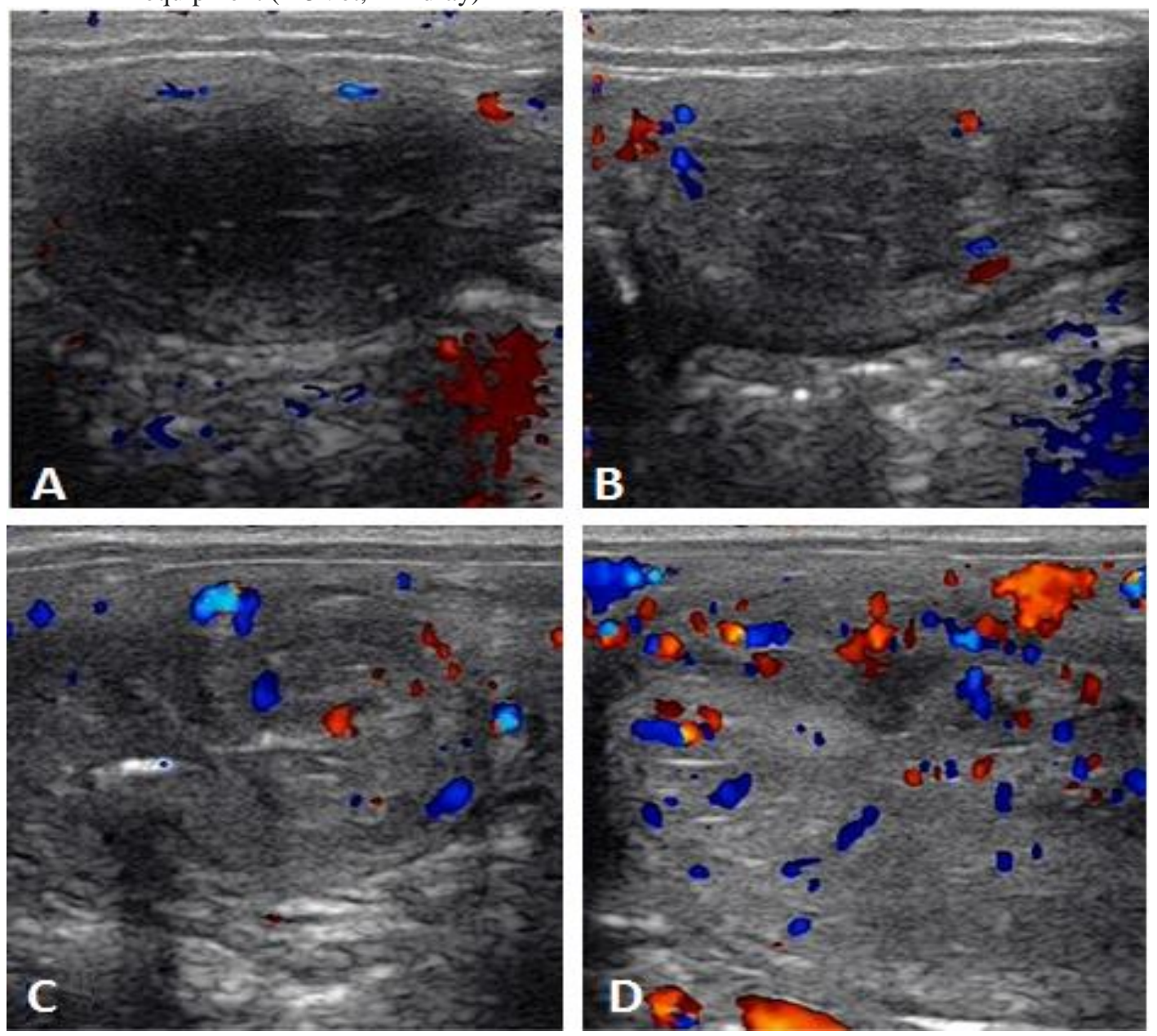

Vascular scoring (VS) system for subjective vascularization of mesometrium.

Considering from less vascularized (A) to more vascularized (D). Score 1 (A), Score 2 (B), Score 3 (C) and Score 4 (D) - Piedade, SP - 2013

Fonte: Tsunoda, R.H. (2013)

Analyses of color flow mode of the left and right horns and spectral mode of the left and right uterine arteries were performed on seven predetermined times: immediately before ovulation induction (T-30), immediately before insemination (TAI), 2 hours after insemination (T2), 6 hours after insemination (T6), 12 hours after insemination (T12), 24 hours after insemination (T24) and 48 hours after insemination (T48). 


\subsubsection{Endometrial Cytology}

Endometrial samples for endometrial cytology were collected. The covered, lubricated instrument was passed through the vagina and advanced through the cervix into the uterine body, at which point the outer tube was retracted far enough to expose the cytobrush. Endometrial cytology samples were collected rotating the cytobrush in a clockwise direction while in contact with the uterine wall. The cytobrush was retracted into the outer tube prior to removal from the uterus. Slides for cytology were prepared by gently rolling the cytobrush onto a glass microscope slide and air-dried.

The cytological slides were stained using Panoptic Stain Method (Panótico Rápido ${ }^{\circledR}$ Laborclin Ltda. Parana, Brazil) stain, air-dried and examined by microscopy (Nikon, Eclipse E200, Tokio, Japan) at 400x magnification. Three hundred cells per slide were examined and classified as endometrial epithelial cells (cubic or columnar cells with basal round nucleus) and neutrophils (polymorphonucleated cells, PMNs).

Inflammatory response was graduated in normal ( $<5 \%$ of polymorphonucleated cells), slight (between 5 and $25 \%$ of polymorphonucleated cells), mild (between 25 and $75 \%$ of polymorphonucleated cells) and severe (> $75 \%$ of polymorphonucleated cells) according to Williams et al. (1987).

\subsection{STATISTICAL ANALYSES}

All data were evaluated using SAS System for Windows (SAS Institute Inc., Cary, NC, USA). The effect of insemination groups (Groups C, E, EP, S, and SP) in the different 
moments of evaluation (T-30, TAI, T2, T6, T12, T24, and T48) were determined using parametric (Student t test and General Linear Model procedure-PROC GLM, respectively) and non-parametric (Mann Whitney U and Kruskall Wallis, respectively) tests, according to the residue normality (Gaussian distribution) and variance homogeneity of each variable.

A probability value of $\mathrm{P}<0.05$ was considered statistically significant. Results are reported as untransformed means \pm S.E.M.

\subsection{RESULTS}

\subsubsection{Vascular perfusion of the endometrium}

Once was not found interaction between treatment $\mathrm{x}$ group, the effect of treatments (Control, Extender, Extender+PTX, Semen and Semen+PTX) referent to the vascular perfusion, regardless of the time, are described in tables 14 and 15.

Table 14 - Means \pm standard error of resistance index (RI, 0-1) and vascularity score (VS, 1-4) of groups: with no deposition of semen, or extender, just mimicking the AI procedure (Control), after infusion of skim milk extender (SM Extender) or skim milk extender plus pentoxifylline (SM Extender + PTX), and semen diluted in skim milk extender (Semen) or semen diluted in skim milk extender plus pentoxifylline (Semen + PTX), regardless on time of analysis - Piedade - SP - 2013

\begin{tabular}{cccccc} 
End Points & Control & SM Extender & $\begin{array}{c}\text { SM Extender+ } \\
\text { PTX }\end{array}$ & Semen & Semen + PTX \\
\hline RI (0-1) & $0.77 \pm 0.006$ & $0.76 \pm 0.006$ & $0.77 \pm 0.006$ & $0.77 \pm 0.007$ & $0.77 \pm 0.005$ \\
VS(1-4) & $2.98 \pm 0.10$ & $2.75 \pm 0.09$ & $2.82 \pm 0.10$ & $2.98 \pm 0.10$ & $2.78 \pm 0.09$ \\
\hline
\end{tabular}

No statistical difference was found $(\mathrm{p}>0.05)$.

No statistical difference $(\mathrm{p}>0.05)$ was found between groups, pentoxifylline did not exert any additional effect on endometrial vascular perfusion after infusion. 
Comparing all the analysis moments, for resistance index, T48 was significantly higher $(\mathrm{p}<0.05)$ from $\mathrm{T}-30$, which means lower perfusion at 2 days after infusion. However for endometrial vascularity score T48 was higher and statistically different $(\mathrm{p}<0.05)$ from T24 (Table 15).

Table 15 - Means \pm standard error of resistance index (RI, 0-1) and vascularity score (VS, 1-4) of groups: with no deposition of semen, or extender, just mimicking the AI procedure (Control), after infusion of skim milk extender (SM Extender) or skim milk extender plus pentoxifylline (SM Extender +PTX), and semen diluted in skim milk extender (Semen) or semen diluted in skim milk extender plus pentoxifylline (Semen + PTX), at T-30 (immediately before ovulation induction), TIA (immediately before infusion), and 2 (T2), 6 (T6), 12 (T12), 24 (T24), and 48 hours after infusion (T48) - Piedade - SP - 2013

\section{Time relationship to procedure}

\begin{tabular}{cccccccc}
\cline { 2 - 7 } & T-30 & TAI & T2 & T6 & T12 & T24 & T48 \\
\cline { 2 - 7 } RI (0-1) & $0.75 \pm 0.007^{\mathrm{b}}$ & $0.77 \pm 0.007^{\mathrm{ab}}$ & $0.76 \pm 0.006^{\mathrm{ab}}$ & $0.76 \pm 0.007^{\mathrm{ab}}$ & $0.77 \pm 0.008^{\mathrm{ab}}$ & $0.77 \pm 0.008^{\mathrm{ab}}$ & $0.78 \pm 0.007^{\mathrm{a}}$ \\
VS (1-4) & $2.97 \pm 0.12^{\mathrm{ab}}$ & $2.77 \pm 0.11^{\mathrm{ab}}$ & $2.79 \pm 0.12^{\mathrm{ab}}$ & $2.87 \pm 0.11^{\mathrm{ab}}$ & $2.91 \pm 0.12^{\mathrm{ab}}$ & $2.68 \pm 0.11^{\mathrm{b}}$ & $3.02 \pm 0.11^{\mathrm{a}}$ \\
\hline
\end{tabular}

Moreover, were considered the effects of treatment groups within each analysis time and the effects of time at each treatment for RI (Table 16) and VS (Table 17 and Graphic 1).

For RI there were statistical differences $(\mathrm{p}<0.05)$ on Control, Extender and Semen groups among time. On control group the RI value was higher at T12 $(0.80 \pm 0.02)$ than at T6 $(0.73 \pm 0.02)$. For skim milk extender group, RI value was higher at T24 $(0.79 \pm 0.01)$ than at T30, TAI and T6 $(0.75 \pm 0.01$ for all of them).

On group semen, the RI was significantly higher $(\mathrm{p}<0.05)$ at T48 $(0.80 \pm 0.01$ for both) than at T2 $(0.74 \pm 0.01)$.

There was no statistical difference $(\mathrm{p}>0.05)$ between groups at any of the analyzed moments. Pentoxifylline did not exert any additional effect on vascular perfusion, since its behavior did not present any statistical difference. 
Table 16- Means \pm standard error of resistance index (RI, 0-1) of uterine arteries. Effect of infusion of groups: with no deposition of semen, or extender, just mimicking the AI procedure (Control), after infusion of skim milk extender (SM Extender) or skim milk extender plus pentoxifylline (SM Extender +PTX), and semen diluted in skim milk extender (Semen) or semen diluted in skim milk extender plus pentoxifylline (Semen + PTX), at T-30 (immediately before ovulation induction), TIA (immediately before infusion), and 2 (T2), 6 (T6), 12 (T12), 24 (T24), and 48 hours after infusion (T48) - Piedade - SP - 2013

\begin{tabular}{cccccc}
\hline $\begin{array}{c}\text { Time related to } \\
\text { Treatment }\end{array}$ & Control & SM Extender & Extender+PTX & Semen & Semen+PTX \\
\hline T-30 & $076 \pm 0.01^{\mathrm{a}, \mathrm{b}}$ & $0.75 \pm 0.01^{\mathrm{b}}$ & $0.75 \pm 0.01$ & $0.75 \pm 0.01^{\mathrm{a}, \mathrm{b}}$ & $0.76 \pm 0.01$ \\
TAI & $0.76 \pm 0.01^{\mathrm{a}, \mathrm{b}}$ & $0.75 \pm 0.01^{\mathrm{b}}$ & $0.78 \pm 0.01$ & $0.78 \pm 0.02^{\mathrm{a}, \mathrm{b}}$ & $0.76 \pm 0.01$ \\
T2 & $0.78 \pm 0.01^{\mathrm{a}, \mathrm{b}}$ & $0.78 \pm 0.01^{\mathrm{a}, \mathrm{b}}$ & $0.77 \pm 0.01$ & $0.74 \pm 0.01^{\mathrm{b}}$ & $0.78 \pm 0.009$ \\
T6 & $0.73 \pm 0.02^{\mathrm{b}}$ & $0.75 \pm 0.01^{\mathrm{b}}$ & $0.76 \pm 0.02$ & $0.76 \pm 0.02^{\mathrm{a}, \mathrm{b}}$ & $0.75 \pm 0.01$ \\
T12 & $0.80 \pm 0.02^{\mathrm{a}}$ & $0.78 \pm 0.01^{\mathrm{a}, \mathrm{b}}$ & $0.77 \pm 0.01$ & $0.77 \pm 0.02^{\mathrm{a} . \mathrm{b}}$ & $0.77 \pm 0.02$ \\
T24 & $0.79 \pm 0.01^{\mathrm{a}, \mathrm{b}}$ & $0.79 \pm 0.01^{\mathrm{a}}$ & $0.76 \pm 0.02$ & $0.77 \pm 0.02^{\mathrm{a}, \mathrm{b}}$ & $0.77 \pm 0.01$ \\
T48 & $0.77 \pm 0.02^{\mathrm{a}, \mathrm{b}}$ & $0.77 \pm 0.01^{\mathrm{a}, \mathrm{b}}$ & $0.78 \pm 0.01$ & $0.80 \pm 0.01^{\mathrm{a}}$ & $0.78 \pm 0.01$ \\
\hline
\end{tabular}

${ }^{\mathrm{a}, \mathrm{b}}$ Means within column with different superscripts differ significantly $(\mathrm{p}<0.05)$.

Table 17 - Means \pm standard error of of vascularity score (VS, 1-4) of uterine horns. Effect of infusion of groups: with no deposition of semen, or extender, just mimicking the AI procedure (Control), after infusion of skim milk extender (SM Extender) or skim milk extender plus pentoxifylline (SM Extender + PTX), and semen diluted in skim milk extender (Semen) or semen diluted in skim milk extender plus pentoxifylline (Semen + PTX), at T-30 (immediately before ovulation induction), TIA (immediately before infusion), and 2 (T2), 6 (T6), 12 (T12), 24 (T24), and 48 hours after infusion (T48) - Piedade - SP - 2013

\begin{tabular}{cccccc}
$\begin{array}{c}\text { Time related to } \\
\text { Treatment }\end{array}$ & Control & $\begin{array}{c}\text { SM } \\
\text { Extender }\end{array}$ & $\begin{array}{c}\text { SM } \\
\text { Extender+PTX }\end{array}$ & Semen & Semen+PTX \\
\hline T-30 & $3.37 \pm 0.19^{\mathrm{a} a}$ & $2.86 \pm 0.19^{\mathrm{a}, \mathrm{bB}}$ & $3.03 \pm 0.35^{\mathrm{a}}$ & $3.07 \pm 0.27$ & $2.87 \pm 0.30$ \\
TAI & $3.12 \pm 0.30^{\mathrm{a}, \mathrm{b}}$ & $2.86 \pm 0.22^{\mathrm{a}, \mathrm{b}}$ & $2.71 \pm 0.33^{\mathrm{a}, \mathrm{b}}$ & $2.79 \pm 0.33$ & $2.53 \pm 0.15$ \\
T2 & $2.50 \pm 0.37^{\mathrm{b}}$ & $2.37 \pm 0.24^{\mathrm{b}}$ & $2.78 \pm 0.32^{\mathrm{a}, \mathrm{b}}$ & $3.00 \pm 0.33$ & $2.67 \pm 0.11$ \\
T6 & $2.93 \pm 0.18^{\mathrm{a}, \mathrm{b}}$ & $2.75 \pm 0.18^{\mathrm{a}, \mathrm{b}}$ & $2.71 \pm 0.21^{\mathrm{a}, \mathrm{b}}$ & $3.14 \pm 0.29$ & $2.91 \pm 0.23$ \\
T12 & $2.87 \pm 0.41^{\mathrm{a}, \mathrm{b}}$ & $2.65 \pm 0.24^{\mathrm{a}, \mathrm{b}}$ & $2.54 \pm 0.30^{\mathrm{b}}$ & $3.21 \pm 0.30$ & $3.14 \pm 0.27$ \\
T24 & $2.92 \pm 0.24^{\mathrm{a}, \mathrm{b}}$ & $2.70 \pm 0.19^{\mathrm{a}, \mathrm{b}}$ & $2.50 \pm 0.28^{\mathrm{b}}$ & $2.64 \pm 0.28$ & $2.50 \pm 0.26$ \\
T48 & $3.17 \pm 0.20^{\mathrm{a}, \mathrm{b}}$ & $3.06 \pm 0.18^{\mathrm{a}}$ & $2.85 \pm 0.28^{\mathrm{a}, \mathrm{b}}$ & $3.10 \pm 0.18$ & $2.95 \pm 0.43$ \\
\hline
\end{tabular}

a,b Means within column with different superscripts differ significantly $(\mathrm{p}<0.05)$.

A,B Means within line with different superscripts differ significantly $(\mathrm{p}<0.05)$.

For vascular perfusion by scoring system quantitation, statistical difference $(\mathrm{p}<0.05)$

was found between moments of analysis on groups control, skim milk extender with and 
without pentoxifylline. There was also significant difference $(\mathrm{p}<0.05)$ between group control, showed higher vascularity score, than group extender at moment T0.

Graphic 1 - Means \pm standard error of endometrial vascularity score (VS, 1-4) of mares in each treatment, from immediately before ovulation induction time until 48 hours after insemination - Piedade - SP 2013

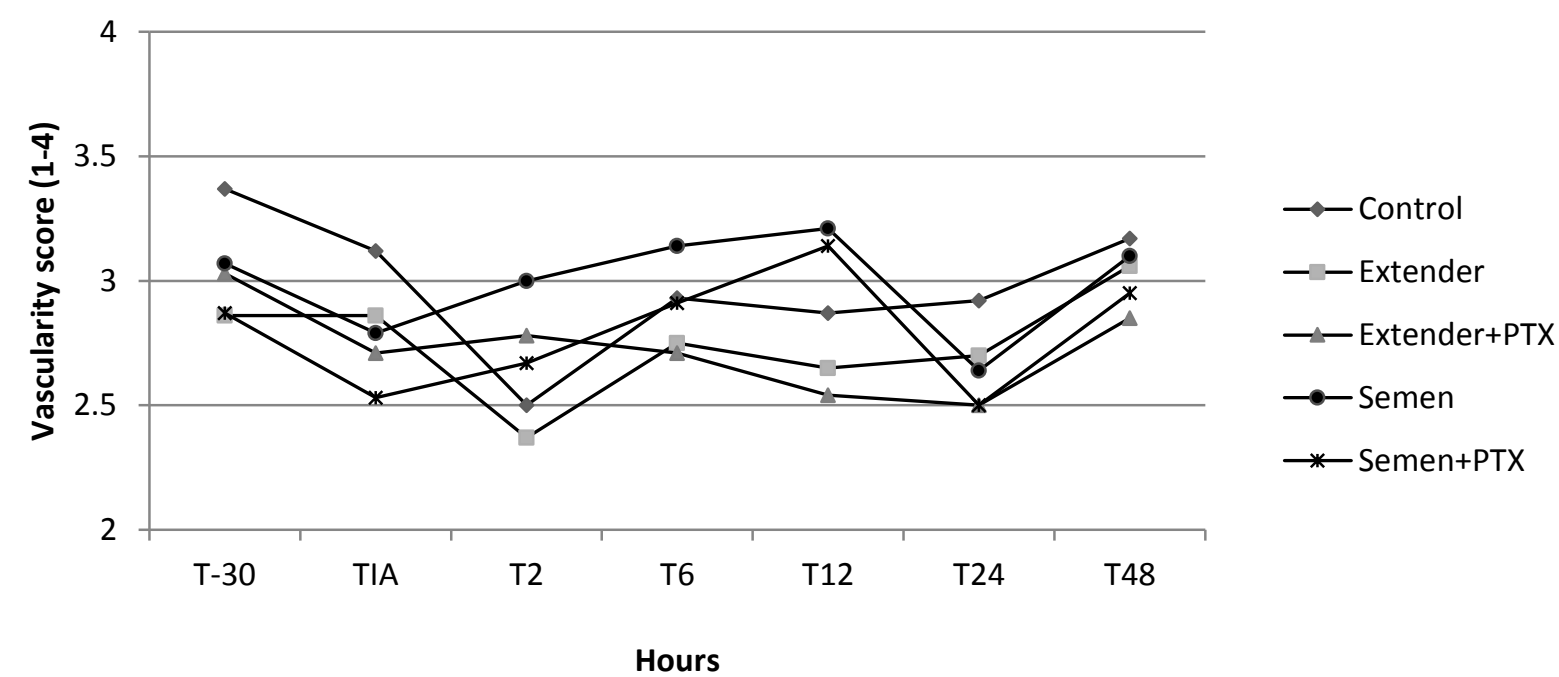

Control showed higher vascular score (0 to 4$)$ at T-30 moment $(3.37 \pm 0.19)$ than at T2

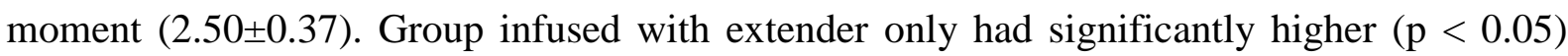
perfusion at T48 $(3.06 \pm 0.18)$ than at T2 moment $(2.37 \pm 0.24)$. For skim milk extender plus pentoxifylline group T-30 showed higher perfusion (3.03 \pm 0.35$)$ than T12 and T24 $(2.54 \pm 0.30$ and $2.50 \pm 0.28)$ statistically different $(\mathrm{p}<0.05)$. For the other groups there were no statistical differences between time of analysis.

\subsubsection{Endometrial Cytology}

It is clearly shown that groups extender plus pentoxifylline and semen plus pentoxifylline induced a major inflammatory response $(57.89 \pm 9.42$ and $82.84 \pm 5.71)$ when compared to groups extender and semen only $(20.20 \pm 6.63$ and $47.83 \pm 10.61)$ respectively. 
The results referent to percentage of inflammatory cells found on endometrial cytology according to each treatment are shown in table 18 and graphic 2.

Table 18 - Endometrial cytology of mares after 6 hours of infusion of the five experimental groups: with no deposition of semen, or extender, just mimicking the AI procedure (Control), after infusion of skim milk extender (SM Extender) or skim milk extender plus pentoxifylline (SM Extender + PTX), and semen diluted in skim milk extender (Semen) or semen diluted in skim milk extender plus pentoxifylline (Semen + PTX). Inflammatory cells in three hundred cells counted per slide - Piedade - SP -2013

Experimental Groups $\quad$ Inflammatory cells (\%)

\begin{tabular}{cc}
\hline Control & $35.60 \pm 6.30^{\mathrm{b}, \mathrm{c}}$ \\
SM Extender & $20.20 \pm 6.63^{\mathrm{c}}$ \\
SM Extender + PTX & $57.98 \pm 9.42^{\mathrm{b}}$ \\
Semen & $47.83 \pm 10.61^{\mathrm{b}}$ \\
Semen + PTX & $82.84 \pm 5.71^{\mathrm{a}}$ \\
\hline $\mathrm{a}, \mathrm{b}$ & Means within column with different superscripts differ significantly $(\mathrm{p}<0.05)$.
\end{tabular}

$\mathrm{a}, \mathrm{b}$ Means within column with different superscripts differ significantly $(\mathrm{p}<0.05)$.

Graphic 2 - Means and standard error of percentage of polymorphonuclear (PMN) cells found in mares after 6 hours from treatment - Piedade - SP - 2013

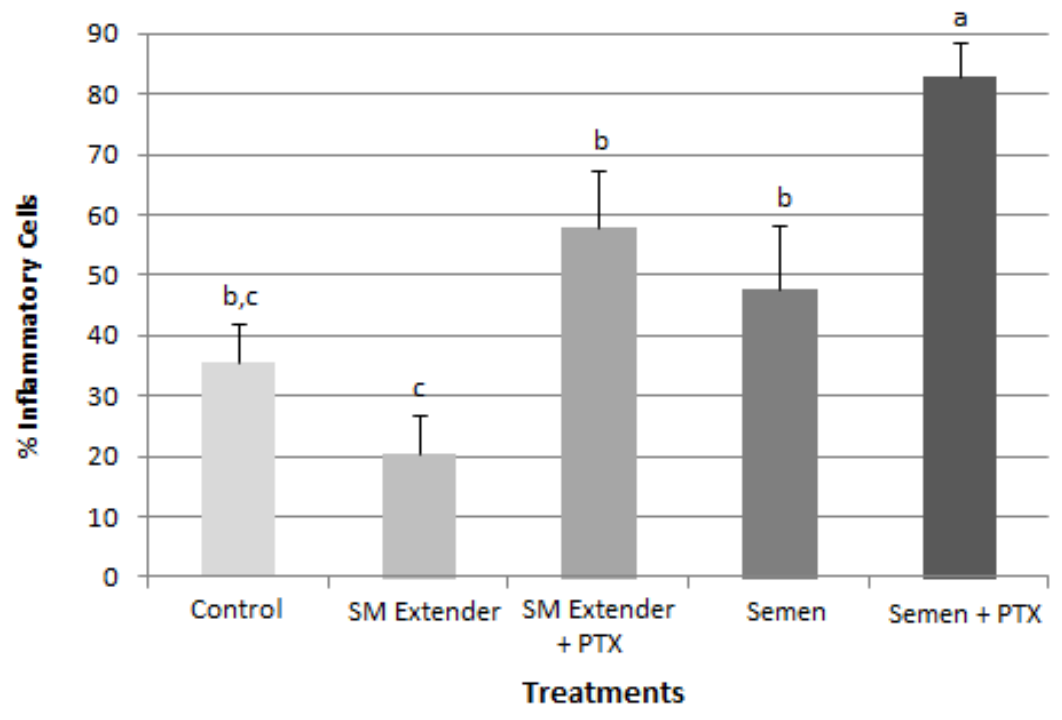

No deposition of semen, or extender, just mimicking the AI procedure (Control), after infusion of skim milk extender (SM Extender) or skim milk extender plus pentoxifylline (SM Extender + PTX), and semen diluted in skim milk extender (Semen) or semen diluted in skim milk extender plus pentoxifylline (Semen + PTX). 


\subsection{DISCUSSION}

There have been a number of studies concerning the local effects of intrauterine infusion on the equine uterus, with the main focus on humoral and cellular defense mechanisms (TROEDSSON et al., 2005). Impairment of uterine defense mechanisms after insemination is considered a cause of subfertility in mares (HURTGEN, 2006; CAUSEY, 2007; MALSCHITZKY et al., 2007; COCCHIA et al., 2012). In this experiment, we analyzed the effect of pentoxifylline, semen and extender on the uterine inflammatory response until 48 hours after infusion in order to characterize which factors were responsible for variations in blood flow or neutrophils migration.

\subsubsection{Vascular perfusion of the endometrium}

In recent years, a positive relationship between genital perfusion and fertility has been established (BOLLWEIN, 2004). Adequate blood supply to the uterus is necessary for all mechanisms involved in reproduction (ESTELLER-VICO et al., 2007).

To assess blood flow, Doppler ultrassonography has been used to answer many questions regarding blood perfusion in horses under physiologic conditions, as pregnancy (SILVA et al., 2005), luteal blood flow (BOLLWEIN et al., 2002b), endometrial impairment assessed by biopsy (BLAICH et al., 1999), and in response to several interventions, such as insemination (BOLLWEIN et al., 2003b), exogenous administration and anti-inflammatory medication (BAILEY, 2012). 
Besides, in this experiment, the rheological properties of pentoxifylline, once its intrauterine infusion did not show statistical difference $(\mathrm{p}>0.05)$, neither group of skim milk extender only, nor group of semen diluted in skim milk.

In contrast, Bollwein, Sowade and Stolla (2003b) observed an increase in uterine fluid as early as one hour after infusion of semen extender, seminal plasma or raw semen. Moreover, the infusion with skim milk semen extender had no effect on uterine blood flow; however, the authors observed within one hour after infusion of seminal plasma or raw semen, an increase in the TAMV values of both uterine arteries $(\mathrm{p}<0.05)$.

It must consider that Bollwein, Sowade, Stolla, (2003b) detected changes in blood flow by evaluating the mean time-averaged maximum velocity (TAMV), different from our study, that the evaluations were made through resistance index (RI) values.

The RI is frequently used, it is the negative relationship between the extent of resistance in the tissues and the extent of vascular perfusion - the higher the resistance, or RI, the lower the perfusion, whereas TAMV is an average of the maximum values over the time of a cardiac cycle is called the time-averaged maximum velocity (GINTHER; MATTHEW, 2004).

Silva et al. (2005) observed that time-averaged maximum velocity (TAMV) was higher, and resistance index was lower, in the uterine arteries of pregnant mares compared to those of non pregnant mares.

There is another measurement, the pulsatility index (PI), an expression of the extent of the difference between the peak systolic velocity (PSV) and end diastolic velocity (EDV) of the blood pulse in the vessel at the level of the arterial examination. RI and PI are highly correlated ( $r>0.9)$ and usually only one is necessary (GINTHER; MATTHEW, 2004). For example, pentoxifylline when administered orally, showed effect by decreasing both RI and 
PI, which diminished vascular resistance of testicular artery of stallion, increasing vascular perfusion (POZOR et al., 2011).

From that we can utilize studies where PI was the measurement, to compare to our results. Bollwein et al. (2002a) observed a significant time trend in changes of uterine blood flow resistance during the estrous cycle, whereas high PI values were measured on day 0 (ovulation) and 1, followed by a decline until day 5 .

This could also be clearly seen in our study where vascularity score increased between day 1 to day 2, which can be related to the increase of progesterone on plasma due to prepare uterus for embryo arrival at day 5.

There are several studies testing the best concentration of pentoxifylline on semen samples, Centola, Cartie and Cox (1995), observed that $2.5 \mathrm{mg} / \mathrm{mL}$ may be the maximum beneficial concentration whereas, concentration $>5 \mathrm{mg} / \mathrm{mL}$ may be detrimental to sperm. In another study, an improvement on motility was observed only when semen was diluted on 1 $\mathrm{mM}$ pentoxifylline concentration (BLANES et al., 2004). It was found an increase on percentage of hiperactived spermatozoa, higher progressive motility at $3.5 \mathrm{mM}$ (GRADIL; BALL, 2000; MARQUES et al., 2002; ORTIGIES et al., 2012). Concentration of $7.18 \mathrm{mM}$ was able to improve motility characteristics of recently recovered epididymal sperm and had no deleterious effect on plasma membrane integrity and freezability of equine epididymal sperm (GUASTI et al., 2013). However, as in our study pentoxifylline did not acutely increased uterine blood flow, concentration of $7.18 \mathrm{mM}$, may not be enough to cause effect on uterine vascular perfusion in mares, but on the other hand, higher concentrations could be deleterious to sperm.

Pentoxifylline when administered orally, $17 \mathrm{mg} / \mathrm{kg}$ did not increase uterine artery blood flow either. This information could be suggested that the effects of endometrosis were not overcome by pentoxifylline treatment. Long-term pentoxifylline treatment appears to 
increase placental vascular resistance which could be potentially harmful (OUSEY et al., 2010).

Besides, there are individual variations in blood flow between mares, older pluriparous mares had a higher resistance to uterine blood flow than younger uniparous mares (BOLLWEIN; MAYER; STOLLA, 2003a) it is possible that the technique and parameter used to determine blood flow could have affected the results in each of these studies. There is a need to standardize research methodology and Doppler parameters in order to enhance the applicability of the various studies performed with this technique.

\subsubsection{Endometrial Cytology}

Regardless of the cause of endometritis, the common denominator is the inflamed state of the endometrium, manifested by the presence of neutrophils and fluid accumulation (TROEDSSON et al., 2006; WOODWARD et al., 2012). For assessment, cytobrush, is a quick method that has a relatively high reliability in diagnosing endometrial inflammation in the mare (CARD, 2005; NIELSEN et al., 2010) and is the preferred collection method for use on field (COCCHIA et al., 2012).

Pentoxifylline has antiinflammatory and immunomodulatory capabilities. It is known to inhibit the inflammatory effect of tumor necrosis factor- $\alpha$ (TNF- $\alpha)$, a cytokine released by mononuclear cells (BAUMGARTNER, 2007). According to Zhang et al. (2004), patients with endometriosis, which presents elevated levels of TNF- $\alpha$, may benefit from the use of pentoxifylline without significantly affecting the embryo development. Therefore this drug is not embryotoxic. 
In our study is clearly shown that pentoxifylline exert effect on inflammatory reaction. Group extender plus pentoxifylline (57.98\%), considered mild inflammation, induced 2.87 times more inflammatory response than group extender only (20.20\%) considered slight inflammation.

As immunomodulatory agent, pentoxifylline and its metabolites appears to increase the rate of neutrophil migration and exert a protective effect in animal models of infection (SAMLASKA; WINFIELD; 1994). The results show that pentoxifylline may have different effects on migration, depending on its concentration (ELFERINK; HUIZINGA; KOSTER, 1997).

This suggests that the addition of pentoxifylline induce an intense inflammatory response. Weaker insult to endometrium causes a longer residual inflammation (NIKOLAKOPOULOS; WATSON, 2000) whereas greater stimulation of defense mechanisms, promote faster endometrial recovery (FIALA et al., 2007a).

The same happened to groups of semen diluted in extender containing or not pentoxifylline, whereas the one which contain pentoxifylline $(82.84 \%)$, considered, by Williams et al. (1987), as severe inflammation, showed 1.7 times higher inflammatory degree than semen without pentoxifylline $(47.83 \%)$ slight inflammation. In our results when groups containing semen were compared to groups of extenders, semen presented more intense inflammatory reaction.

This happens because the presence of spermatozoa is the major factor responsible for inflammatory reaction (DELL'AQUA Jr. et al., 2006). Spermatozoa themselves are chemotactic for equine neutrophils (TROEDSSON et al., 2001). The spermatozoa that will be the one to fertilize the oocyte are present in the uterine tube by 4 hours after artificial insemination, at which time they become a target for the polymorphonuclear cells (PMNs) through complement activation (TROEDSSON; LIU; CRABO, 1998). 
Therefore, several experiments confirm the higher inflammatory reaction when semen is present, and even more intense when frozen semen is used. Mares bred with frozen semen develop marked persistent inflammation that has been attributed to the removal of seminal plasma during the process of cryopreservation, which play a modulator role in inflammatory reaction by suppressing complement activation, PMN-chemotaxis and phagocytosis in vitro (TROEDSSON et al., 2001; CARD, 2004).

In agreement, frozen semen inseminations which use a low volume of highly concentrated sperm produce a greater uterine response than inseminations with higher volumes containing lower concentrations (KOTILAINEN; HUHTINEN; KATILA, 1994). Higher sperm numbers or concentration probably induced a stronger chemotaxis of PMNs, resulting in rapid and efficient phagocytosis of sperm and bacteria (FIALA et al., 2007a).

\subsection{CONCLUSION}

In conclusion pentoxifylline did not exert additional effect on blood flow enough to be detected by ultrasonography Doppler. However, did stimulate a greater mechanisms defense, since increased neutrophils migration to uterine lumen as early as 6 hours of infusion, whereas may promote faster endometrial recovery. 


\section{CONSIDERAÇÕES FINAIS}

Diante dos resultados apresentados nos artigos 1 e 2 é possível considerar que:

1. O diluidor seminal contendo pentoxifilina, quando adicionado ao sêmen equino pósdescongelação, não foi capaz de aumentar a motilidade, porém melhorou as características de velocidade espermática. Quanto ao efeito nas membranas celulares e na cromatina, tanto a pentoxifilina como apenas diluidor à base de leite desnatado, ambos não afetaram a integridade, mas manteve-as íntegras por até duas horas.

2. O diluidor contendo pentoxifilina, não foi suficiente para aumentar o fluxo sanguíneo uterino, de forma detectável por ultrassonografia Doppler, podendo as variações encontradas estar relacionadas com variações hormonais, independente do tratamento que foi utilizado.

3. Não houve aumento do fluxo sanguíneo uterino, portanto não deve-se considerar que este tenha sido responsável por auxiliar na remoção de resíduos uterinos depositados no momento da inseminação artificial.

4. A ação imunomodulatória da pentoxifilina, foi claramente demonstrada, desde que a infusão de diluidor contendo pentoxifilina, induziu uma maior migração de neutrófilos para o lúmen uterino. O sêmen exerce papel fundamental na resposta uterina, sua presença intensificou ainda mais a migração leucocitária. 


\section{REFERÊNCIAS}

ALGHAMDI, A. S.; FOSTER, D. N.; CARLSON, C. S.; TROEDSSON, M. H. T. Nitric oxide levels and nitric oxide synthase expression in uterine samples from mares susceptible and resistant to persistent breeding-induced endometritis. American Journal of Reproductive Immunology, p. 230-237, 2005.

ALONSO, M. A. Efeito da aplicação da hCG em diferentes dias do ciclo estral sobre a concentração sérica de progesterona e fluxo sanguíneo uterino e ovariano em éguas. 2013. 179f. (Doutorado em Medicina Veterinária) - Faculdade de Medicina Veterinária e Zootecnia, Universidade de São Paulo, São Paulo, 2013.

AMANN, R. P.; PICKETT, B. W. Principles of cryopreservation and a review of cryopreservation of stallion spermatozoa. Journal of Equine Veterinary Science, v. 7, n. 3, p. 145-173, 1987.

APARICIO, N. J.; SCHWARZSTEIN, L.; DE TURNER, E. A. Pentoxifylline (BL 191) by oral administration in the treatment of asthenozoospermia. Andrologia, v. 12, n. 3, p. 228$231,1980$.

ARAVINDAN, G. R.; BJORDAHL, J.; JOST, L. K.; EVENSON, D. P. Susceptibility of human sperm to in situ DNA denaturation is strongly correlated with DNA strand breaks identified by single-cell electrophoresis. Experimental Cell Research, v. 236, n. 1, p. 231237, 1997.

ARIAS-DÍAZ, J.;VARA, E.;TORRES-MELERO, J.;GARCÍA, C.; HERNÁNDEZ, J.;

BALIBREA, J. L. Local production of oxygen free radicals and nitric oxide in rat diaphragm during sepsis: effects of pentoxifylline and somatostatin. European Journal Surgery, n.8, p.619-625, 1997.

ARRUDA, R. P.; CELEGHINI, E. C. C.; ALONSO, M. A.; CARVALHO, H. F.; OLIVEIRA, L. Z.; NASCIMENTO, J.; SILVA, D. F.;AFFONSO, F. J.; LEMES, K. M.; JAIMES, J. D. Metodos de avaliação da morfologia e função espermática: momento atual e desafios futuros. Revista Brasileira de Reproducao Animal, v.35, n.2, p.145-151, 2011.

AURICH, C. Factors affecting the plasma membrane function of cooled-stored stallion spermatozoa. Animal Reproduction Science, v. 89, p. 65-75, 2005.

BAILEY, C. S.; SPER, R. B.; SCHEWMAKER, J. L.; BUCHANAN, C. N.; BEACHLER, T. M.; POZOR, M. A.; WHITACRE, M. D. Uterine artery blood flow remains unchanged in pregnant mares in response to short-term administration of pentoxifylline. Theriogenology, $\mathrm{v}$. 77, n. 2, p. 430-436, 2012.

BAUMGARTNER, T. Pentoxifylline. Journal of Exotic Pet Medicine, v. 16, n. 2, p. 118-121, 2007. 
BELETTI, M. E.; COSTA, F.; GUARDIEIRO, M. M. Morphometric features and chromatin condensation abnormalities evaluated by Toluidine blue staining in bull spermatozoa.

Brazilian Journal of Morphology Science, v. 22, n. 2, p. 85-90, 2005.

BERGERON, A.; MANJUNATH, P. New insights towards understanding the mechanisms of sperm protection by egg yolk and milk. Molecular Reproduction and Development, n. 73, p. 1338-1344, 2006.

BLAICH, U.; PETZOLD, S.; BARTMANN, C. P.; LORBER, K.; SCHOON, H. A.; RAILA, G.; BOLLWEIN, H. Doppler ultrasonographic studies of the uterine blood flow in mares. Pferdeheikunde, v. 15, p. 547-550, 1999.

BLANES, R.; FERNANDEZ, P. J.; JIMENEZ, A.; ROMEU, A. La pentoxifilina como agente antioxidante en el processo de criopreservacion espermatica. Revista Iberoamericana de Fertilidad, v. 21, n. 4, 2004.

BOLLWEIN, H.; MAIERL, J.; MAYER, R.; STOLLA, R. Transrectal color doppler sonography of the a.uterina in cyclic mares. Theriogenology, n. 49, p. 1483-1488, 1998.

BOLLWEIN, H.; MAYER, R.; STOLLA, R. Transrectal Doppler sonography of uterine blood flow during early pregnancy in mares. Theriogenology, v. 60, n. 4, p. 597-605, 2003a.

BOLLWEIN, H.; MAYER, R.; WEBER, R.; STOLLA, R. Luteal blood flow during the estrous cycle in mares. Theriogenology, v. 57, n. 8, p. 2043-2051, 2002 b.

BOLLWEIN, H.; SOWADE, C.; STOLLA, R. The effect of semen extender, seminal plasma and raw semen on uterine and ovarian blood flow in mares. Theriogenology, v. 60, n. 4, p. 607-616, 2003b.

BOLLWEIN, H.; WEBER, F.; KOLBERG, B.; STOLLA, R. Uterine and ovarian blood flow during the estrous cycle in mares. Theriogenology, n.65, p. 2129-2138, 2002a.

BOLLWEIN, H.; WEBER, F.; WOSCHEE, I.; STOLLA, R. Transrectal Doppler sonography of uterine and umbilical blood flow during pregnancy in mares. Theriogenology, v. 61, n. 23, p. 499-509, 2004.

BORG, K.; COLENBRANDER, B.; FAZELI, A.; PARLEVLIET, J.; MALMGREN, L. Influence of thawing method on motility, plasma membrane integrity and morphology of frozen-thawed stallion spermatozoa. Theriogenology, v. 48, n. 4, p. 531-536, 1997.

BRENNAN, A. P.; HOLDEN, C. A. Pentoxifylline-supplemented cryoprotectant improves human sperm motility after cryopreservation. Human Reproduction, v. 10, n. 9, p. 23082312, 1995.

BRINSKO, S. P.; RIGBY, S. L.; VARNER, D. D.; BLANCHARD, T. L. A practical method for recognizing mares susceptible to post-breeding endometritis. Disponível em : <http://www.ivis.org/proceedings/aaep/2003/brinsko2/ivis.pdf>. Acesso em : 03 jul 2013. 
BRINSKO, S. P.; VARNER, D. D.; BLANCHARD, T. L. The effect of uterine lavage performed four hours post insemination on pregnancy rate in mares. Theriogenology, v. 35, n. 6, p. 1111-1119, 1991.

BRITO, L. F. C. Evaluation of stallion sperm morphology. Clinical Techniques in Equine Practice, n. 6, p. 249-264, 2007.

BUNGE, R. G. Caffeine-stimulation of ejaculated human spermatozoa. Urology, v. 1, n. 4, p. $371,1973$.

CALOGERO, A. E.; FISHEL, S.; HALL, J.; FERRARA, E.; VICARI, E.; GREEN, S.; HUNTER, A.; BURRELLO, N.; THORNTON, S.; D'AGATA, R. Correlation between intracellular cAMP content, kinematic parameters and hyperactivation of human spermatozoa after incubation with pentoxifylline. Human reproduction, v. 13, n. 4, p. 911-915, 1998.

CARD, C. Post-breeding inflammation and endometrial cytology in mares. Theriogenology, v. 64, n. 3 , p. $580-588,2005$.

CARD, C.; CARLEY, S.; GREEN, J.; CHIRINO-TREJO, M. Endometrial cytology in mares bred with frozen semen. In: AMERICAN ASSOCIATION EQUINE PRACTTITIONERS, 20., 2004. Proceedings... Denver, Colorado, USA, 2004. p. 505-509.

CARRETERO, M. I.; GIULIANO, S. M.; CASARETTO, C. I.; GAMBAROTTA, M. C.; NEILD, D. M. Evaluation of the effect of cooling and of the addition of collagenase on llama sperm DNA using toluidine blue. First International Journal of Andrology, v. 44, p. 239$247,2012$.

CARVALHO, F. P.; SILVA, J. F. S.; SOUZA, G. V.; QUIRINO, C. R.; CARVALHO, C. S. P. Different extenders on sperm motility and plasmatic membrane integrity after ovine semen freezing and thawing. Revista Brasileira de Saúde e Produção Animal, v.9, n.3, p. 15199940, 2008.

CAUSEY, R. C. Making sense of equine uterine infections: the many faces of physical clearance. The Veterinary Journal, v. 172, n. 3, p. 405-421, 2006.

CAUSEY, R. C. Mucus and the mare: how little we know. Theriogenology, v. 68, n. 3, p. 386-394, 2007.

CELEGHINI, E. C. C.; ANDRADE, A. F. C.; RAPHAEL, C. F; NASCIMENTO, J.; TICIANELLI, J. S.; ARRUDA, R. P. Damage assessment of the equine sperm membranes by fluorimetric technique. Brazilian Archives of Biology and Technology (Impresso), v. 53, n. 6, p. 1285-1292, 2010a.

CELEGHINI, E. C. C.; ARRUDA, R. P.; ANDRADE, A. F. C.; NASCIMENTO, J.;

RAPHAEL, C. F. Practical techniques for bovine sperm simultaneous fluorimetric assessment of plasma, acrosomal and mitochondrial membranes. Reproduction of Domestic Animals, v. 42, p. 479-488, 2007. 
CELEGHINI, E. C. C., ARRUDA,R. P., ANDRADE, A. F. C., NASCIMENTO, J., RAPHAEL, C. F., RODRIGUES, P. H. M. Effects that bovine sperm cryopreservation using two different extenders has on sperm membranes and chromatin. Animal Reproduction Science, n. 104, p. 119-131, 2008.

CELEGHINI, E. C. C.; NASCIMENTO, J.; RAPHAEL, C. F.; ANDRADE, A. F. C.; ARRUDA, R. P. Simultaneous assessment of plasmatic, acrosomal, and mitochondrial membranes in ram sperm by fluorescent probes. Arquivo Brasileiro Medicina Veterinária e Zootecnia, v. 62, n. 3, p. 536-543, 2010 b.

CENTOLA, G. M.; CARTIE, R. J.; COX, C. Differential responses of human sperm to varying concentrations of pentoxifylline with demonstration of toxicity. Journal of Andrology, v. 16, n. 2, p. 136-142, 1995.

CFMV. Brasil tem o quarto maior rebanho equino do mundo, com 5,8 milhões de cabeças, 2010. Disponivel em: <http://www.cfmv.org.br/portal/noticia.php?cod=606>. Acesso em: 01 jul 2013.

COCCHIA, N.; PACIELLO, O.; AULETTA, L.; UCCELLO, V.; SILVESTRO, L.; MALLARDO, K.; PARAGGIO, G.; PASOLINI, M. P. Comparison of the cytobrush, cottonswab, and low-volume uterine flush techniques to evaluate endometrial cytology for diagnosing endometritis in chronically infertile mares. Theriogenology, v. 77, n. 1, p. 89-98, 2012.

CROSS, N. L.; MEIZEL, S. Methods for evaluating the acrosomal status of mammalian sperm. Biololy Reproduction, v. 41, n. 4, p. 635-641, 1989.

ANDRADE, A. F.; ARRUDA, R. P.; CELEGHINI, E. C.; NASCIMENTO, J.; MARTINS, S. M.; RAPHAEL, C. F.; MORETTI, A. S. Fluorescent stain method for the simultaneous determination of mitochondrial potential and integrity of plasma and acrosomal membranes in boar sperm. Reproduction on Domestic Animals, v. 42, n. 2, p. 190-194, 2007.

DELL'AQUA, J. A.; PAPA, F. O.; LOPES, M. D.; ALVARENGA, M. A.; MACEDO, L. P.; MELO, C. M. Modulation of acute uterine inflammatory response after artificial insemination with equine frozen semen. Animal Reproduction Science, v. 94, p. 270-273, 2006.

DOTT, H.M. Morphology of stallion spermatozoa. Journal of Reproduction Fertility Supplement, p.41-46, 1975.

ERENPREISS, J.; SPANO, M.; ERENPREISA, J.; BUNGUM, M.; GIWERCMAN, A. Sperm chromatin structure and male fertility: biological and clinical aspects. Asian Journal of Andrology, v. 8, n. 1, p. 11-29, 2006.

ERICSSON, S. A.; GARNER, D. L.; THOMAS, C. A.; DOWNING, T. W.; MARSHALL, C. E. Interrelationships among fluorometric analyses of spermatozoal function, classical semen quality parameters and the fertility of frozen-thawed bovine spermatozoa. Theriogenology, v. 39, p. 1009-1024, 1993. 
ESTELLER-VICO, A.; LIU, I. K. M.; STEFFEY, E. P.; VAUGHAN, M. E.; BROSNAN, R. $\mathrm{J}$. Effect of vascular degeneration on utero-ovarian blood-flow and perfusion in the cyclic mare. Theriogenology, v. 68, p. 492-518, 2007.

ESTEVES, S. C.; SHARMA, R. K.; THOMAS, A. J.; AGARWAL, A. Cryopreservation of human spermatozoa with pentoxifylline improves the post-thaw agonist-induced acrosome reaction rate. Human reproduction, v. 13, n. 12, p. 3384-3389, 1998.

ESTEVES, S. C.; SPAINE, D. M.; CEDENHO, A. P. Effects of pentoxifylline treatment before freezing on motility, viability and acrosome status of poor quality human spermatozoa cryopreserved by the liquid nitrogen vapor method. Brazilian Journal of Medical and Biological Research, v. 40, n. 7, p. 985-992, 2007.

FERREIRA, J. C.; MEIRA, C. Aplicação da ultrassonografia colorida Doppler em programas de transferência de embriões equinos. Ciência Rural, v. 41, n. 6, p. 1063-1069, 2011.

FIALA, S. M. E. Transporte espermático e resposta inflamatória na égua após a inseminação com diferentes concentrações de espermatozóides. 2004. 73 f. Tese (Doutorado em Reproducao Animal) - Faculdade de Veterinaria, Universidade Federal do Rio Grande do Sul, Porto Alegre, 2004.

FIALA, S. M.; PIMENTEL, C. A.; MATTOS, A. L. G.; GREGORY, R. M.; MATTOS, R. C. Effect of sperm numbers and concentration on sperm transport and uterine inflammatory response in the mare. Theriogenology, v. 67, n. 3, p. 556-562, 2007a.

FIALA, S. M. E.; MALSCHITZKY, E.; JOBIM, M. I. M.; GREGORY, R. M.; MATTOS, R. C. Aspectos relacionados ao transporte espermático e resposta inflamatória uterina em éguas. Revista Brasileira de Reprodução Animal, v. 31, n.1, p. 3-7, 2007 b.

FUMUSO, E. A.; AGUILAR, J.; GIGUERE, S.; RIVULGO, M.; WADE, J.; ROGAN, D. Immune parameters in mares resistant and susceptible to persistent post-breeding endometritis: effects of immunomodulation. Veterinary Immunology and Immunopathology, v. 118, n. 1-2, p. 30-39, 2007.

GARNER, D. L. PINKEL, D.; JOHNSON, L. A.; PACE, M. M. Assessment of spermatozoal function using dual fluorescent staining and flow cytometric analyses. Biology of Reproduction, v. 34, p. 127-138, 1986.

GINTHER, O. J. Ultrasonic imaging and animal reproduction: color-doppler ultrasonography. Cross Plains, WI: Equiservices Publishing, 2007. Book 4.

GINTHER, O. J.; MATTHEW, D. Doppler ultrasound in equine reproduction: principles, techniques, and potential. Journal of Equine Veterinary Science, v. 24, n. 12, p. 516-526, 2004.

GOULART, H. M.; SILVA, A. E. D. F.; McMANUS, C.; PAPA, F. O. Efeitos da pentoxifilina sobre a viabilidade in vitro dos espermatozóides de eqüinos, após o resfriamento a $5^{\circ} \mathrm{C}$. Revista Brasileira de Zootecnia, v. 33, n. 1, p. 112-122, 2004. 
GRADIL, C. M.; BALL, B. A. The use of pentoxifylline to improve motility of cryopreserved equine spermatozoa. Theriogenology, v. 54, p. 1041-1047, 2000.

GRAHAM, J. K.; KUNZE, E.; HAMMERSTEDT, H. Analysis of sperm cell viability, acrosomal integrity and mitochondrial function using flow cytometry. Biology of Reproduction, n. 43, p. 55-64, 1990.

GRAVANCE, C. G.; GARNER, D. L.; BAUMBER, J.; BALL, B. A. Assessment of equine sperm mitochondrial function using JC-1. Theriogenology, v. 53, n. 9, p. 1691-1703, 2000.

GUASTI, P. N. Efeito do meio diluidor e da dose inseminante sobre a congelabilidade e fertilidade de espermatozóides recuperados da cauda do epidídimo de garanhões. 2010. 80 f. Dissertação (Mestrado) - Faculdade de Medicina Veterinária e Zootecnia, Universidade Estadual Paulista, Botucatu, 2010.

HOLT, W.V. Basic Aspects of frozen storage of semen. Animal Reproduction Science, n. 62, p. 3-22, 2000.

HURTGEN, J. P. Pathogenesis and treatment of endometritis in the mare: a review. Theriogenology, v. 66, n. 3, p. 560-566, 2006.

KATILA, T. Uterine defence mechanisms in the mare. Animal Reproduction Science, v. 42, p. 197-204, 1996.

KATILA, T. Procedures for handling fresh stallion semen. Theriogenology, v. 48, p. 12171227, 1997.

KATILA, T. Sperm-uterine interactions: a review. Animal Reproduction Science, v. 68, n. 3-4, p. 267-272, 2001.

KENNEY, R. M.; BERGMAN, R. V.; COOPER, W. L.; MORSE, G. W. Minimal contamination techniques for breeding mares. Technique and preliminary findings. In: ANNUAL CONVENTION OF AMERICAN ASSOCIATION EQUINE PRACTITIONERS, 21., 1975. Proceedings ... Boston, USA, 1975. p.327-336.

KOTILAINEN, T.; HUHTINEN, M.; KATILA, T. Sperm-induced leukocytosis in the equine uterus.Theriogenology, v. 41, n. 8, p. 629-636, 1994.

LEBLANC, M. M. Persistent mating induced endometritis in the mare : pathogenesis , diagnosis and treatment. Disponivel em :

<http://www.ivis.org/advances/Reproduction_Ball/leblanc/ivis.pdf>. Acesso em: 03 jul 2013.

LEBLANC, M. M.; NEUWIRTH, L.; JONES, L.; CAGE, C.; MAURAGIS, D. Differences in uterine position of reproductively normal mares and those with delayed uterine clearance detected by scintigraphy. Theriogenology, v. 50, n. 1, p. 49-54, 1998.

LIU, I. K. M.; TROEDSSON, M. H. T. The diagnosis and treatment of endometritis in the mare: yesterday and today. Theriogenology, v. 70, n. 3, p. 415-420, 2008. 
MACÍAS GARCÍA, B.; FERRUSOLA, C. O.; APARICIO, I. M.; MIRO-MORAN, A.; RODRIGUEZ, A. M.; GALLARDO BOLANOS, J. M.; GONZALES FERNANDEZ, L.; SILVA, C. M. B.;MARTINEZ, H. R.; TAPIA, J. A.; PENA, F. J. Toxicity of glycerol for the stallion spermatozoa: Effects on membrane integrity and cytoskeleton, lipid peroxidation and mitochondrial membrane potential. Theriogenology, v. 77, n. 7, p. 1280-1289, 2012.

MALOUFI, F.; PIERSON, R.; OTTO, S.; BALL, C.; CARD, C. Mares susceptible or resistant to endometritis have similar endometrial echographic and inflammatory cell reactions at 96 hours after infusion with frozen semen and extender. American association equine practitioners. Proceedings, v. 48, p. 51-57, 2002.

MALSCHITZKY, E.; JOBIM, M. I. M.; GREGORY, R. M; MATTOS, R. C. Endometrite na égua, novos conceitos. Revista Brasileira Reprodução Animal, v. 31, n. 1, p. 17-26, 2007.

MARQUES, A.; ARRUDA, R. P.; CELEGHINI, E. C. C.; GOBESSO, A. A. O; NEVES NETO, J. R. Effects of ascorbic acid and pentoxifylline on equine cryopreserved semen submitted to in vitro incubation. Theriogenology, v. 58, p. 257-260, 2002.

MARRAMA, P.; BARAGHINI, G. F.; CARANI, C.; CELANI, M. F.; GIOVENCO, P.; GRANDI, F.; MONTANINI, V. Further studies on the effects of pentoxifylline on sperm count and sperm motility in patients with idiopathic oligo-asthenozoospermia. Andrologia, v. 17, n. 6, p. 612-616, 1985.

MOEIN, H.; KHALILI, H. A.; KERAMATIAN, K. Effect of methylphenidate on ICU and hospital length of stay in patients with severe and moderate traumatic brain injury. Clinical Neurology Neurosurgery, v. 108, n. 6, p. 539-542, 2006.

NASCIMENTO, J.; RAPHAEL, C. F.; ANDRADE, A. F. C.; ALONSO, M. A.; CELEGHINI, E. C. C.; ARRUDA, R. P. Effects of sperm concentration and straw volume on motion characteristics and plasma, acrosomal, and mitochondrial membranes of equine cryopreserved spermatozoa. Journal of Equine Veterinary Science, v. 28, n. 6, p. 351-358, 2008 .

NIELSEN, J. M.; TROEDSSON, M. H.; PEDERSEN, M. R.; BOJESEN, A. M.; LEHNJENSEN, H.; ZENT, W. W. Diagnosis of endometritis in the mare based on bacteriological and cytological examinations of the endometrium: comparison of results obtained by swabs and biopsies. Journal of Equine Veterinary Science, v. 30, n. 1, p. 27-30, 2010.

NIKOLAKOPOULOS, E.; WATSON, E. D. Effect of infusion volume and sperm numbers on persistence of uterine inflammation in mares. Equine Veterinary Journal, v. 32, n. 2, p. 164-166, 2000.

ORTGIES, F.; KLEWITZ, J.; GORGENS, A.; MARTINSSON, G.; SIEME, H. Effect of procaine, pentoxifylline and trolox on capacitation and hyperactivation of stallion spermatozoa. Andrologia, v. 44, p. 130-138, 2012. 
PAPAIOANNOU, K. Z.; MURPHY, R. P.; MONKS, R. S.; HYNES, N.; RYAN, M. P.; BOLAND, M. P.; ROCHE, J. F. Assessment of viability and mitochondrial function of equine spermatozoa using double staining and flow cytometry. Theriogenology, v. 48, n. 2, p. 299312, 1997.

PEGG, D. E. The history and principles of cryopreservation. Seminars Reproduction Medicine, v. 20, n. 1, p. 5-13, 2002.

PETRUNKINA, A. M. Fundamental aspects of gamete cryobiology. Journal of Reproductive Medicine and Endocrinology, v. 4, n. 2, p. 78-91, 2007.

PICKETT, B. W. Managements of the mare for maximun reprodutive efficience. Bulletin/ Animal Reproduction and Biotechnology Laboratory, 1989.

POZOR, M.A.; MUEHLHAUS, J.; KING, A.; MACPHERSON, M.L.; TROEDSSON, M.H.; BAILEY, C.S. Effect of pentoxifylline treatment on testicular perfusion and semen quality in Miniature horse stallions. Theriogenology, v. 76, n. 6, p. 1027-1035, 2011.

PUGLIESI, G.; CARVALHO, G. R.; RATES, D. M.; KER, P. G.; MATTA, M. P.; OLIVEIRA, R. R.; FILHO, J. M. D. Viability and fertility of cooled equine semen diluted with skimmed milk or glycine egg yolk-based extenders. Revista Brasileira de Zootecnia, v. 41, n. 12, p. 2411-2417, 2012.

PURDY, P. H. A review on goat sperm cryopreservation. Small Ruminant Research, v. 63, n. 3, p. 215-225, 2006.

RAPHAEL, C. F. Efeitos da centrifugação nas características de movimento, integridade e peroxidação lipídica das membranas do espermatozoide equino refrigerado. 2007. 111 f. Dissertação (Mestrado) - Faculdade de Medicina Veterinária e Zootecnia, Universidade de São Paulo, São Paulo, 2007.

REERS, M.; SMITH, T. W.; CHEN, L. B. J-aggregate formation of a carbocyanine as a quantitative fluorescent indicator of membrane potential. Biochemistry, v. 30, n. 18, p. 44804486, 1991.

RIGBY, S. L.; BARHOUMI, R.; BURGHARDT, R. C.; COLLERAN, P.; THOMPSON, J. A.; VARNER, D. D.; BLANCHARD, T. L.; BRINSKO, S. P.; TAYLOR, T.; WILKERSON, M. K.; DELP, M. D. Mares with delayed uterine clearance have an intrinsic defect in myometrial function. Biology of Reproduction, v. 65, n. 3, p. 740-747, 2001.

RODRIGUEZ-MARTINEZ, H. Laboratory semen assessment and prediction of fertility: still utopia? Reproduction of Domestic Animals, v. 38, n. 4, p. 312-318, 2003.

ROTA, A.; PANZANI, D.; SABATINI, C.; CAMILLO, F. Donkey jack (Equus asinus) semen cryopreservation: studies of seminal parameters, post breeding inflammatory response, and fertility in donkey jennies. Theriogenology, v. 78, n. 8, p. 1846-1854, 2012. 
SALAZAR, J. L.; TEAGUE, S. R.; LOVE, C. C.; BRINSKO, S. P.; BLANCHARD, T. L., VARNER, D. D. Effect of cryopreservation protocol on post thaw characteristics of stallion sperm. Theriogenology, v. 76, p. 409-418, 2011.

SAMLASKA, C. P.; WINFIELD, E. A. Pentoxifylline. Journal of the American Academy of Dermatology, v. 30, n. 4, p. 603-621, 1994.

SCHILL, W. B.; JUNGST, D.; UNTERBURGER, P.; BRAUN, S. Combined hMG/hCG treatment in subfertile men with idiopathic normogonadotrophic oligozoospermia.

International Journal of Andrology, v. 5, n. 5, p. 467-477, 1982.

SCHOBER, D.; AURICH, C.; NOHL, H.; GILLE, L. Influence of cryopreservation on mitochondrial functions in equine spermatozoa. Theriogenology, v. 68, n. 5, p. 745-754, 2007.

SHEN, M. R.; CHIANG, P. H.; YANG, R. C.; HONG, C. Y.; CHEN, S. S. Pentoxifylline stimulates human sperm motility both in vitro and after oral therapy. British Journal of Clinical Pharmacology, v. 31, n. 6, p. 711-714, 1991.

SIEME, H.; HARRISON, R. A P.; PETRUNKINA, A M. Cryobiological determinants of frozen semen quality, with special reference to stallion. Animal Reproduction Science, v. 107, n. 3-4, p. 276-292, 2008.

SILVA, K. M. G.; MORAES, T. A. P.; SILVA, E. C. B.; GAMBOA, S. C.; GUERRA, M. M. P. Efeito da adição de trolox e pentoxifilina na motilidade, integridade do acrossoma e do DNA de espermatozoides equinos após descongelação. Arquivo Brasileiro de Medicina Veterinária e Zootecnia, v. 61, n. 1, p. 42-49, 2009.

SILVA, L. A.; GINTHER, O. J. An early endometrial vascular indicator of completed orientation of the embryo and the role of dorsal endometrial encroachment in mares. Biology of Reproduction, v. 74, n. 2, p. 337-343, 2006.

SILVA, L. A.; GASTAL, E. L.; BEG, M. A.; GINTHER, O. J. Changes in vascular perfusion of the endometrium in association with changes in location of the embryonic vesicle in mares. Biology of Reproduction, v. 72, n. 3, p. 755-761, 2005.

SILVA, S. V.; GUERRA, M. M. P. Efeitos da criopreservação sobre as células espermáticas e alternativas para redução das crioinjúrias. Revista Brasileira de Reprodução Animal, v. 35, n. 4, p. 370-384, 2011.

STACHEKI, J. J.; GINSBURG, K. A.; ARMANT, D. R. Stimulation of cryopreserved epididymal spermatozoa of the domestic cat using the motility stimulants Caffeine, Pentoxifylline, and 2'-Deoxyadenosine. Journal of Andrology, v. 15, n. 2, p. 157-164, 1994.

STANIC, P.; SONICKI, Z.; SUCHANEK, E. Effect of pentoxifylline on motility and membrane integrity of cryopreserved human spermatozoa. International Journal of Andrology, v. 25, n. 3, p. 186-190, 2002. 
SUKARDI, S.; CURRY, M. R.; WATSON, P. F. Simultaneous detection of the acrosomal status and viability of incubated ram spermatozoa using fluorescent markers. Animal Reproduction Science, v. 46, n. 1-2, p. 89-96, 1997.

SULLIVAN, J. J.; TURNER, P. C.; SELF, L. C. Survey of reproductive efficiency in the quarter horse and thoroughbred. Journal of Reproduction and Fertility, p.315-318, 1975. Suplemento 23.

TAYLOR, N. J. Investigation of sperm-induced cervical leucocytosis by a double mating study in rabbits. Journal Reproduction of Fertility, n. 66, p. 157-160, 1982.

TERRACIANO, P.B.; BUSTAMANTE-FILHO, I.C.; MIQUELITO, L.V.; ARLAS, T.R.; CASTRO, F.; MATTOS, R.C.; PASSOS, E.P.; OBERST, E.R.; LIMA, E.O.C.

Criopreservação de espermatozoides equinos comparando duas curvas de congelamento combinadas com diluentes comerciais: uma análise laboratorial. Ciência Rural, v.38, n.7, p.1972-1977, 2008.

TESARIK, J.; THEBAULT, A.; TESTART, J. Effect of pentoxifylline on sperm movement characteristics in normozoospermic and asthenozoospermic specimens. Human

Reproduction, v.7, p.1257-1263, 1992.

TROEDSSON, M. H. T. Breeding-induced endometritis in mares. Veterinary Clinical Equine, v. 22, n. 3, p. 705-712, 2006.

TROEDSSON, M. H. T. Therapeutic considerations for mating-induced endometritis. Pferdeheikunde, v. 13, p. 516-520, 1997.

TROEDSSON, M. H. T. Uterine clearance and resistance to persistent endometritis in the mare. Theriogenology, n. 52, p. 461-471, 1999.

TROEDSSON, M. H. T.; DESVOUSGES, A.; ALGHAMDI, A. S.; DAHMS, B.; DOW, C. A.; HAYNA, J.; VALESCO, R.; COLLAHAN, P. T.; MACPHERSON, M. L.; POZOR, M.; BUHI, W. C. Components in seminal plasma regulating sperm transport and elimination. Animal Reproduction Science, v. 89, n. 1-4, p. 171-186, 2005.

TROEDSSON, M. H. T.; LOSET, K.; ALGHAMDI, A. M.; DAHMS, B.; CRABO, B. G. Interaction between equine semen and the endometrium: the inflammatory response to semen. Animal Reproduction Science, v. 68, n. 3-4, p. 273-278, 2001.

TROEDSSON, M. H. T.; LIU, I. K. M.;CRABO, B. G. Sperm transport and survival in the mare. Theriogenology, v. 49, p. 905-915, 1998.

VIDAMENT, M.; DUPERE, A. M.; JULIENNE, P.; EVAIN, A.; NOUE, P.; PALMER, E. Equine frozen semen: freezability and fertility field results. Theriogenology, n. 48, p. 907917, 1997.

VOSS, J. L. Breeding Efficiency. In: McKINNOW, A. O.; VOSS, J. L. Equine Reproduction. Phyladelphya : Lea \& Febiger, 1993. 1114 p. 
WANG, R.; SIKKA, S.C.; VEERARAGAVAN, K.; BELL, M.; HELLSTROM, W.J. Platelet activating factor and pentoxifylline as human sperm cryoprotectants. Fertility and Sterility, v.60, n.4, 1993.

WARD, A.; CLISSOLD, S. P. Pentoxifylline. A review of its pharmacodynamic and pharmacokinetic properties, and its therapeutic efficacy. Drugs, v. 34, n. 1, p. 50-97, 1987.

WATSON, P. F. The causes of reduced fertility with cryopreserved semen. Animal Reproduction Science, v. 60-61, p. 481-492, 2000.

WILLIAMS, E. J.; FISCHER, D. P.; NOAKES, D. E.; ENGLAND, G. C.; RYCROFT, A.; WINGFIELD-DIGBY, N. J. The technique and clinical application of endometrial cytology in mares. Equine Veterinary Journal, v. 10, p. 176-180, 1987.

WOODWARD, E. M.; CHRISTOFFERSEN, M.; CAMPOS, J.; SQUIRES, E. L.; TROEDSSON, M. H. T. Susceptibility to persistent breeding-induced endometritis in the mare: relationship to endometrial biopsy score and age, and variations between seasons. Theriogenology, v. 78, n. 3, p. 495-501, 2012.

ZHANG, X.; SHARMA, R. K.; AGARWAL, A.; FALCONE, T. Effect of immunomodulatory agent - Pentoxifylline on in vitro blastocyst development rate. Fertility \& Sterility, p. 311, 2004. 